\title{
HOW LOCAL PEOPLE USE THEIR INDIGENOUS KNOWLEDGE TO RESPOND TO FLOODS AND DROUGHTS: A CASE STUDY OF TONLE SAP LAKE COMMUNITIES, CAMBODIA
}

\section{Sopheak Seng}

A thesis submitted to Victoria University of Wellington in partial fulfilment of the requirements for the degree of Master of Development Studies

School of Geography, Environment, and Earth Sciences

Victoria University of Wellington 



\begin{abstract}
This thesis investigates the impacts of floods and droughts in the Tonle Sap Lake region and examines to what extent the local communities' indigenous knowledge (IK) is used to deal with floods and droughts. The thesis begins by exploring the Tonle Sap Lake communities' perceptions of climate change, especially floods and droughts and their impacts on local livelihoods. It then examines how the communities have used their IK to develop livelihood adaptation methods to cope with floods and droughts. To conduct this study, a qualitative methodology was adopted using semi-structured interviews, and non-participant and unstructured observation as the main methods. The semi-structured interviews were conducted with local people and local authorities from two communities, and NGO staff.
\end{abstract}

The study found that the intensity of floods and droughts in the Tonle Sap Lake region has increased in the last few years. Floods and droughts have threatened local livelihoods and food security. To mitigate the effects of floods and droughts, the local communities in this region have developed various livelihood adaptation strategies to adapt to the hazards. The communities appeared to use both IK and technologies for their adaptation strategies. IK is seen as an invaluable local community asset in developing livelihood adaptation methods.

Although a mixture of IK and new knowledge has been used to develop various adaptation strategies, the sufficiency of the adaptation is still limited. The current severity of climate change is seen to limit the local communities' response capacities. To strengthen the communities' adaptation capacity, contribution and involvement from non-governmental organisations and the government in developing climate change adaptation policy at a local level are essential.

Keywords: indigenous knowledge, floods, droughts, livelihood, adaptation 


\section{Acknowledgement}

My deepest gratitude goes to my supervisor, Professor John Overton, who always encouraged and motivated me to work hard and complete my research. The support, comments, feedback and motivation from him was invaluable for this research thesis. His motivated guidance helped me in all the time of my thesis and writing. I could not have imagined having a better advisor for my thesis.

I am also profoundly grateful to the government of New Zealand, particularly the Ministry of Foreign Affairs and Trade (MFAT) who have provided me with a scholarship to pursue my master's degree at Victoria University of Wellington. The financial support from MFAT was crucial for both of my studies and living in New Zealand for two years. Moreover, I would like to express my sincere thanks to Victoria International, especially Tim Lawther and Clemmie Newton, who took care of my study progress and helped find me a proof-reader for my thesis.

I would also like to express my great appreciation to commune councillors of Kampong Kleang commune, particularly Mr Sambo Chhang, two village heads of Mukwat and Santey villages, who helped facilitate my field research. Without their help and participation from community people in the two villages, my field research could not have been done smoothly. I really appreciate local communities' participation in my research. They have demonstrated their willingness to participate in my research despite their hardship during a severe drought in their communities.

Finally, yet importantly, my heartfelt thanks to my beloved wife, Kannitha Chan, and my daughter, SovannMalatey Hak whose love, understanding, determined support and encouragement have motivated my daily work on this thesis. Without their understanding, encouragement and support, this thesis would not be easily completed on time. 


\section{Table of Contents}

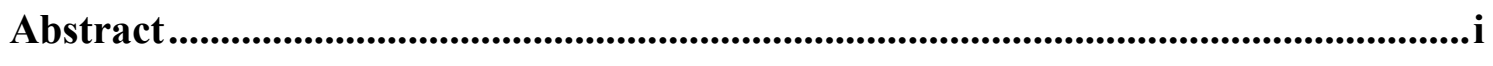

Acknowledgement ........................................................................................................ii

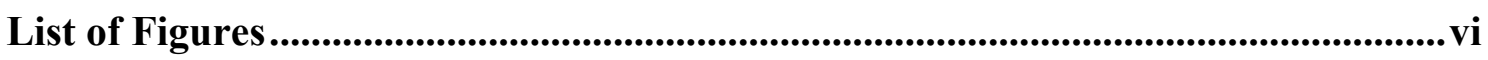

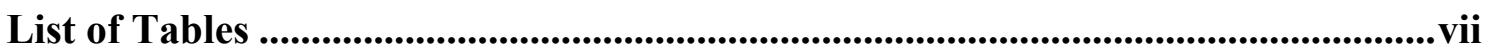

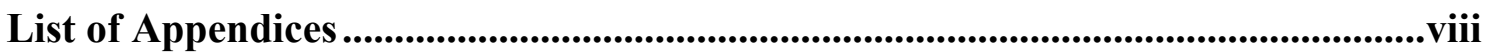

Acronyms ...................................................................................................................................... ix

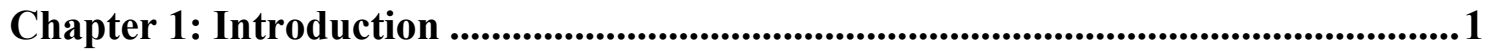

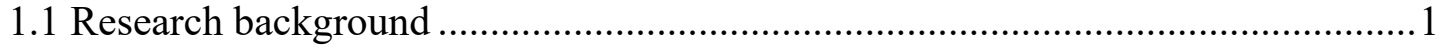

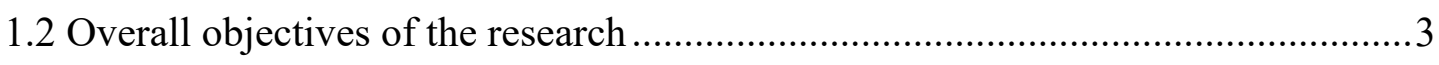

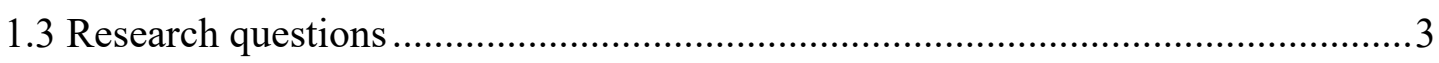

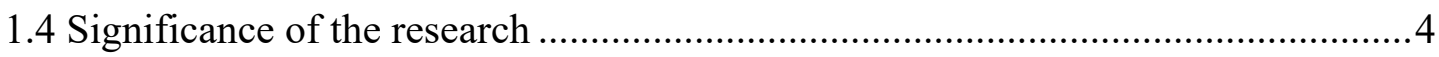

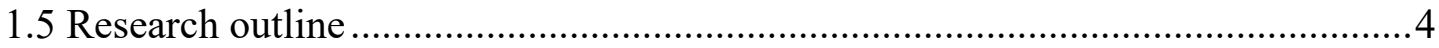

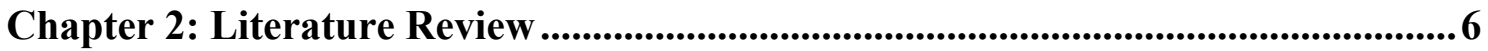

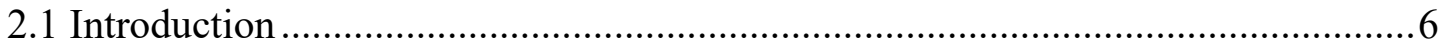

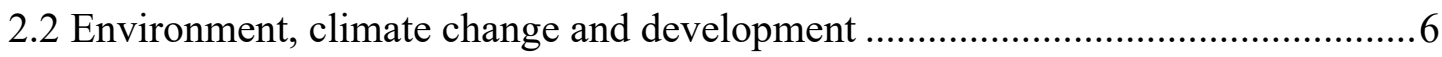

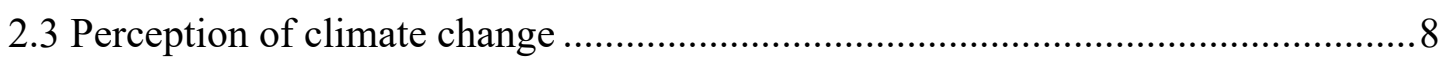

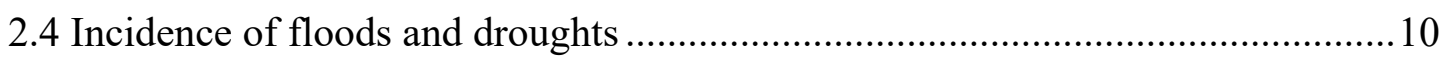

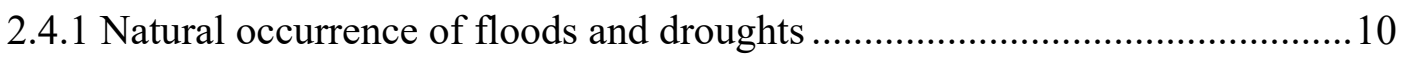

2.4.2 Climate change and floods and droughts ........................................................ 11

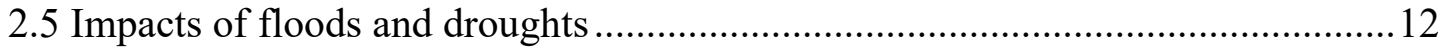

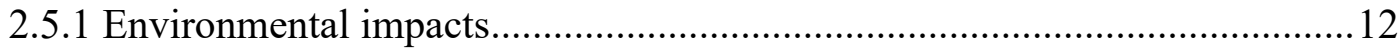

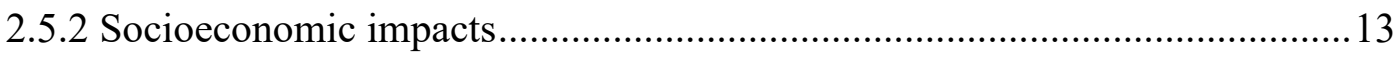

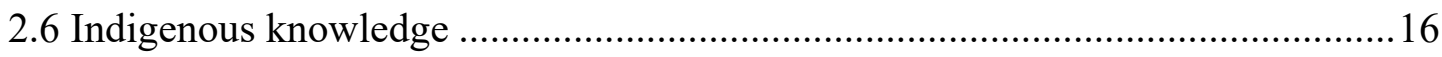

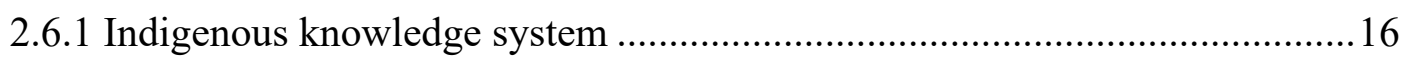

2.6.2 Indigenous knowledge and development ................................................... 17

2.7 Indigenous knowledge and climate change adaptation......................................19

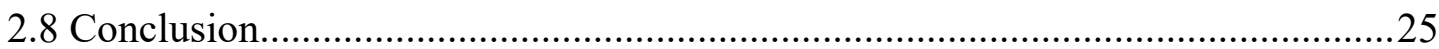

Chapter 3: Research Methodology ..........................................................................................26

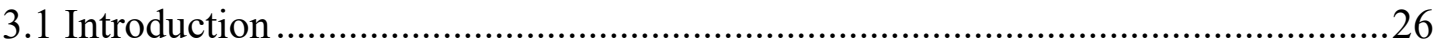

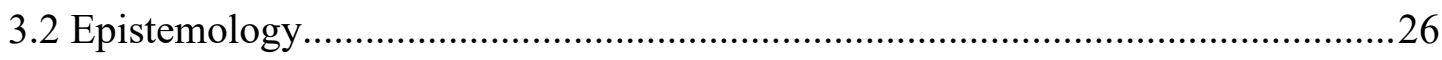

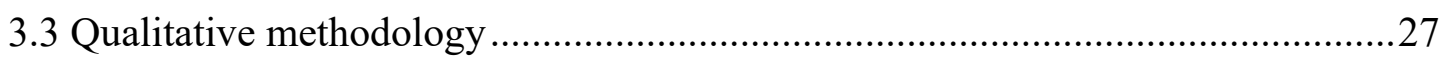

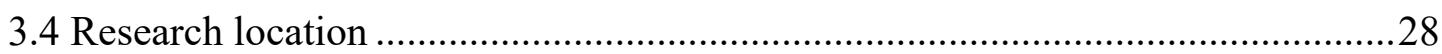

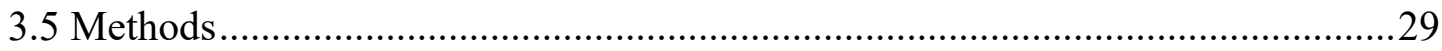

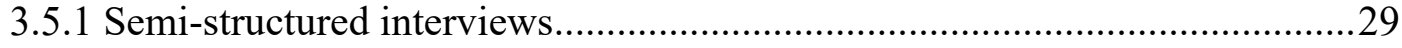

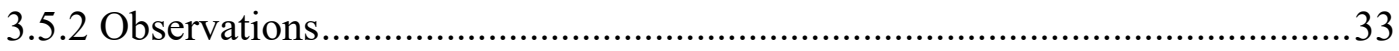

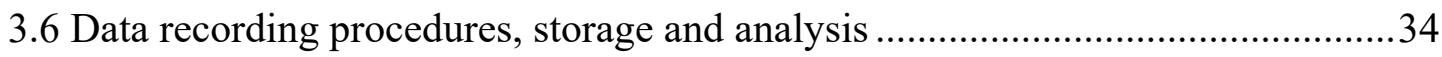

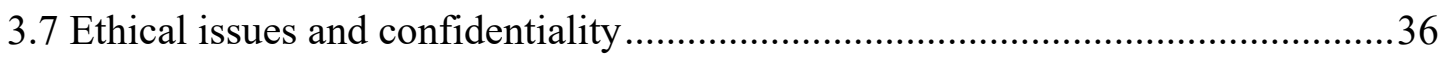




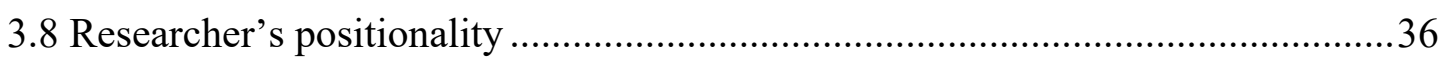

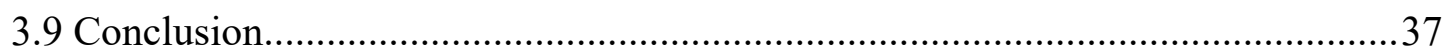

Chapter 4: National Context of Cambodia.......................................................................39

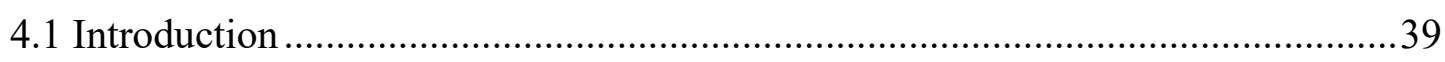

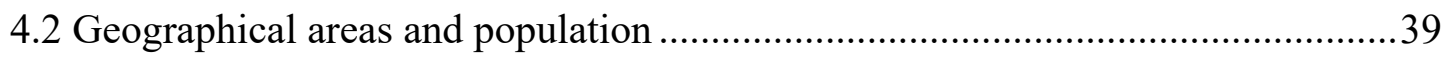

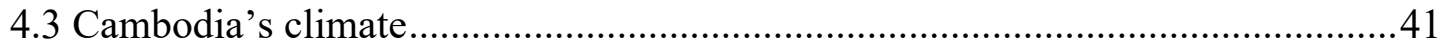

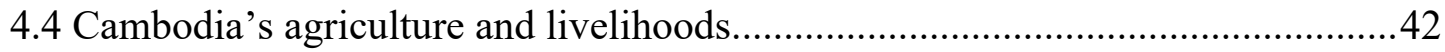

4.5 Climate change, floods and droughts in the context of Cambodia ......................45

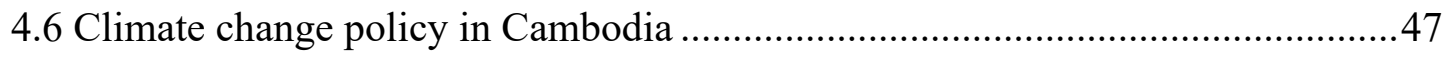

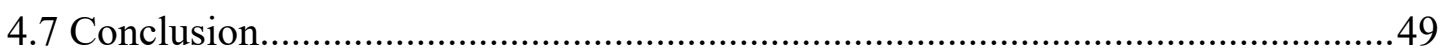

Chapter 5: Perception of Climate Change in the Tonle Sap Lake region ................50

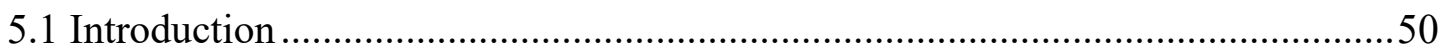

5.2. Local perception of changing the weather as a result of climate change.............50

5.3 Local perception of droughts and high temperature .........................................51

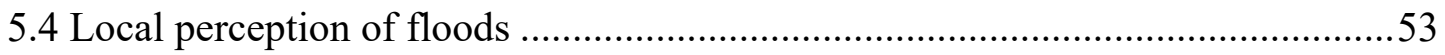

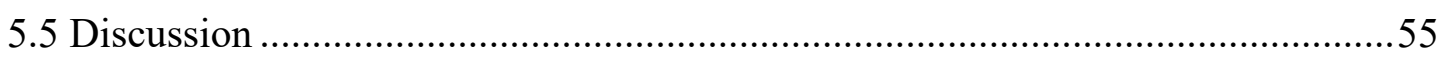

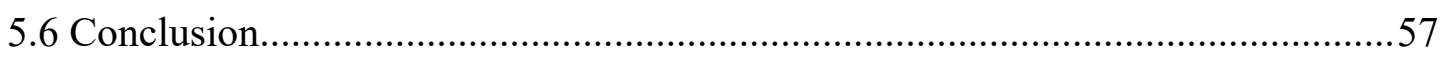

Chapter 6: Impacts of Floods and Droughts on Local Communities and their

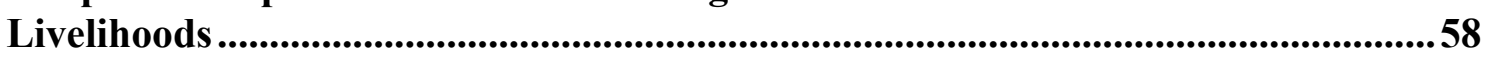

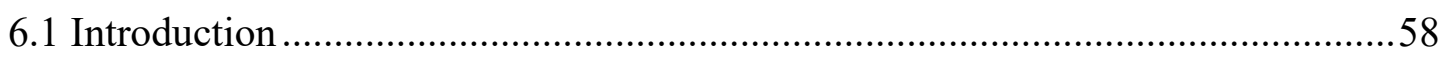

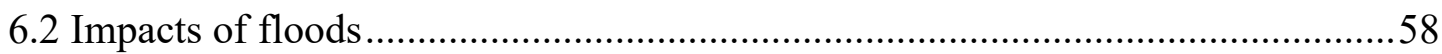

6.2.1 Impacts on individuals and community property .......................................58

6.2.2 Impacts on fishing activities and fish farming ..........................................59

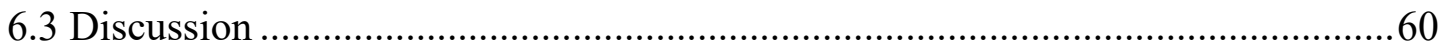

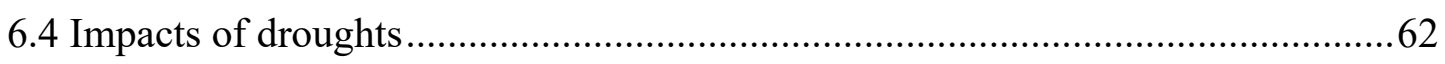

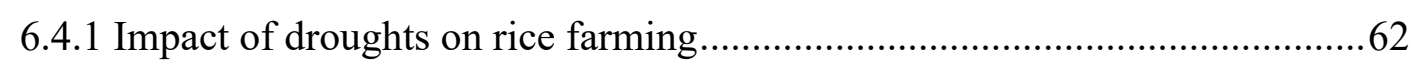

6.4.2. Impacts of droughts on fishing activities ................................................63

6.4.3 Impacts of droughts on secondary livelihood activities ...............................66

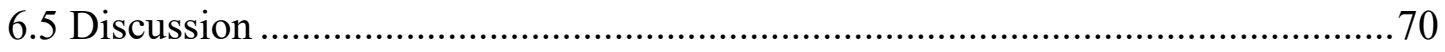

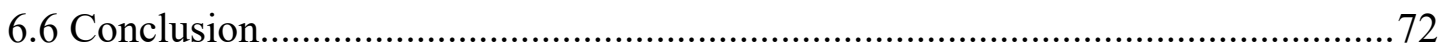

Chapter 7: Local Practices as Adaptation Strategies to Deal with Floods and

Droughts............................................................................................................................................... 73

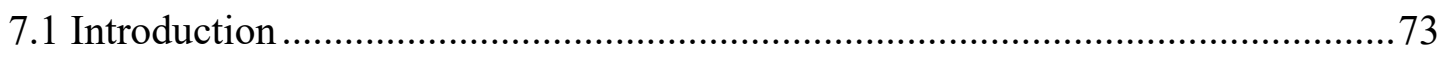

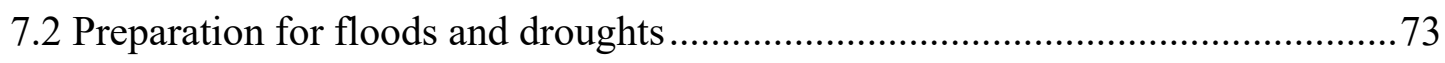

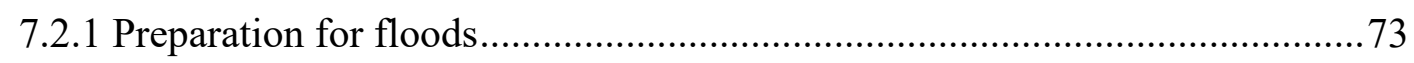

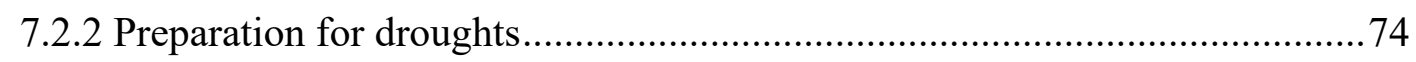

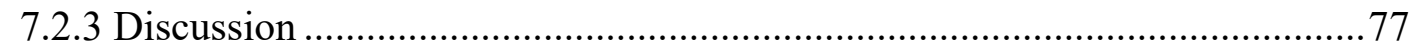

7.3 Local adaptation practices to generate income …............................................ 78

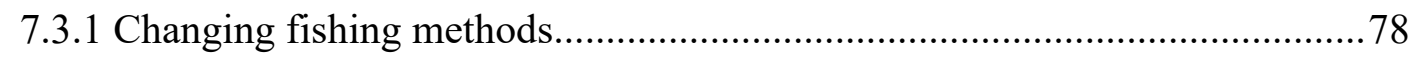




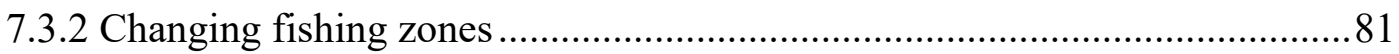

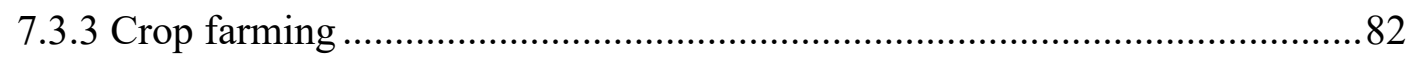

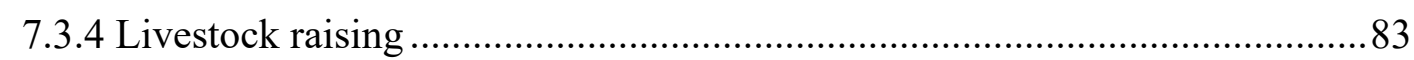

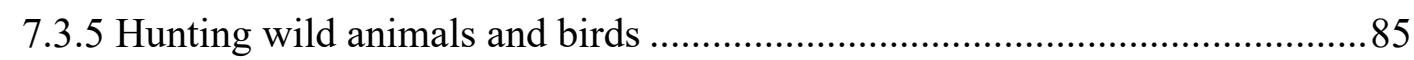

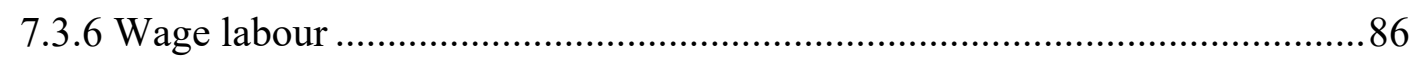

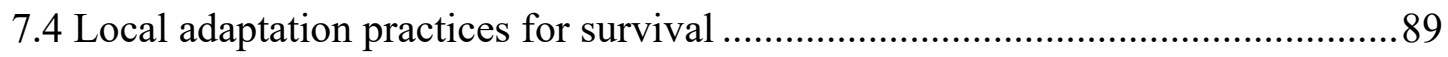

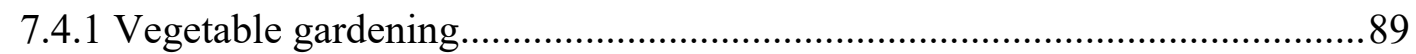

7.4.2 Collecting wild edible vegetables and plants ...........................................90

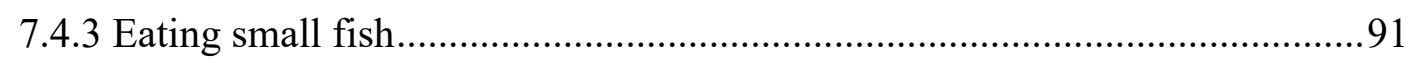

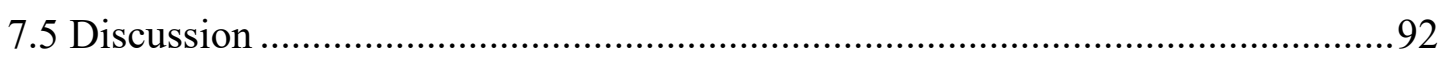

7.6 Indigenous knowledge generation and its roles in developing livelihood

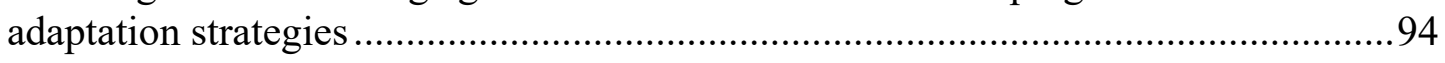

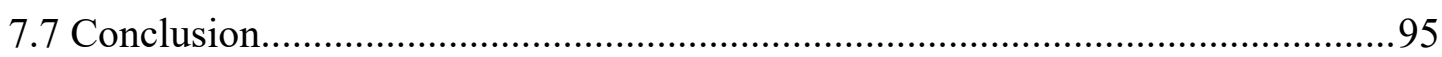

Chapter 8: Conclusion ..........................................................................................97

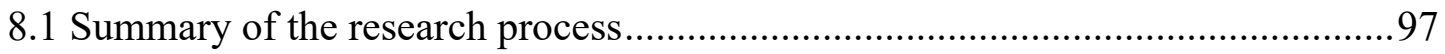

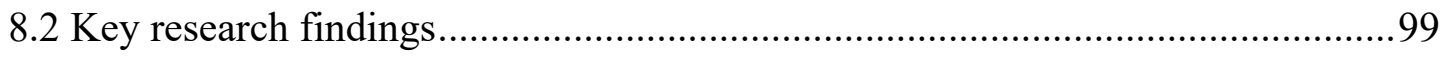

8.2.1 Local perception of climate change, floods and droughts............................99

8.2.2 Impacts of floods and droughts on local livelihoods ..................................101

8.2.3 Local practices and roles of indigenous knowledge in developing adaptation

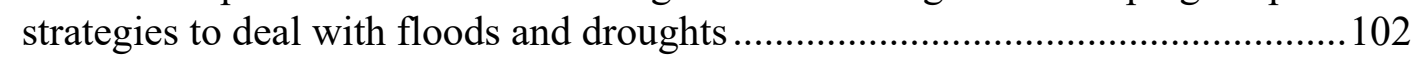

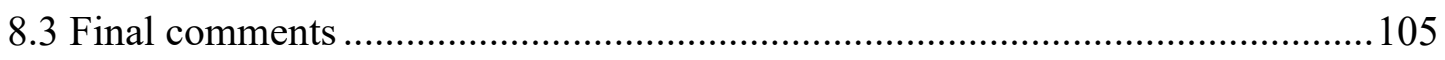

References ...........................................................................................................107

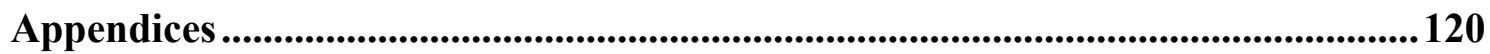




\section{List of Figures}

Figure 1. Map of Tonle Sap Lake - Cambodia. 29

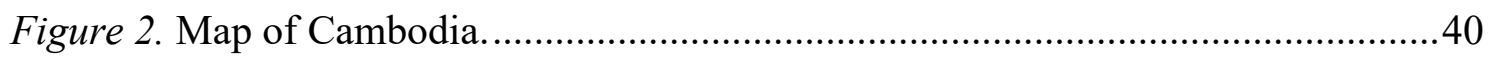

Figure 3. Average monthly temperature and rainfall of Cambodia (1901-2016)..........42

Figure 4. Total imports and exports of fish and fishery products for Cambodia............44

Figure 5. Total capture and aquaculture production for Cambodia (tonnes)..................44 


\section{List of Tables}

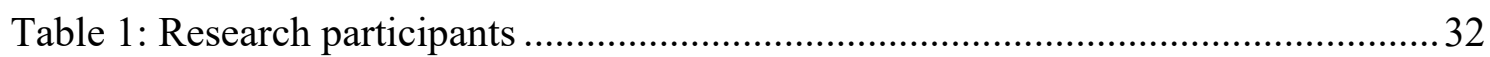

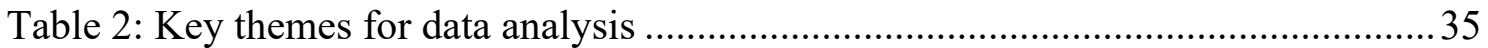




\section{List of Appendices}

$\begin{array}{ll}\text { Appendix 1. Ethical approval } & 120\end{array}$

$\begin{array}{ll}\text { Appendix 2. Participant information sheet in English } & 121\end{array}$

Appendix 3. Participant information sheet in Khmer 123

Appendix 4. Participant consent form in English 125

Appendix 5. Participant consent form in Khmer 126

Appendix 6. Question guide for local communities 128

$\begin{array}{lr}\text { Appendix 7. Question guide for local authorities } & 130\end{array}$

Appendix 8. Question guide for NGO staff 132 


\section{Acronyms}

\begin{tabular}{|c|c|}
\hline AR5 WGII & Assessment Report 5 Working Group II \\
\hline CCCA & Cambodia Climate Change Alliance \\
\hline $\mathrm{CCCO}$ & Cambodia Climate Change Office of Ministry of Environment \\
\hline CCCSP & Cambodia Climate Change Strategic Plan \\
\hline DCC & Department of Climate Change of Ministry of Environment \\
\hline FAO & Food and Agriculture Organisation of United Nations \\
\hline GDP & Gross Domestic Product \\
\hline GSSD & General Secretariat, National Council for Sustainable Development \\
\hline IK & Indigenous knowledge \\
\hline IPCC & Intergovernmental Panel on Climate Change \\
\hline KEI & Korea Environment Institute \\
\hline KHR & Cambodian Riel (currency of Cambodia) \\
\hline MRC & Mekong River Commission \\
\hline NAPA & National Adaptation Programme of Action to Climate Change \\
\hline NCSD & National Council for Sustainable Development \\
\hline NGO & Non-governmental organisation \\
\hline OECD & Organisation for Economic Co-operation and Development \\
\hline SDGs & Sustainable Development Goals \\
\hline $\mathrm{UN}$ & United Nations \\
\hline UNDP & United Nations Development Programme \\
\hline UNDRR & United Nations Office for Disaster Risk Reduction \\
\hline UNESCO & United Nations Educational, Scientific and Cultural Organisation \\
\hline UNFCCC & United Nations Framework Convention on Climate Change \\
\hline UNISDR & United Nations International Strategy for Disaster Reduction \\
\hline USAID & United States Agency for International Development \\
\hline USD & United States Dollar \\
\hline
\end{tabular}




\section{Chapter 1: Introduction}

\subsection{Research background}

Climate change is one of the main challenges for development in every country. Its impacts have been increasingly severe and apparent from year to year. Climate change has been observed to have significant impacts on people and natural systems (IPCC, 2014). According to IPCC's 2018 report, global warming has had great impacts on the human and natural systems. Global warming has changed land and ocean ecosystems (IPCC, 2018). Wuebbles (2018) argues that people are affected by certain types of extreme weather and sea-level rise - the result of climate change. Extreme weatherrelated events such as floods, droughts, storms and heat waves have caused substantial damage to human society, including human health and wellbeing (Thomas, 2017; Wuebbles, 2018).

In the last few decades, scientific studies have shown that climate change has significant impacts on people's livelihoods around the globe (Carvajal, 2007). Livelihoods of the least-developed nations have been most vulnerable to climate change. The IPCC and OECD reports reveal that climate change has increased the frequency and magnitude of severe weather events and threatened local communities that rely on agricultural livelihoods and fisheries (IPCC, 2018; OECD, 2016). Local communities from developing countries have been found to be the most vulnerable to climate change since the natural resources on which they rely, such as land, water, fisheries and forest, have been devastated by climate change (Reid, 2014). Current severe floods and droughts, which are attributable, at least in part, to climate change have significant impacts on communities around the world. According to Smakhtin et al. (2014), floods and droughts are the most economically and socially damaging disasters accounting for approximately $90 \%$ of people affected by all-natural disasters. Güneralp et al. (2015) claim that, among the natural hazards, floods and droughts have caused severe damage to infrastructure and affected livelihoods of millions of people annually.

In the least-developed countries, floods and droughts have been observed as major threats to local people since they have affected their livelihoods and endangered their lives. The majority of local people in the least-developed countries are dependent on 
agricultural production for their primary livelihoods. However, agricultural production in these local communities has been threatened by severe floods and droughts. The Food and Agriculture Organization (FAO, 2016) estimated the economic losses from floods, droughts and storms to be, on average, USD250-300 billion per year. In ten years (2003-2013), crop and livestock production losses due to floods and droughts widely vary across the least-developed countries. The studies of the impact of climaterelated disasters (flood, drought, and storm) on crop and livestock production in leastdeveloped country regions such as sub-Saharan Africa, the Near East, Asia, Latin America and the Caribbean, show that floods and droughts are particularly the most harmful disasters for agriculture (FAO, 2016).

In Cambodia, agriculture plays a significant role in the national economy and accounts for $35 \%$ of the country's gross domestic product (GDP). It also employs a vast majority of the country's population, especially rural people (FAO, 2019a). Nearly $80 \%$ of the Cambodian population live in rural areas, and $65 \%$ of the rural population are dependent on agriculture, fisheries, and forestry for their main livelihoods (USAID, 2019a). In the Tonle Sap Lake region, agriculture and fishery resources are essential for rural communities in this region, and play a crucial role in shaping the country's economy. The flood pulse of the lake is essential in retaining high aquatic productivity. It also brings water and fertile silt to the rice fields promoting rice farming in the floodplain (Nuorteva et al., 2010). Rice and fish in the region are the foundations of food security and income, and thus the local communities living in the region are strongly dependent on fishing and rice farming for their main livelihoods (Johnstone et al., 2013; Nuorteva et al., 2010).

However, in the past few decades, human activities in Tonle Sap Lake and the Mekong River, as well as climate change, have caused significant changes to the lake and its ecosystems (Uk et al., 2018). Increases in water level and extent of flooding, caused by climate change and hydropower development in the Mekong River, have threatened fish production, plants and wildlife (Uk et al., 2018). Changes in flooding duration in the Tonle Sap floodplain have changed wetland habitats and therefore affected fish and other aquatic production and livestock production - the primary sources of local livelihoods (MRC, 2010). Besides flooding, droughts also occur in the region. Droughts are usually reported as more severe than floods. For instance, severe droughts that occurred in 2002 and 2012 led to crop damage, food insecurity and diseases. The 
droughts that happened in these two separate years affected more than two million people and destroyed hundreds of thousand hectares of farming crops and rice fields (Nguyen \& Shaw, 2011; Reuy, 2012). In recent years, droughts in the region have become even more severe with more significant impacts on local communities' livelihoods, threatening their food security. The droughts in recent years have caused the lake to become very shallow, and the tributaries in the Tonle Sap floodplain dried up. The fish catch was reported to have decreased, and thousands of hectares of crops were destroyed (Seiff, 2017; Sullivan, 2019).

\subsection{Overall objectives of the research}

The overall objective of this thesis is to investigate the impacts of floods and droughts in the Tonle Sap Lake region, and examine to what extent the local people's indigenous knowledge (IK) has been used to deal with floods and droughts, and its effectiveness. Since climate change has affected the local communities and their livelihoods, this research aims to study how the local communities perceive climate change, especially floods and droughts. Then, it investigates how the local communities have used their IK to formulate adaptation strategies to adapt to floods and droughts that have happened over time in this region. This study mainly focuses on livelihood adaptation methods that the communities have been practising during severe floods and droughts.

\subsection{Research questions}

To reach the overall objective of this study, a key question was addressed "How do local people in the Tonle Sap Lake region use their indigenous knowledge to respond to floods and droughts?" To answer the key question, I developed four sub-questions:

1. What are the local people's perceptions of the floods and droughts?

2. How have the local people and their livelihoods been affected by floods and droughts?

3. What strategies do local people use to recover from the effects of floods and droughts?

4. How might indigenous knowledge be incorporated into adaptation policies? 


\subsection{Significance of the research}

This research is associated with development theory and the arguments about development and IK. As claimed by some researchers, IK is a very effective strategy in the ongoing struggles against poverty, hunger and underdevelopment. It also allows local people to live in harmony with nature, maintain sustainable resources and achieve balanced development (Agrawal, 1995; Briggs, 2014; Sillitoe, 1998). Furthermore, IK has been recognised for its value regarding climate change hazards and weather forecasting, and it has been a critical resource for communities in understanding the environment, and assessing and adapting to climate change in the past (Deeb et al., 2011; Green \& Raygorodetsky, 2010). Therefore, this research provides academic researchers, development practitioners and policymakers with an insight into IK of the Tonle Sap Lake communities, and how it has been used to combat climate change, particularly floods and droughts. This research contributes to the existing literature of the impacts of floods and droughts in the region since it reports the real situation of current effects of floods and droughts that local communities have experienced. The research also provides final comments for local government and development practitioners so that they are able to support and strengthen local adaptation capacity to climate change effectively and sustainably.

\subsection{Research outline}

This research thesis is divided into eight chapters. This first chapter delivers an introduction to the research by illustrating the research background, research objective, research questions and the significance of the study. The second chapter reviews literature about climate change, its impacts, IK and development, and the importance of IK in adaptation strategies to deal with climate change. The third chapter provides information about the methodology used to achieve the objectives of the research, including epistemology, research methods, research location, participant recruitment and my positionality. The fourth chapter presents a national context including geographical area and population, climate, agriculture and livelihoods, and climate change policy at international and national levels. The fifth chapter explains the Tonle Sap Lake communities' perceptions of climate change, particularly floods and droughts. The sixth chapter describes the impacts of floods and droughts on local livelihood, while the seventh chapter explains how communities have practised their livelihood 
adaptation strategies to deal with floods and droughts. The last chapter concludes the summary of the research process, key findings, and final comments. 


\section{Chapter 2: Literature Review}

\subsection{Introduction}

This chapter reviews literature about climate change, its impacts and local responses to natural hazards. The chapter is divided into four core sections. The first section explores the relationship between environment, climate change and development. The second section examines public perceptions of climate change. The third section investigates the incidence of floods and droughts, and their impacts on environment, society and economy. The last part discusses IK, its relationship with development, and how it has been used by local communities in different countries around the globe to respond to the impacts of climate change, particularly floods and droughts.

\subsection{Environment, climate change and development}

The environment is either a resource or a constraint for development. However, climate change is increasingly changing resource-based development, often in detrimental ways. In the twenty-first century, climate change is one of the most significant development challenges in the world. Its present threat is exacerbating the existing global problems (Morecroft \& Cowan, 2010, p. 170). Climate change is affecting people's daily lives and the environment. Extreme weather-related events such as floods, droughts, storms and heat waves, which are a consequence of climate change, cause considerable damage to human society (Thomas, 2017). Over the last four decades, climate-related disasters such as floods, droughts, storms, heatwaves and temperature extremes have enormously increased (Thomas, 2017). These disasters have had great impacts on human health, agriculture, water resources, energy and transportation infrastructure, and more (Wuebbles, 2018).

Furthermore, climate change has impacts on development and the environment. Since it causes death and diseases, and damages infrastructures, climate change is seen as one of the biggest obstacles to the development of every country in the world, and leastdeveloped countries seem to have been the most severely affected by its impacts. According to IPCC and OECD reports, climate change has increased the frequency and magnitude of severe weather events and threatened local communities that rely on 
agricultural livelihoods and fisheries (IPCC, 2018; OECD, 2016). These poor communities are most vulnerable to the changing weather conditions when the natural resources they need, such as land, water, fisheries and forests, have been ruined (Reid, 2014).

Climate change and development are interconnected in complex ways. Most scientists claim that human actions are the leading cause of changes in climate. It is evident that human-induced actions are the main cause of climate change (Wuebbles, 2018, p. 15). The burning of fossil fuels and land-use changes through deforestation (Wuebbles, 2018) and the rise in industrialisation are causing the atmosphere's increasing temperature (Morecroft \& Cowan, 2010). Boyd also states that global warming is a consequence of the development of industries and the burning of fossil fuels (Boyd, 2014, p. 342). Likewise, conservationists claim that climate change and people's reactions to climate change contribute to the severe threats to the natural environment (Morecroft \& Cowan, 2010).

Since the world population is expected to increase sharply in the next few decades, more food and energy sources will be inevitably needed to feed the increased population. Therefore, the food demand for the world's burgeoning population will likely be one of the main factors contributing to the changing climate and environment. Rockström et al. (2009) argue that contemporary agriculture produces significant environmental pollution and causes environmental change. In order to meet the demand for food for the world population, increasing the farming areas and industrialised agriculture are crucial. Nevertheless, industrialised agriculture contributes much to environmental change. Within five decades, 1950-2000, the use of fertilisers rose by twenty-three times and the use of pesticide rose by fifty-three times, which has had massive impacts on the environment (Serageldin, 2009). Furthermore, the increasing world population produces more environmental stress (Rosa \& Dietz, 2012). Larger population produces more greenhouse-gas emissions through people's daily consumption of food, goods, and services, and there are more carbon dioxide emissions through congested traffic (Rosa \& Dietz, 2012).

Evidence shows that people's actions have caused environmental change and global warming. In return, climate change is affecting environmental resources, people's lives, the planet, and the development of every country. In order to mitigate the effect of 
climate change, a sustainable development approach might be a solution. In 2015 , the United Nations (UN) launched 17 Sustainable Development Goals (SDGs) that all UN members embraced. Combating climate change is one of the goals that all the UN members agreed to achieve by 2030 (UNDP, 2016). Given the unsustainable world economic growth and willing to ensure social and environmental sustainability, several international organisations have launched the initiative of "Green Economy" (MartinezCovarrubias \& Garza-Reyes, 2017). The green economy aims to "reduce dependence on fossil fuels, minimise impacts to ecosystems, and sustain socioeconomic wellbeing for all people by ensuring social equity and a fair distribution of wealth" (Richardson, 2013, p. 8). The green economy is developed through innovation and the development of new skills in green sectors such as energy efficiency, clean energy, alternative transportation, green design and construction, recycling, and organic agriculture (Richardson, 2013). To diminish the threat to future economic growth and stability, the global economy should not damage environmental assets and natural resources (Martinez-Covarrubias \& Garza-Reyes, 2017).

\subsection{Perception of climate change}

Perception is defined as the process by which we receive information from our nature and convert it to psychological knowledge to construct meaningful experiences of the world (Van den Ban \& Hawskins, 2000, as cited in Ahmed \& Atiqul, 2019). Climate change has affected every individual around the world. However, people's perceptions of climate change vary greatly. Thus, understanding of local knowledge and perception of weather and climate is critical for developing an effective climate change policy at a given place (Gamble et al., 2010). Slovic (1987) also suggests that policy regarding hazard management needs to understand people's perception and how they respond to hazards because failure to understand people's perceptions could contribute to ineffective policies. Shukla et al. (2016) argue that local communities' perceptions reflect local issues because the local people live closely with nature and have a close interactive understanding of their environment. The perceptions of these local people are developed from day-to-day connections with their nature and their dependence on climate conditions to ensure food security (Laidler, 2006). 
Likewise, several studies demonstrate that local people could gain knowledge of deviations from what is perceived to be normal weather and climate conditions through their frequent observation of, and interaction with, the surrounding nature even though they have limited knowledge about the science of climate change (Gamble et al., 2010). In addition, Margaret et al. (2018) suggest that how people understand and perceive climate change is significant for developing policies that are intended to address the issues and their willingness to change behaviour. Therefore, people's perceptions of climate change play a significant role in forming natural hazards policies (Shukla et al., 2016).

Every person has a different perception of climate change. Public perceptions of the threats posed by climate change differ between regions and countries (Taylor et al., 2014). Pettenger also points out that "Ask ten people how to define climate change, its causes and effects, and you will get ten different answers" (Pettenger, 2007, p. 5). For instance, researchers have found that residents in the United Kingdom (UK) and the United States (US) have different observations and perceptions about climate change. The UK residents were likely to refer to 'rain' when they described climate change, while the US residents were more likely to mention 'heat' and 'ice caps melting' (Taylor et al., 2014). Even within one country, public perception about climate change could differ in accordance with the viewpoints and observations of local people living in different regions. In the UK, for instance, local people in the northern territory may have experienced hotter summers and warmer winters than those living in the southeastern territory (Palutikof et al., 2004). Perceptions of climate change differ from one individual to another depending on their knowledge, cultural worldviews, weather conditions, and geographical location (Shi et al., 2015; Shukla et al., 2016; Palutikof et al., 2004).

Taylor et al. (2014) suggest that, since the perception of climate risk differs between people and within locations, the support for adaptation policies should be developed differently based on the people's location. Geographical location, knowledge, culture and attitude of people may reflect how the individuals perceive climate change. Thus, proper adaptation policies should be conducted based on the actual people's perception in a specific location. 
Nevertheless, a number of studies that have been conducted in various developing countries across the globe have revealed that local communities with similar knowledge have perceived climate change similarly. Those local people mainly mention about rainfall pattern, flooding, droughts and extreme temperature when they describe climate change. For instance, studies conducted in southwestern Jamaica, India, Pakistan and African Sahel region demonstrated that severe droughts and extreme temperature are the major risks for local people since they have affected people's lives and agriculture production (Abid et al., 2016; Gamble et al., 2010; Nyong et al., 2007; Shukla et al., 2016). The studies also revealed that changes in rainfall pattern have been a major risk for local people in India and Northern Thailand (Manandhar et al., 2015; Shukla et al., 2016).

\subsection{Incidence of floods and droughts}

\subsubsection{Natural occurrence of floods and droughts}

Floods and droughts are hydrologically life threatening. Floods are related to excessive rainfall (from tropical storms, thunderstorms, orographic rainfall, widespread extratropical cyclones, etc.), while droughts are associated with a shortage of rainfalls and frequently severe high temperatures that lead to drying (Trenberth, 2005). Collier and Webb (2002) argue that drought is not as simple as only a shortage of rainfall, but it is a lack of protracted humidity below longstanding average conditions that balance precipitation and evapotranspiration in a specific area. All droughts are not equally formed. Shortage of humidity could have diverse results depending on the time of year when they happen, previous moisture content of the soil, and other climatic features such as temperature, wind, and the amount of moisture in the air. Hydrologic drought happens when there is a shortfall of surface water supply (i.e., stream flow, reservoir and lake levels, ground water) during a dry spell (Collier \& Webb, 2002). According to OECD (2016), drought is defined as a short-term loss of water in rivers or waterways, caused by lengthy deviations from average levels of rainfall. Drought is a normal and frequent feature of climate, and, under certain circumstances, becomes a disaster (OECD, 2016). 
Floods happen in many ways due to an overflow of stream, rivers, lakes or oceans or as a result of excessive rain. Floods result from a number of basic factors. One of the most critical factors is meteorological in nature. Exceeding a river's discharge of its channel's volume causes a river to overflow onto the area surrounding the channel known as the floodplain. This phenomenon is known as flooding (Jackson, 2014, August 2). However, flooding is known as a complex phenomenon. According to (Collier \& Webb, 2002), rainfall on wet ground, falling of warm rain on current snowpack, torrential rainfall throughout a whole basin or changing of basin shape, are all the causes of flooding. Rising temperature and spring melting of winter snow trigger off flooding (Collier \& Webb, 2002). Lancaster et al. (2004) mention that flooding may happen from many bases: the sea (coastal and estuarine flooding), watercourses (fluvial flooding), overland flow of water that does not reach a natural drainage channel (fluvial flooding), rising groundwater, and the failure of artificial water systems. The OECD 2016 report briefly describes floods as rises in the water level of a stream or water body to a peak from which the water level recedes at a slower rate.

\subsubsection{Climate change and floods and droughts}

Floods and droughts occur all over the world, and they affect people's livelihood and development of every country, especially in developing countries. In the last few decades, it is evident that global warming is changing because of natural and anthropogenic greenhouse gas emissions. It is believed that climate change or global warming has a magnifying effect on floods and droughts. According to Van Aalst (2006), the main greenhouse gas, carbon dioxide $\left(\mathrm{CO}_{2}\right)$ has been emitted and dramatically increased in the atmosphere because of the industrial revolution, changes in agriculture and land use. The global warming is a result of rising greenhouse gases in the atmosphere, which leads to extreme weather events such as heatwaves, wildfires, cyclones, floods, and droughts (Van Aalst, 2006). The OECD 2016 report also describes that global warming and changing weather result in flood and drought. Excess or deficit of rainfall, together with other variables such as temperature, humidity, air and soil, and wind, are the main causes of floods and droughts (OECD, 2016). As mentioned by Schwartz (2018), the stalled weather system, caused by the changes in atmospheric circulation, can lead to extreme rainfall and the lack of it (prolonged sunny weather). Likewise, McCarthy (2001) describes that change in climate is likely to change average 
temperature and precipitation values and increase the variability of precipitation events. This may lead to even more extreme and recurrent floods and droughts.

\subsection{Impacts of floods and droughts}

In the last few decades, floods have increasingly affected our ecosystems, local people and socioeconomic activities such as fishing, farming, transportation and human health, while droughts create lengthy disruptions in forests and difficulties in river transportation, farming and fishing, which disrupts the food supply to people, disturbs hydroelectric power generation and affects human health, mainly because of smoke from forest fires (Wongchuig Correa et al., 2017).

\subsubsection{Environmental impacts}

Floods and droughts are natural hazards that can cause harmful impacts on people and environmental resources. The freshwater system is one of the valuable natural resources for daily use of people. Availability of freshwater is essential for both human wellbeing and the economy. The supply of freshwater is used for various purposes, such as drinking, irrigation, hydropower production recreation, fisheries, etc. (Li et al., 2017). However, this resource is affected when flood or drought occur. Drought can affect water quality in many ways. Typically, decreased volume of water during a drought leads to increased salinity, longer hydraulic residence times, promoted toxic cyanobacterial blooms, and lowered dissolved oxygen concentrations (Mosley, 2015). A change in water quality because of drought also affects fish species i.e., lower fish recruitment rates, slower growth rates, and higher mortality rates (Mickle et al., 2018). In addition to freshwater, drought can also be a constraint on plant growth and limit crop yield due to the lack of precipitation and soil moisture (Li et al., 2017). Besides this, drought also causes damage to other ecosystems and environmental resources such as pastures, farms, forests and plants, and animals since they require water for survival (Devisti \& Motamed, 2012).

Flooding is another natural disaster that causes negative impacts on people's lives and environmental resources. Stuyt et al. (2007) states there are very few studies that have been conducted about the impact of flooding events on the environment, instead, the 
studies normally focus on damage to buildings, infrastructure, and economic loss. Nonetheless, flooding has an obvious negative impact on the environment. According to the study of Stuyt et al. (2007), flooding in the area of dense population may cause significant impact on the environment and agriculture because of physical damage to crops and installations and, because of toxic sediments on an agricultural field. Flood water destroys houses, industrial buildings and farms. The damage releases harmful substances such as suspended solids and chemicals that enter the flood water, affecting people and ecosystems in the flooding zone (Stuyt et al., 2007).

Flash floods, on the other hand, can cause problems with drinking water. When a flash flood occurs, floodwater damages water supply systems, causing an inadequate availability of drinking-water supplies for people (Sun et al., 2016). The most severe effect of flooding is when drinking water is contaminated with microorganisms such as bacteria, sewage, heating oil, agricultural or industrial waste, chemicals, and other elements that can cause acute sickness (Sun et al., 2016). Furthermore, the flash flood may also cause damage to other natural vegetation such as riparian forests. According to Kozlowski (2002), riparian forest ecosystems are essential for their high-biomass productivity, which controls erosion and floods, remove nutrients from agricultural runoff, and reduces the impacts of air pollution and soil contamination. Riparian forests also provide critical habitat for various bird species and mammals. However, a sudden rise and fall of flood discharges combined with fast-flow rates during the flash flood may destroy the riparian forests or prevent them from growing (Kozlowski, 2002).

\subsubsection{Socioeconomic impacts}

Floods and droughts are among the regular, hazardous, and pricey of all-natural disasters that cause severe damage to infrastructure and affect the people's livelihoods of millions every year (Güneralp et al., 2015). According to Smakhtin et al. (2014), floods and droughts are the most economically and socially damaging disasters, accounting for approximately $90 \%$ of people affected by all-natural disasters. Between 1900 and 2006, the most devastating events happened 1,000 times in which almost 90\% of the events were involved by water-related hazards such as floods, droughts and windstorms (Güneralp et al., 2015). Since the early 1980s, economic losses because of water-related hazards rose above 500\%. In particular, floods and droughts made up 38\% of the total natural disasters, $45 \%$ of the total causalities, over $84 \%$ of the total number 
of people affected, and $30 \%$ of the total financial losses affected by all-natural disasters (Güneralp et al., 2015). According to the United Nations International Strategy for Disaster Reduction (UNISDR, 2002), in 20 years since 1992, floods and droughts also caused more than USD500 billion worth of damage, which made up 28\% of the total destruction from all disasters. Two other recent examples of great financial losses caused by flooding is in Thailand (2011) and Pakistan (2010). In 2011, Thailand's floods, economically, cost USD40 billion while the cost of Pakistan's flood was estimated at USD43 billion with over 2,000 people being killed (Gopalakrishnan, 2013).

Flooding has great negative impacts on people's lives and socioeconomic activities such as fishing, farming, transportation and human health (Wongchuig Correa et al., 2017). Rapsomanikis et al. (2017) state that 20-300 million people worldwide are affected by floods each year. The vulnerability to floods has increased, and more property, assets and lives have suffered from flooding. In the floodplain of Northern Italy, severe flood events have been remarkable in the last two decades. From the year 2000 to 2014, floods in this floodplain region have caused 200,000 dead animals, more than 40,000 people to become homeless, more than 500,000 displaced people, $8 \mathrm{missing}$ and/or dead people, and over a billion euros' worth of damages, including private, public, and industrial properties (Roder et al., 2017). In Pakistan, during 2010-2011 more than 2,500 people died in severe floods, and 27 million were affected. The floods also caused livestock to die and destroyed agricultural lands, resulting in billions of US dollar loss (Smakhtin et al., 2014).

Agriculture plays a vital role as the primary source of people's livelihoods in all countries in the world. Natural disasters such as floods and droughts are the most significant challenges to agriculture development. Floods and droughts have caused significant damage to agricultural development, particularly in developing countries. The Food and Agriculture Organization (FAO, 2016) estimated the economic losses from natural disasters such as floods, droughts and storms at the average of USD250300 billion per year. During 2003-2013, the crop and livestock production losses due to climate-related disasters vary widely across developing countries. The studies of the impact of climate-related disasters (flood, drought, and storm) on crop and livestock production in developing country regions such as sub-Saharan Africa, the Near East, Asia, Latin America and the Caribbean, show that floods and droughts are the most harmful disasters for agriculture (FAO, 2016). In these four regions, the economic 
losses of crop and livestock production due to floods and droughts account for $95 \%$ (USD67 billion), while storm accounts for only 5\% (USD3 billion) (FAO, 2016).

Agriculture is a critical economic sector for most developing countries in the world, particularly in sub-Saharan African countries. However, in these countries where agriculture contributes to its national economy, droughts have caused major direct impacts such as reducing crop yields and forest productivity, reducing the water level, creating a fire hazard, devastating wildlife and fish habitats, and increasing livestock and wildlife mortality (UNISDR, 2015). Studies in Nepal and India also revealed that droughts have caused great damage on agricultural production of the rural communities. Agricultural production is the primary livelihood and food security of the rural people in these two countries. However, the impacts of severe droughts on agricultural production have threatened rural food security (Adhikari, 2018; Udmale et al., 2014). For example, the severe drought in one of the Indian states, Maharashtra, 2012, caused a huge impact on local livelihood. The local people in Maharashtra state experienced a shortage of water for their daily consumption and for agriculture. The severe drought in this state caused a vegetable production decrease of $11 \%$ compared to the previous year, and the inland fishery suffered a 16\% production loss (Udmale et al., 2014). Likewise, in Nepal, agriculture is an important livelihood activity of rural people. Crop growing including rice, wheat, maize, millet, barley, and buckwheat, and livestock farming are major forms of food security in the rural communities. Yet, droughts that have happened over several years have made the agriculture in Nepal less stable and less productive (Adhikari, 2018). According to the UNDP (2009) report, meteorological events from 1971-2007 caused, roughly, 90\% of the crop or agricultural land loss in Nepal. Of the different disasters in Nepal, drought had the most severe impact on agriculture and crop loss accounting for $39 \%$ of the impact. Moreover, severe droughts that happened in Africa have caused huge losses of crop and livestock production. According to the FAO (2015) report, the absolute losses were more than USD14 billion, accounting for about $6 \%$ of the projected value of production. Severe droughts have caused most countries in Africa to experience rapid declines in yields. Such losses pose a great threat to food availability, rural livelihoods and the overall economy, especially given the important contribution of agriculture to food security and the economies of sub-Saharan Africa (FAO, 2015). 
Given the affected agriculture and natural resources and decreasing incomes of local people as a consequence, together with rising food and timber rates, indirect impacts on the whole society such as malnutrition in children, increased unemployment rate, migration, reduced tax revenue, and the risk of foreclosures on bank loans to farmers (UNISDR, 2015) need to be considered.

\subsection{Indigenous knowledge}

\subsubsection{Indigenous knowledge system}

The concept of indigenous knowledge (IK) has frequently been related in the Western context to the basic, the wild, and the natural (Semali \& Kincheloe, 1999). Condescending Western viewpoints have meant that the insight into, and understanding of, IK have been only lightly appreciated. However, for the millions of indigenous peoples of Africa, Latin America, Asia, and Oceania, IK is a daily rationalisation that rewards local communities. To some extent, to these local communities, IK reflects the vigorous means in which the people of a given place have come to understand themselves in association with their natural environment and how they organise that local knowledge of nature, cultural beliefs, and history to improve their lives (Semali \& Kincheloe, 1999). According to UNESCO (2017), local and indigenous knowledge refers to the understandings, abilities and ideologies evolved by societies with long histories of interaction with their natural environment.

For over half a century, IK systems have caught the attention of anthropologists (Hunn, 2007). Recently, interest among researchers and development workers from different backgrounds such as international development, resource management, sustainability and resilience, disaster response, climate change, ethnobotany, ethnomedicine, and ethnoveterinary studies has increased both within and beyond the discipline (UNESCO, 2009). Senanayake (2006) argues that IK is the social capital of the poor communities. It is a valuable asset that the poor use to invest in the struggle for survival, to make food, to provide for shelter and to control their lives. 


\subsubsection{Indigenous knowledge and development}

Since the second World War, the agenda for development has moved through several phases; from focusing on economic growth, equity growth, to basic needs, to participatory development, to sustainable development (Agrawal, 1995). Over recent eras, IK has an been appealing phrase in the rhetoric of development. The phrase "indigenous knowledge" has been used by development practitioners and theorists all over the world. In the 1980s, IK gained its interest due to the dissatisfaction of modernisation theory (Briggs, 2014). Through the distribution of formal scientific and technical knowledge from the North to the global South, modernisation theory was defined as a practical approach to reduce poverty and improve living standards of the poor population in the global South. As a result, the influential science discourses from Europe and North America have conceptualised development as a technical issue in the global South and IK was largely discounted. By the 1980s, it was clear that the modernisation approach could not be used successfully to transform many of the poor population, particularly in African countries (Briggs, 2014, p. 127). Likewise, postdevelopment theorists argue that the failure of development is not only because the entire concept of development and its practice has become theoretical, illustrating the domination of the West over the rest of the world; but also because the process of development has been taken out of the hands of local people (Dada, 2016, p. 75).

Accordingly, other alternatives should be pursued in order to foster local development movement. Dada (2016) mentions that development is a cultural process and people should be involved in this process since they are the objects of the development. Tradition and lived experiences of the people need to be considered in the development process. Moreover, it should be acknowledged that people have their own effective science, resources, knowledge, and management systems that are essential for development (Sillitoe, 1998). In this regard, IK has been considered one of the essential elements of the development process. Sillitoe (1998) illustrate the example that research in IK has started to make connections between local people's understandings and practices and researchers and development practitioners, especially in the natural resources and health sectors. This research seeks to obtain in-depth understanding of people's experiences and objectives and to link them to scientific knowledge with the purpose of contributing, in the longer term, to positive change, and promoting culturally appropriate and environmentally sustainable adaptation for people who deplete their resource for profitable purposes (Sillitoe, 1998). 
Some researchers have emphasised that IK is the latest and best strategy in the longstanding combat against poverty, hunger, and underdevelopment (Agrawal, 1995; Briggs, 2014; Sillitoe, 1998). Since IK has allowed people to live in harmony with their environment, using it sustainably is essential in discussions of sustainable resources use and balanced development (Agrawal, 1995; Briggs, 2014). This position stands in complete contrast to the viewpoints of modernisation theorists, who saw IK and institutions as inferior and barriers to development. However, modern formulations acknowledge that it is careless and naïve when the knowledge of the poor and marginalised people is disregarded (Agrawal, 1995).

IK is not only an essential and appropriate method to allow poor communities to develop themselves, but it is also beneficial to the sustainable development of local communities. Breidlid (2009) suggests that the lack of respect for IK and the assumption of many Western researchers about the dominance of Western knowledge and scientific discourse is a grave problem to sustainable development in view of evident failure to meet human development needs and, at the same time, to protect environment and ecosystem. Nevertheless, some Western scientists have started to realise that they may learn something from the developing countries and that IK might depend on their scientific understanding of natural phenomena, which could be vital for sustainable development (Breidlid, 2009). Sillitoe also claims "it is increasingly recognised that development initiatives that pay attention to local perceptions and ways are more likely to be relevant to people's needs and to generate sustainable interventions" (Sillitoe, 1998, p. 224). For centuries, indigenous communities have been practising their knowledge and adapting it to their lands. For them, their lands are extremely important; it is where social, cultural and environmental activities happen. Sustainable production and consumption practices together with resource conservation and management methods are among these activities, primarily based on their IK and routine governance structures (Magni, 2017). The importance of IK has been recognised and incorporated into the SDG (2030 Agenda) because IK can be used to address universal problems by explaining its meanings, natures and purposes; by understanding how it is put into practice and its consequences; and by underlining the significance for indigenous people to be able to entirely understand their rights. However, in order to ensure the effective incorporation of IK to address the primary concern of the 2030 Agenda, participatory methods are crucial to ensure the right and balanced 
representation of different knowledge systems, especially of indigenous and scientific knowledge (Magni, 2017).

In climate change research, IK has been progressively recognised for its value concerning environmental problems, particularly climate-related hazards and weather forecasting (Green \& Raygorodetsky, 2010). In many recent studies, the IK role has been integrated into works that are related to climate hazards and development (Green \& Raygorodetsky, 2010; Raygorodetsky, 2019). Given the importance of IK for sustainable development and adaptation to climate change, UNESCO launched its "Local and Indigenous Knowledge Systems" programme aiming to promote local and indigenous knowledge and its inclusion in global climate change science and policy processes (UNESCO, 2019).

\subsection{Indigenous knowledge and climate change adaptation}

Adaptation has been acknowledged as a critical topic in international and local debates on climate change (Levina \& Tirpak, 2006), and has been considered the most appropriate approach for vulnerable communities to combat climate change. UNFCCC (2019) defines the adaptation as an adjustment in environmental, social, or economic structures in order to respond to real or anticipated climate-related hazards and their impacts. The adaptation concerns the alterations in processes, practices, and structures to reduce serious harm or to get the advantage of the effects of climate change (UNFCCC, 2019).

In recent decades, using IK to adapt to climate change has been an exciting topic for research. Yohe et al. (2007) claim that studies on indigenous environmental knowledge have been conducted in various countries in the world, usually in the context of understanding indigenous oral histories and cultural attachment of local people to their location. Since the interest in climate change and global environmental change has begun to grow, current studies have discovered how IK can be part of a shared learning effort to address climate-change effects and adaptation, and its connections with sustainability (Yohe et al., 2007). Deeb et al. (2011) also suggest "indigenous and local knowledge is a key resource for communities in understanding the environment and assessing and adapting to climate change". 
Indigenous people make up only $4 \%$ of the total world population (250-300 million people), but they use $22 \%$ of the world's land surface (Raygorodetsky, 2019). However, these people have been severely affected by climate change. Indigenous people who are close to the environmental resources frequently witness the activities around them and are the first to recognise and adapt to any changes (Gyampoh et al., 2009, p. 70). With shared knowledge of the land, sky and sea, these people are outstanding in observing and interpreting the changes in ecosystems (Raygorodetsky, 2019). The resulting community-based and shared knowledge provide valued understandings, supplementing scientific information with sequential and landscape-specific accuracy and detail that is vital for validating climate models and evaluating climate change situations developed by scientists at a much fuller spatial and temporal scale. Furthermore, IK offers an essential basis for local adaptation and mitigation programmes that sustain the resilience of social-ecological systems at the interlinked local, regional and global scales (Raygorodetsky, 2019). The IPCC also recognises that IK is a valuable foundation for designing strategies of adaptation and natural resource management to respond to changing of the environment and other forms (Hiwasaki et al., 2015).

Studies and projects on IK and its relevance to the understanding of climate change and formulating adaptation plans have been growing (Hiwasaki et al., 2015). Having seen the importance of IK in adaptation policies and its underrepresentation in previous IPCC assessments, Ford et al. (2016) suggest that IK and experience should be included in the next IPCC assessment reports. Ford et al. give an analysis on how indigenous content should be covered and framed in the Assessment Report 5 Working Group II (AR5 WGII) and propose four methods by which indigenous issues can be more thoroughly incorporated into the IPCC process. The first method is about a specific IKfocused or traditional knowledge chapter in the AR5 WGII. The significance of the chapter exposes the unique sensitivity, adaptability, resilience, and vulnerability of indigenous peoples to climate change, and other perceptions of impacts and adaptation represented in IK systems. The second method is that the Assessment Report 6 should foster more extensive involvement of authors with expertise working with indigenous communities, especially indigenous researchers, leaders, and reviewers because authorship has a critical role to shape content in the IPCC assessment reports. The third method is that the IPCC should create particular guidelines for assessing and integrating IK. The guidelines need to include invaluable information on the human dimensions of climate change that happen outside the scholarly journals; the oral histories, traditional 
practices, and the research documents. These guidelines also need to be developed with IK owners. Lastly, Ford et al. suggest developing a special report on indigenous peoples and climate change in the next IPCC reports, merging both the efforts of WGII and WGIII, which permit global indigenous issues to be documented and examined more deeply and discussing greater flexibility for incorporating IK and the myths, stories, culture, and histories (Ford et al., 2016).

It is clear from the above that IK is a potential asset and it plays a significant role in climate change adaptation. Nyong et al. (2007) have shown an example of how local people in the African Sahel have used their IK to develop a strategic plan to adapt to, and mitigate, the impacts of climate change. In the region of African Sahel, drought has been a serious and frequent natural hazard. The water shortage and high temperature have reduced agricultural productivity in the region. Having faced this extreme event, the local people in the Sahel region used mitigation and adaptation strategies that were developed locally and collectively to solve this problem. The adaptation approach that the local people used was the adoption of adequate environmental resources such as planting early maturing crops, adopting hardy varieties of crops and keeping livestock in areas where rainfall is lower. They also used technology to help them work appropriately in the new conditions. Having continuously adapted their farming, livestock keeping, and other income-generation activities, the local people in the Sahel region successfully improved their sustainable livelihoods level (Nyong et al., 2007).

There are more examples of IK being used by local people to adapt to environmental changes in different places in the world. Below, Lebel (2013) illustrates a number of examples of how local communities in different countries, e.g., Asia-Pacific, use IK for adaptation strategies to cope with natural hazards.

\section{- Land, water and natural resource management}

In Bolipara, Bangladesh, indigenous communities' preparations for extreme rainfall events they have estimated through bioindicators and physical witnesses include harvesting crops early and covering domestic animals. When drought is expected to happen, the communities shift cultivation to earlier and save fish before ponds dry out. The local communities of the Rongelap Atoll, Marshall Islands have experienced shortage of freshwater for their daily consumption. Having faced the lack of freshwater, the local communities dig pits lined with mulch and coral rubble to minimise the use of 
freshwater. Furthermore, the communities explore fresh groundwater bodies that exist on top of saline water, and they manage them by growing shade plants to prevent water evaporation from the holes.

\section{- Site selection and built infrastructure}

In Papua New Guinea, local communities living along the Markham River build their houses on high stilts to avoid the effect of annual rainy season flooding. These people also build drains to direct water away from their cropping areas. The communities of Khok Kham, Thailand, experience coastal erosion and use two adaptation options to cope with the impact of coastal erosion. The two options are walls made from concrete and sandbags, and bamboo fences with mangrove plants. The benefit of the bamboo system is that when the fence collapses, the mangroves have developed and continue to trap sediments, while the wall option has to be rebuilt at much expense.

A study of Gyampoh et al. (2009) also shows how local people living in the Offin River basin, Ghana use their IK to cope with low rainfall, drought and crop failure. Most of the indigenous people living in the Offin River are subsistence farmers who rely on the rivers, streams and rainfall for their agriculture and daily home use. However, decreasing rainfall, increasing air temperature, increasing sunshine intensity, and seasonal changes in rainfall patterns as a result of climate change have all affected these indigenous people recently (Gyampoh et al., 2009). The prolonged rainfall shortages and changes in rainfall pattern have caused crop failures in the basin, reduced water availability in the rivers and streams. High temperature has caused their vegetables to ripen too early, leading to a decrease in sale value of their produce. Heat and waterrelated diseases have occurred in the basin. Having become aware of this threat to their survival, the local people in the basin developed numerous strategies to adapt. One is to reuse water from washing clothes or household tools to water back gardens and nurseries. The second method is rainwater harvesting. It is traditional to collect and store rainwater in big barrels that are placed under the roofs of their houses. Later on, the local communities abandoned this method and installed wells and boreholes instead. The traditional and local authorities of communities in the Offin River realised that the clearing of riparian plants was the main factor for increased soil erosion, causing water to become dirty, and eventually reducing stream flow. Subsequently, the traditional and local authorities created an awareness campaign of the effects of deforestation around the rivers and streams, instructing the communities on the prevention of bushfires, 
promoting local-based management of forests and levying fines on those who set fire to the forests, and cleared riparian plants.

\section{Indigenous knowledge and livelihood adaptation strategies}

In rural communities, local livelihoods and food security are threatened by droughts and floods. In order to secure their livelihoods, the rural communities have used their knowledge to develop various adaptation strategies. A number of studies have revealed how rural communities in different countries such as Bangladesh, India, Nepal, Indonesia and Ghana use their knowledge to respond to natural hazards, especially floods and droughts. A study by Lebel (2013) reveals that farmers in the lower part of north-eastern Bangladesh use their livelihood adaptation strategies, including crop diversification, floating gardens and aquaculture to cope with disaster risks. Floatinggardening methods are a conventional practice that local people in this area use to recover from severe flooding and as a way to survive during future floods. Likewise, local communities in Orissa, India who have experienced severe droughts use their knowledge of indigenous varieties and biodiversity conservation to store, grow and exchange seeds of local varieties of main crops. The communities use the local varieties because they are more drought-tolerant and able to cope with abnormal rainfall. The local communities also claim that the varieties do not require expensive organic fertiliser and pesticide to grow well. Usually, the local communities in this region grow 6 to 14 crops at the same time, allowing them to cope with severe droughts (Lebel, 2013).

A study by Jones and Boyd (2011) also indicates how local people in Shreenagar, Nepal use livelihood adaptation strategies to cope with droughts and abnormal rainfalls. Shreenagar is a village in midwestern Nepal. The village is located on a steep slope, with poor soil and a dry climate, limiting the capability for agriculture. Cultivation in this region happens twice in a year and relies mainly on rainfall and the natural environment. However, the changes in rainfall pattern and occurrences of drought, resulting from climate change, have affected the agricultural production in this region. In order to deal with these natural hazards, the local communities use their IK to develop livelihood adaptation strategies, such as harvesting wild food, reducing food consumption, trading livestock, seeking financial and nutritional support from others, and short-term migration (Jones \& Boyd, 2011). 
Armah et al. (2013) have conducted a study in 31 communities in Northern Ghana to explore how IK of the local communities is used to cope with climate change. The local farmers in these communities are heavily dependent on the natural environment for their agricultural production. Climate factors such as high temperature, drought, and flooding have caused reduction in yields of farmers' agricultural production. To cope with the production loss, farmers use their indigenous methods, such as crop management strategy, land management strategy, livestock strategy, and off-farm activities. More than half of the local farmers engage in livestock production as a method to cope with the production loss. Livestock production and sales provide work for the entire year and are one of the main sources of income for the local farmers. Livestock raising also helps farmers improve food security and the manure from livestock can be used to maintain soil fertility and increase crop productivity (Armah et al., 2013).

Severe droughts, abnormal rainfall and high temperature, resulting from climate change, have posed a major threat to many local livelihoods in Indonesia. Binternagel et al. (2010) reveal that severe drought and high temperature have impacted greatly on local communities' cacao agroforestry in an Indonesian province of Central Sulawesi. The impacts of severe drought have caused yield loss and loss of the local household incomes. Binternagel et al. (2010) also reveal how various types of adaptation strategies are used to deal with the severe drought. The most common strategies are reactive or past adaptations, which help the local people to deal with the impacts of the droughts. The reactive strategies comprise reducing food expenditure and changing food patterns, paid labour, raising a loan, rattan collection, hand irrigation techniques, and land-use change. The reducing food expenditure and changing food patterns strategies involve the local households reducing the number of meals by eating twice instead of three times a day, and replace rice, the main food component, with cassava, young rattan or sago. Furthermore, the local households reduce the amount of food in the meals by eating smaller portions (Binternagel et al., 2010).

Various studies have demonstrated a variety of local adaptation strategies in different countries that have been used to cope with climate change. However, Lebel (2013) argues that the IK that used to deal with climate change may not always be sufficient. Lebel suggests that the IK needs to be strengthened and integrated with scientific knowledge in order to expand the adaptation. Likewise, Gyampoh et al. (2009) notice that the knowledge the indigenous people in the Offin River basin use to cope with 
climate change has not always succeeded. They claim that the IK of agriculture and water management that people used in the past has become more challenging to apply in recent years because of changes in rainfall patterns. For instance, the local people in the Offin River basin who switched to wells and boreholes instead of placing barrels under their house roofs reported that their new method did not work due to the current severe climate. Gyampoh et al. (2009) then suggest that in order to exploit, improve and mainstream IK adaptation methods into global adaptation strategies, IK should be studied more, supported and incorporated into scientific research (Gyampoh et al., 2009). Additionally, Hiwasaki et al. (2015) mention that in order to make the best use of IK for adapting to climate change, it is essential to understand how knowledge can be incorporated into science. It can be done through a process in which researchers, development workers, communities jointly undertake observation, documentation, and validation. The incorporation of IK with science could allow community people to formulate the best strategic plan to adapt to climate change and moderate the impacts of climate-related disasters (Hiwasaki et al., 2015).

\subsection{Conclusion}

The chapter has explored previous studies about climate change and its relationship with development. The chapter also discussed the public perception about climate change and drew examples of local perception about climate change in different countries. It then investigated the impacts of floods and droughts on the environment, socioeconomics and local livelihoods. Next, it discussed the importance of IK in development and its significant roles in developing adaptation strategies to deal with climate change. As can be seen, IK has been used in the past effectively to adapt to droughts and floods. However, climate change has been increasing in severity and frequency. Therefore, IK needs to be studied more, strengthened and integrated with scientific knowledge in order to deal with the new situation of climate change. We need to understand better how local communities not only perceive and adapt to climate change but also, we need to examine the extent to which IK and practices can be used and modified to deal effectively with the effects of climate change. 


\section{Chapter 3: Research Methodology}

\subsection{Introduction}

This chapter outlines the methodology used to achieve the objectives of the research thesis. The chapter begins by investigating social constructivism as the epistemology that guides this research study. It then explains how this epistemology forms part of an overall qualitative methodology comprising methods such as in-depth semi-structured interview and observation. Research location, participant recruitment, data recording and analysis are also included in the chapter.

\subsection{Epistemology}

This research studies how local people have constructed knowledge to solve problems happening in their community. For this study, it is the people's perceptions and experiences of, and knowledge about, floods and droughts that I am interested in; and how they give meaning to, and use, that knowledge and those experiences. The research specifically looks at how farmers and fishers in the Tonle Sap Lake region have constructed knowledge about floods and droughts and have used their livelihood practices to respond to such hazards. In this case, social constructivism is the most suitable epistemology for this research. According to Creswell (2014), in constructivism, people seek to understand the world where they live and work, and they interpret the meaning of their life and work based on their experiences. Likewise, Ultanir (2012) states that constructivism is a study of knowledge, a theory of learning or meaning making, which offers an explanation of the nature of knowledge and how people learn. Thus, the real understanding of how local people have constructed their IK is developed based on their experiences and practice. This theory helped me to look for the complexity of people's views rather than limiting meanings of a few sets of ideas. The goal of this research relies on the participants' views of the studied situation (Creswell, 2014). The study of the context of local people, collaborating with multiple participants, employing ideas and values of participants is necessary for my research (Dudovskiy, 2019). As a constructivist researcher, I addressed the processes of communication with the participants of this research project. I specifically focused on 
the context of IK with which local people live and work to understand the historical and cultural settings of my participants (Creswell, 2014).

\subsection{Qualitative methodology}

The research investigates, in particular, the IK around livelihood strategies that local communities have used to prepare for floods and droughts and recover from the effects of such natural hazards. To do this, qualitative methods are appropriate and practical for my research because this methodology allows researchers to deepen the understanding of the ways people interpret and make sense of their own experiences and the setting where they live. The research employed a qualitative approach to develop a case study of the use of IK by local people in two villages in the Tonle Sap Lake region to develop livelihood strategies to deal with regular floods and droughts. Qualitative research has been employed frequently in academic and applied social studies. The qualitative approach mainly follows the exploratory analysis and is used to explain what happens at a local setting and sometimes raises or formulates new hypotheses and theories (Johnson, 2014). Researchers adopt a qualitative methodology to discover or learn more about a little-known topic or phenomenon. Commonly, it is used to understand people's experiences and to express their perspectives (Johnson, 2014). According to StewartWither et al. (2014), qualitative research is commonly used to seek understanding of complex social facts that happen in a real place, where the goal is to both understand and find meanings, and perhaps bring about change (Stewart-Withers et al., 2014, p. 60). Qualitative research is also used to collect information in natural sites, rather than unreal or created settings (Brockington \& Sullivan, 2003). This approach helps my research explore the meanings of IK by interacting with, and interpreting, the actions and views of local people in a particular setting. Tracy (2013) mentions that qualitative research focuses on the thick description where researchers engage themselves in a culture, and examine a specific situation existing in that scene. This allows researchers to explore lived experiences, located in its perspective, appreciate participants' local meanings and interpret participants' standpoints and stories. 


\subsection{Research location}

The research was conducted in two villages (Mukwat and Santey) in the Tonle Sap Lake region. Mukwat village is located along a tributary and is adjacent to Tonle Sap Lake. This village is known as a land and water-based village because it is flooded for six months and dry for the other six months of the year. This village is also known as a fishing village because the primary livelihood activity of the local communities in the village is fishing. Santey village is located about $7 \mathrm{~km}$ from Tonle Sap Lake and is known as a land-based or farming village because the primary livelihood activity of the villagers is rice farming. The two villages are administratively located in Siem Reap province. Siem Reap province is located in northwest Cambodia and is approximately $300 \mathrm{~km}$ far from the Cambodian capital city, Phnom Penh.

Tonle Sap Lake is the biggest freshwater lake in Southeast Asia, making a significant part of the Mekong River system (Kummu et al., 2014). The lake is very productive, driven by an annual mono-modal flood pulse (Kummu et al., 2014). The lake is a dynamic flood-pulsed ecosystem that has a connection with the Mekong River. The lake surface area rises annually from approximately $2,500 \mathrm{~km}^{2}$ to over $12,500 \mathrm{~km}^{2}$ driven by seasonal flooding from the Mekong River (Holtgrieve et al., 2013). This flooding is believed to promote many of the significant ecological developments, including primary and secondary aquatic yield. The lake is also rich in fishery sources and a productivity area for rice production that support the livelihoods of nearly two million people (Holtgrieve et al., 2013; Johnstone et al., 2013). The local communities living in the region are strongly dependent on fishing and rice farming for their main livelihood (Johnstone et al., 2013). However, in the past few decades, human activities and climate change have caused significant changes of the lake and its ecosystems (Uk et al., 2018). 


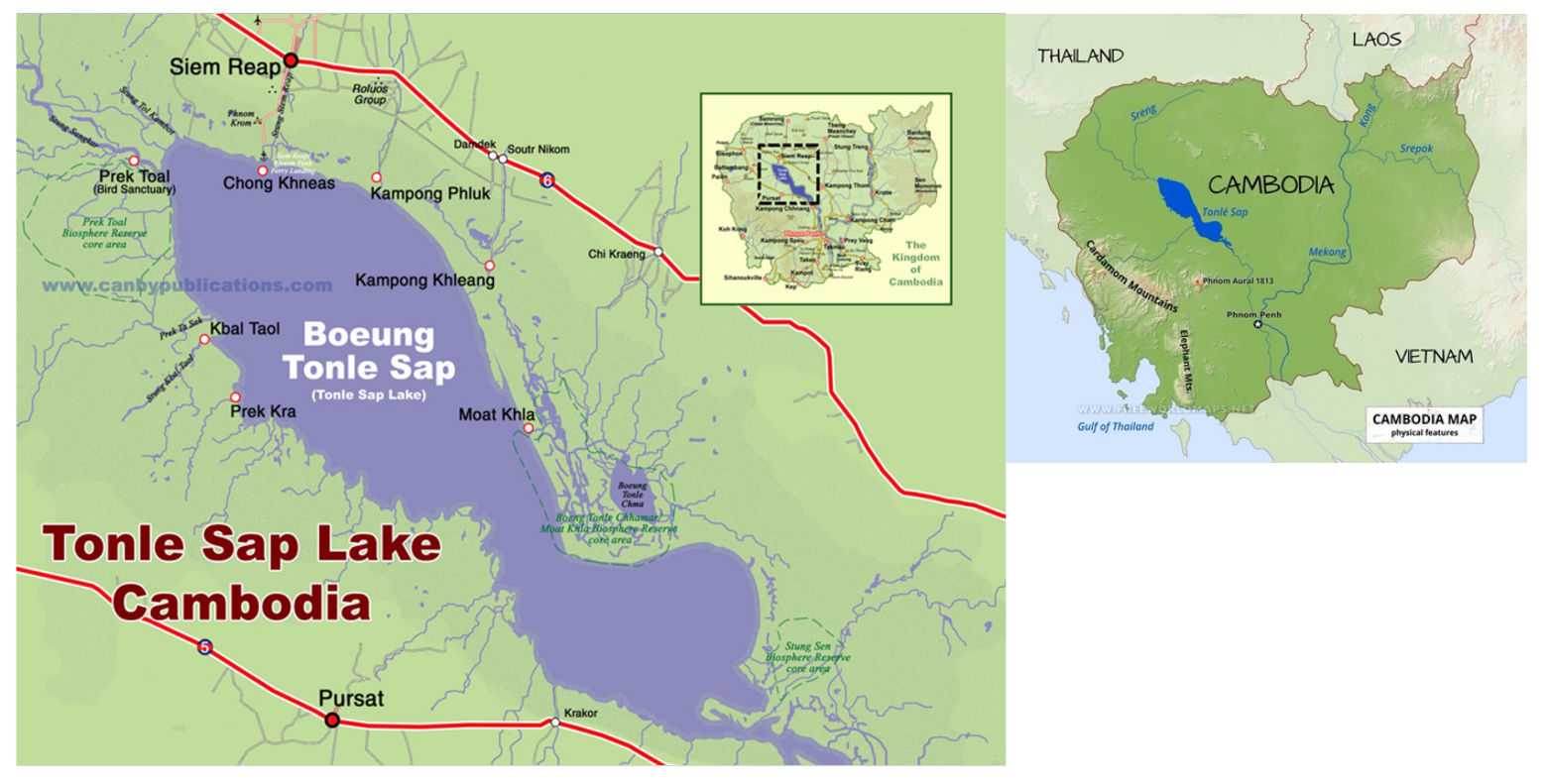

Figure 1. Map of Tonle Sap Lake - Cambodia.

Source: canbypublications.com

There are two main reasons Tonle Sap Lake was chosen for my study. The first reason is that the local people who rely on fishery resources and agricultural farming in this region have been affected by climate change, particularly floods and droughts. The second reason is that I worked in the region for nearly three years, and I am familiar with the location and the local people in the studied communities. More importantly, I have a network of non-governmental organisations (NGO) in the region, which helped facilitate this research.

\subsection{Methods}

With a qualitative methodological approach, this research study employed semistructured interviews and observations as the main methods. The two methods are detailed as below.

\subsubsection{Semi-structured interviews}

Interviewing is one of the most significant methods that qualitative researchers usually use to collect various forms of data (Creswell, 2014). According to C. L. Briggs (1986), interviews are the most popular tool used in social science studies, and they provide 
researchers with opportunities for mutual findings, understanding, reflection, and explanation through a way that is natural, adaptive and frequently stimulating (Tracy, 2013, p. 132). The interviews help explore individually lived experiences and the respondents' viewpoints (Tracy, 2013). Moreover, the interviews enable the researchers to access and comprehend the way the respondents perceive, give meaning to, and define settings for, the real world (Creswell, 2014). Hence, the interviews allowed me to understand the way the local communities in the Tonle Sap Lake region perceive climate change, especially floods and droughts, and how they develop adaptation strategies to respond to the natural hazards. Interviews offer the researcher different approaches, such as face-to-face, by telephone or through focus groups (Creswell, 2014). However, in my research, I used only one-on-one face-to-face interviews with the research participants. This type of interview helped me to deeply understand how the individuals of local communities perceive the impacts of floods and droughts and respond to them using their IK and experiences.

A semi-structured interview is one form of qualitative interviews, allowing researchers to use open-ended questions to discover views and opinions of the participants (Creswell, 2014). The semi-structured interview allows both researchers and participants to engage in a dialogue and the participants have the space to answer on their own terms (Edwards \& Holland, 2013). Therefore, the semi-structured interview is the most suitable method for my research study since it allowed me to interact with the respondents to explore their viewpoints about the impacts of floods and droughts. Because of the open-ended questions and informal protocol, the semi-structured interview allowed the respondents to have enough space to answer different questions. It also enabled me to discover how the local people in the region use their knowledge and experiences to respond to the natural hazards.

During the interviews, all the participants were voice recorded. For their convenience and, as suggested by the participants, most of the interviews were conducted at the participants' houses. However, the interviews with NGO staff and commune councillors were conducted at their offices. By conducting the interviews at their suggested places, the participants could express their viewpoints freely in a relaxed manner. The interviews were conducted in Khmer (the official language of Cambodia) using a question guide in Khmer as well. 


\subsubsection{Sampling selection}

In this research, the participants were selected using snowball sampling. According to Walliman (2011), snowball sampling is a non-probability sampling, which is based on the selection by non-random means. The snowball sampling is a useful technique for a study or survey where it is hard to get access to the entire group of people (Walliman, 2011, p. 111). Since my research aim was to explore the livelihood strategies adaptation to floods and droughts, I wished to talk to people who were involved with different livelihood activities in the communities, and because of time constraints, I used snowball sampling for my research. As mentioned by Tracy (2013), the researcher starts to identify some participants who fit the criteria of the study and then asks those people to suggest a colleague, a friend, or a family member be involved in the study.

Using the snowball sampling technique, I was introduced by the village head to talk to two participants who fit my research criteria. I then approached and asked them if they were willing to take part in my research. Once I had conducted the interview with these two participants, I approached other potential participants who were recommended by those two participants. I kept asking the participants whom I interviewed to recommend other potential participants who were appropriate for the study until I reached the number planned.

However, this process was not always smooth. Sometimes, the participants who were recommended to me were not willing to participate in my research because they were busy with their fishing and farming activities. Other participants had little knowledge about the topic and could not contribute any useful information. One more important thing, some participants only recommended their close friends and family members because they wanted them to receive the small gift that I provided for participating in the interview. This did not allow me to get information from a wide range of community people.

\subsubsection{Participant and data collection procedure}

The research participants of this study were primary fishers and farmers in the two communities in the region. There were 19 participants in total, including fishers, farmers, commune councillors, village heads and NGO staff (see Table 1). To gain access to the local participants (farmers and fishers), I requested permission from the 
commune councillor and village heads and had a meeting to discuss and get detailed information about the communities and people before meeting with them.

For this research, the local participants (fishers and farmers) were the main research participants because they could contribute to the aim of the study, which was to understand how the communities perceive floods and droughts and respond to these natural disasters using their IK. The interviews were conducted in two different villages. In the fishing village, most of the local participants were fishers. In the farming village, most of the local participants were farmers. I spent one week in each village to conduct my interviews. Usually, I interviewed only two people in a day so that I had time to reflect on the process of the interviews and review the recordings.

The local authorities (commune councillors and village heads) were included in this research because they have valuable information about the people, local livelihoods and other relevant development programmes. The research also included one NGO staff member who was working in the farming village. This NGO staff worked directly with the local farmers to provide technical support on chicken farming, which was part of the NGO's livelihood project.

Table 1: Research participants

\begin{tabular}{|l|l|l|}
\hline Respondents & Gender & Role in community \\
\hline 1. Participants from local authorities & Male & Commune Councillor \\
\hline Respondent MW-CC09 & Female & Commune Councillor \\
\hline Respondent ST-CC09 & Male & Village Head \\
\hline Respondent ST-VH08 & Male & Village Head \\
\hline Respondent MW-VH06 & \multicolumn{2}{|l}{} \\
\hline 2. Participant from NGO & Male & \\
\hline Respondent NGO-01 & \multicolumn{2}{|l|}{} \\
\hline 3. Participants from farming village & Male & Farmer \\
\hline Respondent ST-FA01 & Female & Farmer \\
\hline Respondent ST-FA02 & Male & Farmer \\
\hline Respondent ST-FA03 & Male & Farmer \\
\hline Respondent ST-FA04 &
\end{tabular}




\begin{tabular}{|l|l|l|}
\hline Respondent ST-FA05 & Male & Farmer \\
\hline Respondent ST-FI06 & Male & Fisher \\
\hline Respondent ST-FA07 & Female & Farmer \\
\hline Respondent ST-FA08 & Male & Farmer \\
\hline 4. Participants from fishing village & \multicolumn{2}{|l|}{} \\
\hline Respondent MW-FI01 & Male & Fisher \\
\hline Respondent MW-FI02 & Male & Fisher \\
\hline Respondent MW-FI03 & Male & Farmer \\
\hline Respondent MW-FI04 & Male & Fisher \\
\hline Respondent MW-FI05 & Female & Fisher \\
\hline Respondent MW-FI07 & Male & Fisher \\
\hline Respondent MW-FI08 & Female & Fisher \\
\hline
\end{tabular}

\subsubsection{Observations}

According to Scheyvens and Storey (2003), observations can be used for both qualitative and quantitative research to collect data and they provide a direct and apparently accurate method of data collection. The observations are one of the most essential tools for researchers, whether they result in making 'hard data' or simply impressions and surprises, which help researchers shape and interpret their research (Scheyvens \& Storey, 2003). In qualitative research, the researchers use the observation method to take note of the behaviour and activities of people at the research site (Creswell, 2014). The observations can be done in an unstructured or semi-structured way, which requires researchers to be engaged in various roles from a non-participant to a complete participant (Creswell, 2014). Stewart-Withers et al. (2014) suggest researchers should be involved in the place they are studying so they are able to deeply understand the way the people look at, and interpret, the world. The method also assists the researchers to check for nonverbal expressions of feeling and allows the researchers to observe events that the respondents are unable or unwilling to share during the interview (Kawulich, 2005).

In this study, I employed non-participant and unstructured observation, which included transect walks and informal meetings with non-participant villagers in the two communities to observe how IK is used to develop livelihood adaptation strategies to 
respond to floods and droughts. Non-participant and unstructured observation allowed me to study how the local communities in the region practise their daily livelihood activities. I spent half a day in each village to conduct a transect walk to explore the villages and the rice fields. The transect walk helped me to capture the essential things, such as location of communities' farming lands, natural and human-made ponds, and other water reservoirs that the participants did not mention in their interviews. It also allowed me to see the reality of resource use and compare it with the data I collected from the interviews.

In the fishing village, I also spent half a day on the lake to explore how the local people used their fishing gear to catch fish. During the interviews, the participants had mentioned some of the unfamiliar fishing gear and explained how it was used. Hence, spending a half-day at the lake enabled me to see the unfamiliar fishing gear and how it was used. Moreover, it allowed me to explore the reality of the lake during severe drought. In the farming village, I spent half a day in the rice fields to see how severely the rice fields had been affected by droughts, and was able to have an informal discussion with one of the farmers about the impacts of severe droughts on the local rice farming and how they prepared for and responded to the droughts.

Additionally, in the afternoon after the interviews, I usually spent about 15 to 20 minutes meeting with groups of non-participant villagers in the fishing village, who gathered to fix their fishing gear and boats, to talk about their perceptions of climate change and livelihood practices. These informal meetings allowed me to capture additional interesting information that was not mentioned in the interviews.

\subsection{Data recording procedures, storage and analysis}

All the participants were interviewed using voice recording. Before starting the interview, I explained the purpose of the study, the process of recording, and asked the participants for their consent. I used two devices, a mobile phone and voice recorder, to record the interviews in case one of them was broken or lost during the fieldwork. During the interviews, I also took notes on interesting points and keywords that required clarification from the participants and triggered further questions. As soon as the interviews had been conducted in one village, I copied all the voice recordings to my 
laptop and uploaded them to Google drive to avoid information loss. After the completion of the data collection in the two villages, all the voice recordings were transcribed and translated into English in word-documents. I carried out both the transcription and the translation.

The collected data were then analysed manually and carefully using Microsoft Word 2016 .

After the completion of the transcription and translation, I read through all the data and searched for similarities. Then I coded the data in accordance with themes and type of responses, and classified following the format of the question guide (see Table 2):

Table 2: Key themes for data analysis

\begin{tabular}{|c|c|}
\hline Key themes & Sub themes \\
\hline Local perceptions of climate change & $\begin{array}{l}\text { - Changing of weather } \\
\text { - Extreme heat and water shortage } \\
\text { - Floods } \\
\text { - Droughts }\end{array}$ \\
\hline Local livelihood activities & - Primary and secondary livelihood \\
\hline \multirow{2}{*}{$\begin{array}{l}\text { How floods and droughts have impacted } \\
\text { on the local livelihood }\end{array}$} & - Impacts of floods on local livelihood \\
\hline & - Impacts of droughts on local livelihood \\
\hline \multirow{2}{*}{ Preparation for floods and droughts } & - Local preparation for floods \\
\hline & - Local preparation for droughts \\
\hline \multirow[t]{2}{*}{$\begin{array}{l}\text { Livelihood strategies to respond to } \\
\text { floods and droughts }\end{array}$} & $\begin{array}{l}\text { - Local livelihood strategies to respond to } \\
\text { floods }\end{array}$ \\
\hline & $\begin{array}{l}\text { - Local livelihood strategies to respond } \\
\text { droughts }\end{array}$ \\
\hline $\begin{array}{l}\text { How IK was generated for the } \\
\text { adaptation strategies }\end{array}$ & $\begin{array}{l}\text { - Effectiveness of adaptation strategies } \\
\text { - What methods have been changed }\end{array}$ \\
\hline How IK is shared & $\begin{array}{l}\text { - Knowledge sharing in community } \\
\text { - Knowledge sharing in family }\end{array}$ \\
\hline \multicolumn{2}{|l|}{$\begin{array}{l}\text { Local perceptions of future climate } \\
\text { change and droughts }\end{array}$} \\
\hline $\begin{array}{l}\text { Possible preparation/prevention of } \\
\text { floods }\end{array}$ & \\
\hline
\end{tabular}




\begin{tabular}{|l|l|}
\hline Livelihood support from outsiders & $\begin{array}{l}\text { - Support from NGOs } \\
\text { - Support from government }\end{array}$ \\
\hline $\begin{array}{l}\text { Integration of IK and new technologies } \\
\text { to respond to climate change }\end{array}$ & \\
\hline
\end{tabular}

\subsection{Ethical issues and confidentiality}

In qualitative research, ethical issues are related to the concern of research participant protection (Merriam \& Tisdell, 2016, p. 187). As a social researcher, I took the participants' needs and concerns into account and ensured their dignity, privacy and safety (Scheyvens \& Storey, 2003). I also made sure that all the participants received the same treatment and respect.

There were minor ethical considerations that arose during the interview, including voice recording and my positionality. Some participants were afraid of providing detailed information for the interview when they knew that their voice would be recorded. These participants assumed that their voice would be shared with other people, such as government officials or NGO staff. Moreover, some participants were afraid of sharing, and/or not willing to share, the information with a person whom they did not know, especially an outsider. To ease this situation, I always spent at least five minutes with the participant before the interview and explained to them the purpose of voice recording and how the data would be used. I also discussed general aspects, such as the participants' families and their communities. Spending time with the participants and having informal discussions helped me gain trust and build a good relationship with the participants so that they were not afraid of sharing information during their interview. Before starting to record their voice, I also confirmed with the participant that they were happy to provide information with voice recording.

\subsection{Researcher's positionality}

Positionality refers to the insider/outsider status of researchers, including race, gender, social class background, and sexual orientation (Merriam \& Tisdell, 2016). Being a researcher engaging with the community context required me to think about how my background and experience play a role in building relationships with the research 
participants, and in how I conduct the research (Call-Cummings \& Ross, 2019). I am aware that my gender, class, educational background might affect the way I interact with my research participants. Nevertheless, my position as a Cambodian and academic student, provided me with both benefits and challenges to my research.

As a Cambodian citizen, I am fully aware of what requirements need to be prepared for the field research in a specific place. Being a Cambodian, I could approach my research participants with ease. Since both my participants and I shared the same language and culture, it was easy for me to interpret and understand the facial expression, gestures and behaviours used by the participants during the interview. This could help me to interact well with the participants and keep them engaged in the conversation in a safe, relaxed and friendly environment.

Nonetheless, I understand that the positionality that I used to work in the studied communities might affect the participants' opinions, which could impact my research result. The fact that I used to be a social worker in the studied communities could influence how I interpreted the participants' views and create a power gap between them and me. To avoid this, I always clearly explained to the participants that I was there as a student to study about the community. I told the participants that I was enthusiastic to learn more from them. During the interview, I always reminded myself to pay as much attention as possible to the way the participants expressed their opinions by not interrupting them. I also pretended that I did not know anything about what the participants mentioned by letting them talk, and I listened to them carefully. I always expressed that I wished to learn from them by asking them further questions in order to clarify and explore more about the topic that the participants mentioned.

\subsection{Conclusion}

This chapter explained the methods and methodology used to explore how local people in the Tonle Sap Lake use their IK to respond to floods and droughts. The study was driven by a social constructivist epistemology to understand how local communities have constructed their knowledge and understand the changes in weather. To explore this, a qualitative research consisting of semi-structured interviews and observation were used to investigate how the local communities perceive climate change and its impacts on their livelihood, and how they respond to the natural hazards. The chapter 
also discussed my positionality as an insider and outsider, its benefits and challenges, and how I managed it for this research. 


\section{Chapter 4: National Context of Cambodia}

\subsection{Introduction}

This chapter reviews the climate change impacts in the context of Cambodia and existing adaptation policies made at the national level. This chapter is divided into five sections. The first section explores the geographical area and the population of Cambodia. The second section presents the climate in Cambodia. The third section provides a brief overview of Cambodian agriculture and livelihoods. The fourth section investigates the climate change, floods and droughts in the context of Cambodia. The last part explores the existing climate change adaptation policies in Cambodia.

\subsection{Geographical areas and population}

Cambodia is located in mainland Southeast Asia on the coast of the Gulf of Thailand and has a total area of 181,035 square kilometres (Figure 2). The international borders of Cambodia are shared with Thailand and the Lao People's Democratic Republic on the west and the north, and Vietnam on the east and the southeast (FAO, 2012). Cambodia also shares the Mekong River basin with these three countries as well as Myanmar and China. The river flows from China and crosses the country from the north to the south. The water surfaces of the country, including Tonle Sap Lake, cover about $2.2 \%$ of the total area of the country (FAO, 2012). In the southeast, Cambodia is bordered by the Gulf of Thailand with a $435 \mathrm{~km}$ coastline and an exclusive economic zone of 55,600 $\mathrm{km}^{2}$. The coastal region comprises estuaries and bays and roughly 64 islands of different sizes (MoE, 2009).

With regard to Cambodia's topography, the country is divided into two parts. The first part is the central low-lying or the central plains and the flat coastal areas. The second part is the mountainous and highland areas surrounding the low-lying land. The central plains of the country mainly contain the flat landform of the Mekong River and the Tonle Sap basin. The central plains cover $75 \%$ of the country's total area. Around the central plains, are highlands with dense forest and a low population. These highlands include the Cardamom and Elephant Mountains of the southwest and western regions; the Dangrek Mountain to the north adjacent to the Korat plateau of Thailand; and the 
Ratanakiri plateau and Chlong highlands on the east connecting with the central highlands of Vietnam (MoE, 2009).

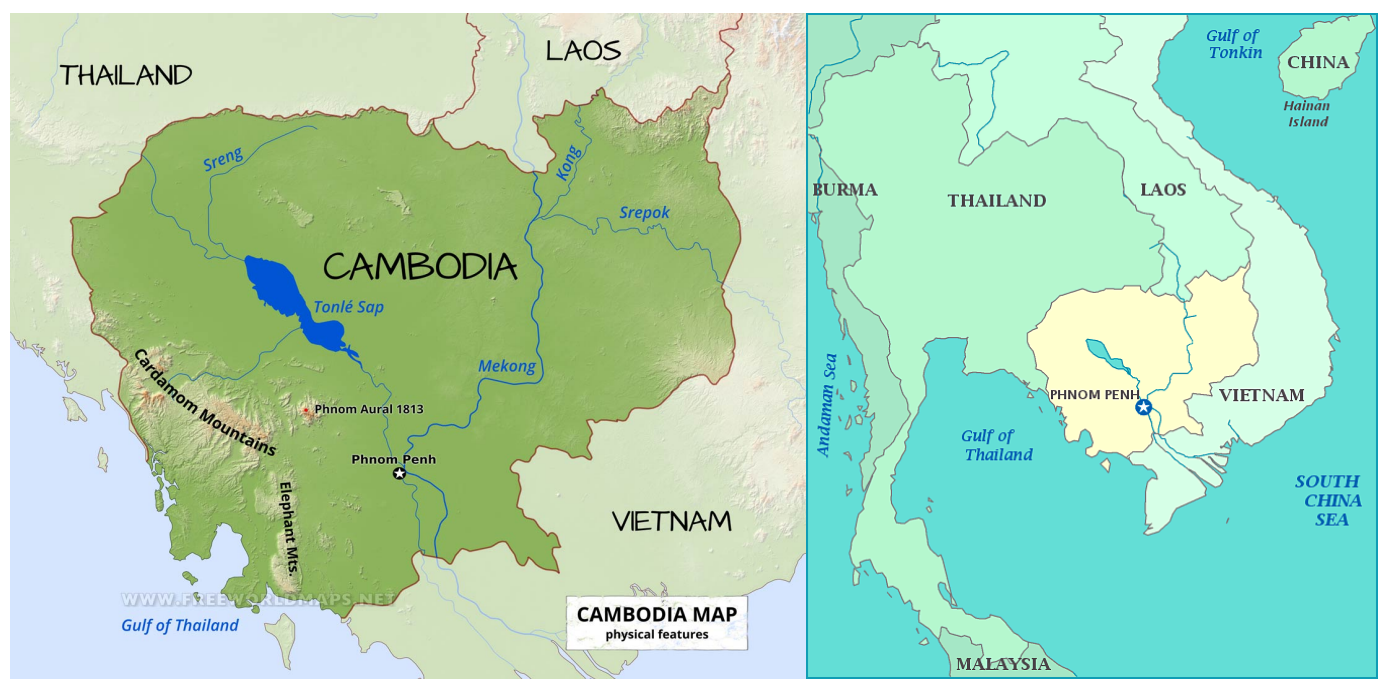

Figure 2. Map of Cambodia.

Source: freeworldmaps.net

In 2019, the total population of Cambodia was 16.2 million (World Bank, 2019a). Nearly $80 \%$ of the Cambodian population lives in the countryside, and $65 \%$ are heavily dependent on agriculture, fisheries, and forestry for their livelihoods (USAID, 2019a). According to World Bank (2011), the majority of Cambodian people tend to live in the central plains and around the Tonle Sap Lake. Of the country's population, 52\% live in the central plains, and 30\% live in the surroundings of the lake. Only $11 \%$ live in the highlands and mountains, while $7 \%$ live along the shoreline. The average population density of Cambodia is considerably low for the region, which is at only 75 people per square kilometre.

With regard to poverty in Cambodia, in the last two decades, Cambodian household income has increased while the poverty rate has rapidly fallen. Between 2000 and 2015, the average annual growth in the country's GDP was 7.8\%, which boosted the GDP per capita from USD300 in 2000 (World Bank, 2019a) to USD1,225 in 2015 (OECD, 2017). Within three years, the Cambodian GDP per capita increased to USD1,380 in 2018 (World Bank, 2019a). The poverty rate drop happened at different times for rural and urban regions. In rural areas, the sharpest reduction in poverty happened between 2007 and 2009, driven by the increase in crop prices and agricultural wages. In urban 
regions, the dramatic decline in poverty occurred between 2004 and 2007 (OECD, 2017). Although Cambodia has experienced a decrease in poverty in the last two decades, most poor rural households, who escaped poverty, have not risen far from the poverty line. About 4.5 million people are still near-poor, and vulnerable to falling back into poverty if economic and other external shocks occur (World Bank, 2019b).

\subsection{Cambodia's climate}

Geographically, Cambodia is situated in Southeast Asia between latitudes $10^{\circ}$ and $15^{\circ}$ North and longitude $102^{\circ}$ and $108^{\circ}$ East, with a tropical climate that is warm all year round. Cambodia has two main seasons; the dry season from November to April and the wet season from May to October (Ministry of Environment, 2009). In the wet season, the northwest monsoon brings $90 \%$ of the annual precipitation, which is usually between 1,200 and 2,000 millimetres per year throughout the country (Ministry of Environment, 2009). However, the rainfall during the wet season was higher than 2,000 millimetres in some years. In some places, the mean monthly rainfall is higher than 5,000 millimetres (World Bank, 2019c). In several regions, the rainfall fluctuates considerably from year to year, and even in June and July (the wet season), they may experience up to half a month without rain (Ministry of Environment, 2009). The average temperature of Cambodia is between $26^{\circ} \mathrm{C}$ and $40^{\circ} \mathrm{C}$. The temperature is ordinarily cool between November and January in the dry season, and is hotter otherwise (World Bank, 2019c) (Figure 3). The warmest month of the year is April when the temperature may go above $38^{\circ} \mathrm{C}$ (Ministry of Environment, 2009). The humidity in the country varies depending on the time. For instance, in January and February, the humidity ranges from $65-70 \%$ while in August and September, the humidity goes up to $85-90 \%$ (Ministry of Environment, 2009). 


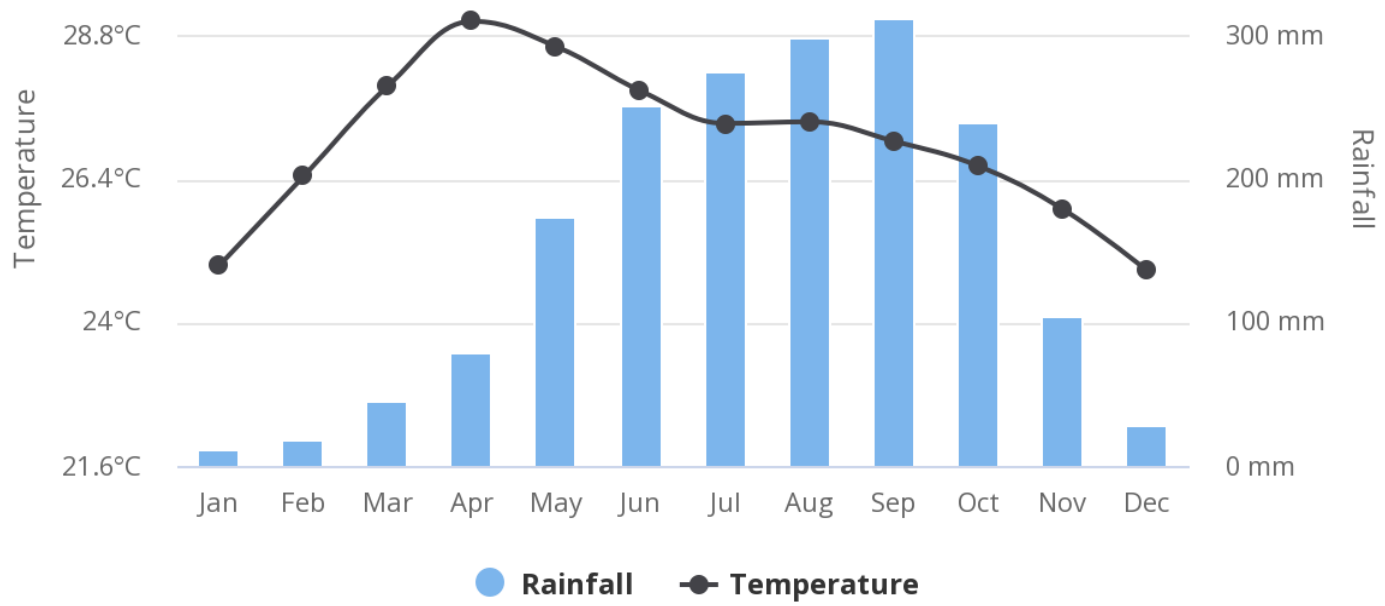

Figure 3. Average monthly temperature and rainfall of Cambodia (1901-2016).

Source: (World Bank, 2019c)

\subsection{Cambodia's agriculture and livelihoods}

Cambodian agriculture is not only essential for rural communities, but it also significantly contributes to the economic growth of the country. The agricultural sector of Cambodia accounts for 35\% of the national GDP and creates job opportunities for many Cambodian people (FAO, 2019a). The agricultural sector has been prominently placed in the National Rectangular Strategy and highly prioritised in the development agenda of the country (Ministry of Agriculture, Forest and Fisheries, 2015). By prioritising the agricultural sector in the national development agenda, the Cambodian government anticipates that agricultural development could reduce poverty rate through food security, increasing household incomes, and job creation. The Cambodian government also expects agricultural development to contribute to economic growth and macro-economic stability (Ministry of Agriculture, Forest and Fisheries, 2015).

In relation to the agriculture sector, crop production makes up the largest portion of the sector's GDP. It accounts for 54\%, while the combination of fisheries and livestock contribute $40 \%$, and forestry and logging account for only $6 \%$. Despite inadequate irrigation systems for rice cultivation, rice production has gradually increased. The increase in rice production has made Cambodia not only self-reliant in rice, but it has 
also made Cambodia a significant rice exporter (FAO, 2019a). In 2017, Cambodia was one of the ten biggest rice-exporting countries in the world. Cambodia exported approximately 635,000 tons of milled rice; almost double compared to 2013 (Royal Government of Cambodia, 2018). Other important Cambodian food crops include corn, soybean, mung bean, cassava and fruits such as mango, pineapple, jackfruit, durian, rambutan and banana. Cash crops such as sugar cane, rubber, and palm oil have also significantly increased (FAO, 2019a). Most of the crops exported are raw, i.e., unprocessed. They are mainly exported to neighbouring countries such as Thailand and Vietnam, where they are processed (Netherlands Embassy, 2018).

Fisheries have played an essential role in the economy of Cambodia (FAO, 2019b). A vast wetland consisting of floodplains around Tonle Sap Lake, and along the Tonle Sap and Mekong rivers, covering 30\% of Cambodia's land area delivers one of the largest, most diverse and intensive freshwater fisheries worldwide. In 2012, the freshwater fishery production value was estimated at USD1.2-1.6 billion per year, and it contributed up to $12 \%$ of the national annual GDP (Joffre et al., 2012). In 2017, the fisheries sector provided jobs to 654,692 people directly, and more than 2 million people gained some livelihood benefit from the involvement in this sector (FAO, $2019 b$ ). The fishery sector has not only made a significant contribution to the employment and livelihoods of Cambodian people, but it has also contributed to national economic growth. In 22 years, the value of fish and fishery products exported increased from USD15,106,000 in 1995 to USD69,091,000 in 2017 (FAO, 2019b) (Figure 3).

Aquaculture also plays a significant role in the total fish production of the country. Although the aquaculture sector is small compared to fish capture, the contribution of aquaculture to total fish production has gradually increased from $10.9 \%$ in 2010 to $24 \%$ in 2017 (FAO, 2019b). In 2017, the Cambodian government estimated the aquaculture production was at 205,3000 tonnes while the capture production was at 649,500 tonnes (Figure 4). 


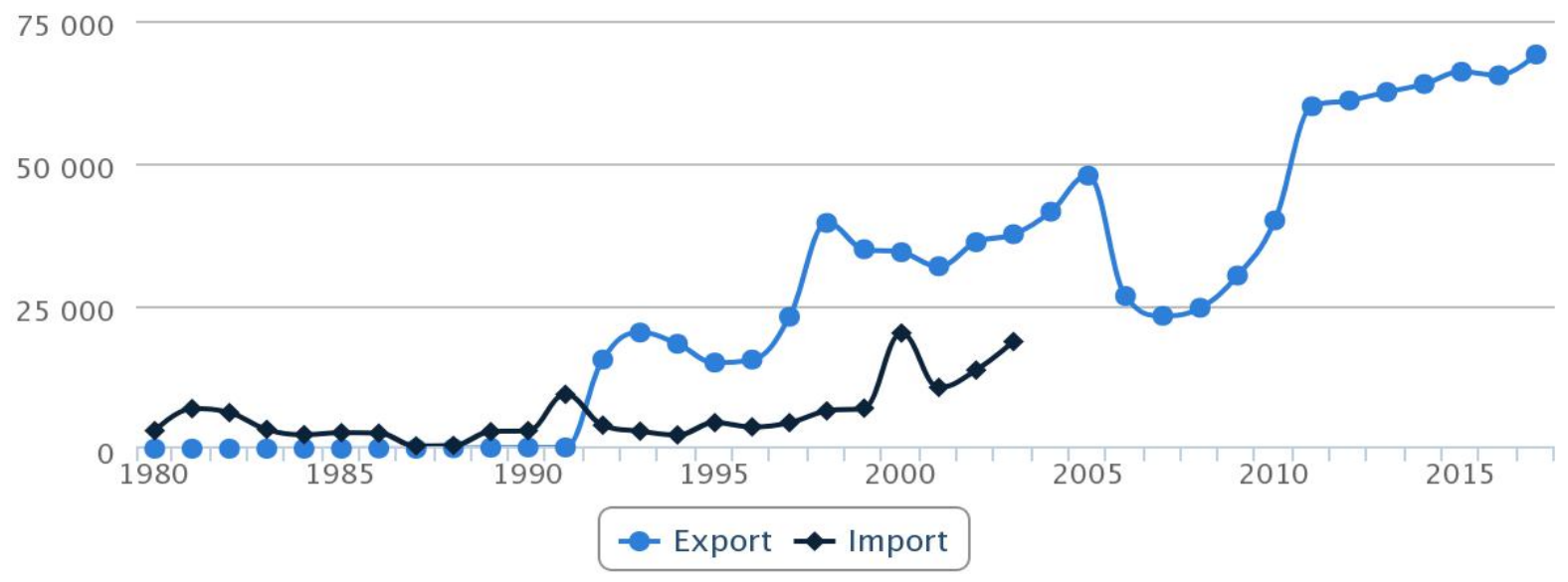

Figure 4. Total imports and exports of fish and fishery products for Cambodia (USD1000) Source: (FAO, 2019b)

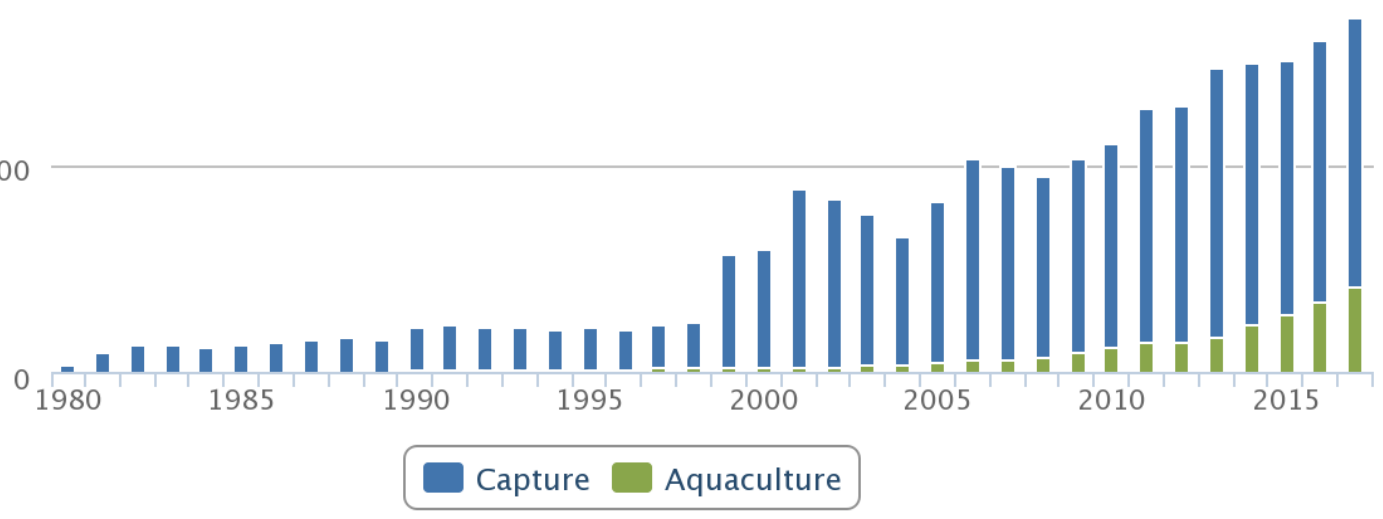

Figure 5. Total capture and aquaculture production for Cambodia (tonnes).

Source: (FAO, 2019b) 


\subsection{Climate change, floods and droughts in the context of Cambodia}

Cambodia is a country highly exposed to the impacts of climate change and was ranked 13th in the Global Climate Risk Index from 1995-2015. It was then ranked 8th in the World Risk Index 2016. In 2014, the Standard and Poor's Rating Services ranked Cambodia as the most vulnerable to the effects of climate change in the world in terms of climate-risk exposure on its economy (GSSD, 2017). In 2017, the Notre Dame Global Adaptation Index also gave Cambodia a high score in terms of its vulnerability to climate disruption, and a low score in terms of its readiness to leverage private and public sector investment for adaptive actions (University of Notre Dame, 2019).

Keo (2014) states that Cambodia's vulnerability to climate change is not only because of climate risk but also because of the lack of the capacity to adapt to it. The vast majority of the country's population lives in rural areas with limited knowledge, inadequate infrastructure and little opportunities. More than $70 \%$ of those rural communities are dependent on agriculture, which is massively sensitive to climate disruption, placing Cambodia's economic and social development at risk (Keo, 2014). Cambodia has abundant natural resources that are essential for livelihoods and food security. However, natural resources have been threatened by climate change (USAID, 2019b). Climate change has significantly affected Cambodian livelihoods and destroyed infrastructure, with average damage at USD235 million annually (World Bank, 2017). Changing climate poses continuing threats to Cambodia's sustainable development goals. In 2015 alone, it was estimated that climate change impacts caused Cambodia to lose roughly USD1.5 billion, which is equivalent to $10 \%$ of the annual GDP (USAID, 2019b).

In the last decade, Cambodia has experienced extreme weather events such as droughts, floods and windstorms, which placed a high social and economic cost on the country's economy and people's livelihoods (Kim et al., 2014). Due to the geographical area, the incidence of floods and droughts in Cambodia is diverse. While floods affect lowland areas, droughts occur elsewhere across the country (GSSD, 2017). Rising temperature and changing rainfall patterns have also had high impacts on Cambodia's economy. Since 1960, the average temperature in Cambodia has increased by $0.8^{\circ} \mathrm{C}$, at a rate of approximately $0.18^{\circ} \mathrm{C}$ per decade (World Bank, 2019c). The increasing rate is fastest in the dry season (December to February and March to May), increasing $0.20-0.23^{\circ} \mathrm{C}$ per decade. In the wet seasons (June to August and September to November), the increasing 
rate is slower, increasing only $0.13^{\circ}-0.16^{\circ} \mathrm{C}$ per decade (World Bank, 2019c). Cambodia's Climate Change Strategic Plan report predicts that the temperature in Cambodia could continue rising between $0.13^{\circ} \mathrm{C}$ and $0.36^{\circ} \mathrm{C}$ per decade in the future (NCSD \& CCCA, 2018). Rising temperature is likely to damage the productivity in agriculture, fisheries and forestry, and decrease labour productivity in most sectors. Every $1{ }^{\circ} \mathrm{C}$ rise is predicted to cause rice yields to decline by $10 \%$ (NCSD \& CCCA, 2018).

Rainfall patterns in Cambodia are not clear, with some regions experiencing increases while other regions are experiencing decreases (World Bank, 2019c). In the mountainous areas, rainfall has increased its average in the wet season and decreased in the dry season. The changing rainfall patterns has led to increased flooding, droughts and storms, which reduced productivity in agriculture and fisheries (NCSD \& CCCA, 2018). In the past 20 years, floods account for $62 \%$ for the losses of agriculture, forest and fisheries productivity while droughts account for 36\% (GSSD, 2017). Under the future climate conditions, floods and droughts have also been predicted to have huge impacts on most of Cambodia's agricultural lands. Floods and droughts will reduce the growing period of farming areas to less than five months per year, which could affect the agricultural yields (GSSD, 2017).

Among the natural hazards, floods and droughts have been seen as the most disastrous phenomenon in Cambodia. Floods in Cambodia occur frequently and extensively. The Mekong River, Tonle Sap Lake, tributary flash floods, urban flooding, and failure of structures such as protection dams and water storages are the source of floods in Cambodia (KEI, 2018). Current severe floods in the Mekong River affected Cambodia in 1978, 1991, 1994, 1996, 2000, 2001, 2002, 2011, and 2013. The flood that occurred in 2000 was reported the worst in more than 70 years and the worst in Cambodia's history (KEI, 2018) — then followed by the flood in 2011. The 2000 and 2011 floods caused thousands of people to evacuate, killed hundreds of people, and caused considerable damages to rural and urban infrastructures in the Tonle Sap and Mekong floodplains (Kim et al., 2014). In 2009, Cambodia also experienced flash floods following heavy rainfall during the wet season and tropical storms, affecting 180,000 households and causing 43 deaths and many injured (USAID, 2019b). 
Droughts in Cambodia frequently correlate with crop productions because most of the agricultural production mainly relies on rainfall (KEI, 2018). Over the last 25 years, Cambodia has experienced a significant number of various drought events, which occurred in 1986-1987, 1994, 1997-1998, 2001, 2002, 2004, 2005, 2009, 2011, 2012, 2014, and 2015 (KEI, 2018). In 1997 and 1998, Cambodia was reported to have food shortages because of prolonged droughts (Pech, 2015) followed by consecutive prolonged droughts in 2001, 2002, 2004, 2005, 2011, and 2012 (KEI, 2018; Nguyen \& Shaw, 2011; Reuy, 2012). The drought that occurred in 2002 was considered the most severe drought since it affected more than 2 million people, damaged more than 100,000 hectares of rice fields, and led to only $35 \%$ of the agricultural land being planted with rice (Nguyen \& Shaw, 2011). Then, the drought in 2004 was ranked the second-worst drought in the history of Cambodia. It destroyed cultivated lands and affected food security, including food reserve and food accessibility for poor households over the year (Nguyen \& Shaw, 2011).

In recent years, droughts in Cambodia have become more extreme. For instance, the Cambodian Prime Minister declared the 2016 drought as the country's worst disaster in 100 years (UNDRR, 2019). It affected all the provinces and cities in Cambodia. It was estimated that at least 2.5 million people were affected by this severe and prolonged drought (KEI, 2018). In 2019, severe drought and a rise in high temperatures affected more than 20,000 hectares of rice fields in 13 provinces across the country (UNDRR, 2019).

\subsection{Climate change policy in Cambodia}

The Cambodian government and other development agencies have put a lot of effort into combating the effects of climate change. The Cambodian government recognises the issues of climate change and is fully committed to the global efforts to address climate change, at both national and international levels. At the international level, Cambodia signed the United Nations Framework Convention on Climate Change (UNFCCC) on 18 December 1995. In 2002, Cambodia ratified the Kyoto Protocol, which entered into force in February 2005 (Ministry of Environment, 2006).

Both treaties (UNFCCC and Kyoto Protocol) primarily aim to steady greenhouse gas concentrations in the atmosphere at a level that might prevent hazardous human 
involvement with the climate system (GSSD, 2015). The signing and ratification of the UNFCC and the Kyoto Protocol by Cambodia was evidence of its commitment to fulfilling the responsibilities under the Convention. It also indicates that Cambodia is concerned about the impacts of climate change on its people and on their survival and development (GSSD, 2015).

Cambodia also started to develop various climate change-related policies at the national level after signing the two treaties. In 2003, the Ministry of Environment founded a separate office titled "Cambodia Climate Change Office (CCCO)", which was responsible for all activities related to climate change in Cambodia (DCC, 2019). In 2009, this office was upgraded to the Climate Change Department of the Ministry. Its mission was to contribute to sustainable development under climate change conditions and according to the policy of the Cambodian government (DCC, 2019).

Having acknowledged the negative effects of climate change on social and economic development, the environment and livelihoods, especially for poor rural communities, the Ministry of Environment collaborated with other government ministries and organisations, and international donors and partners to develop the National Adaptation Programme of Action to Climate Change (NAPA). The NAPA was then sanctioned by the Council of Ministries in 2006 (Ministry of Environment, 2006). The NAPA was developed in line with Cambodia's development objectives, and its crucial goal was to provide a framework to guide the coordination and implementation of adaptation plans through a participatory method and to build collaborations with other relevant environment and development programmes (Ministry of Environment, 2006). More specifically, the NAPA's objectives were to understand the key features of climate hazards, and existing local communities' adaptation strategies, then identify appropriate adaptation responses to climate change (Ministry of Environment, 2006).

Furthermore, in 2013, the Cambodian government issued a Cambodia Climate Change Strategic Plan 2014-2023 (CCCSP). The CCCSP was developed with contributions from various organisations such as national ministries and agencies, development partners, NGOs, academia, and private sectors (Royal Government of Cambodia, 2013a). This CCCSP was the first all-inclusive national policy document to respond to climate change issues. Its primary purpose was to reduce climate change vulnerability on vulnerable groups and ecosystems; to promote low-carbon development and 
technologies through green development; and to disseminate education and participation of people in climate change adaptation activities (Royal Government of Cambodia, 2013a). In the meantime, the Cambodian government also issued another national policy named "Green Growth" and the National Strategic Plan on Green Growth 20132030. The National Policy on Green Growth was created to improve people's wellbeing and livelihoods in harmony with ecological welfare through green growth, based on a green economy, environment protection, social safety nets system and maintenance of national and cultural identity (Royal Government of Cambodia, 2013b).

Besides the national policies, many climate change adaptation-related projects have been implemented by local and international NGOs in Cambodia. Nevertheless, Cambodian people, particularly rural communities, have still been the most vulnerable to the impacts of climate change. This is because there are some challenges that have rendered the implementation of climate change policies and projects in Cambodia ineffective. Those challenges include budget limitation for project implementation, lack of human capacity, limited reliable data and research related to climate change, and lack of technology transfer capacity (Un, 2018).

\subsection{Conclusion}

This chapter described the geographical area, population and climate of Cambodia. It then provided a brief outline of Cambodian agriculture and livelihoods. Additionally, it investigated climate change, floods and droughts, and their impacts on people's livelihoods, environment and county's economy. Lastly, it discovered the existing climate change policies at both international and national level that have been developed by the Cambodian government and development partners. The current climate change policies and climate change-related projects, which have been implemented in Cambodia, still have some challenges. Rural communities, in particular, yet have been seen as vulnerable to the effects of climate change. More research regarding the impacts of climate change on rural communities and local adaptation practices need to be studied in order to contribute to climate change policy. 


\section{Chapter 5: Perception of Climate Change in the Tonle Sap Lake region}

\subsection{Introduction}

The purpose of this chapter is to explore the Tonle Sap Lake communities' unprompted perceptions and feelings about the weather that is happening in their region. This chapter will begin by exploring the local people's experiences of changing weather patterns in the studied area. The chapter will also investigate the other faces of climate change, such as droughts, high temperatures and floods. The investigation compares and contrasts the local people's experiences of these natural disasters in the present day to those of past years. The data was collected from the interviews and observation during field research.

\subsection{Local perception of changing the weather as a result of climate change}

Climate change has many faces such as high temperatures, storms, floods and droughts. People perceive it in a number of different ways. According to the data from the interviews, most participants in the region reported that the weather in their communities has changed. In general, most responses to the question about climate reflected negative feelings. The majority of the respondents said that the weather in their region has become more irregular. The irregularity of weather has been noticed since 2016 or 2017 when it became hotter and the two main seasons in Cambodia have become abnormal. The participants have also noticed that climate change reflects changes to the natural rainfall pattern in the last few years. The wet season that is supposed to have a high rainfall has been drier than normal causing a shortage of water. The dry season that used to have a short period of rainfall has become completely dry. As mentioned by a farmer in Santey, a farming village:

"The weather is now changing. It is not regular. Sometimes, it rains at the beginning of the year (wet season) and dries at the end of the year. Sometimes it is dry at the beginning of the wet season and rains at the end of the season. This year, it has been dry since November 2018. Sometimes, when it rains too much, we cannot do anything. If we want to throw rice seeds in the rice field, and there is too much rainfall. It 
damages our seeds as there is too much water in the field. Sometimes, when we need water for our rice farming, there is no rainfall. It is very different from before when the rainfall was regular, and it was easy for us to do rice farming. In the past, there was enough water in the irrigations and natural lakes, and it was so easy for dry-season rice farming as well." (Respondent ST-FA02)

Regarding irregularity of weather, some participants in Mukwat village (fishing village) have witnessed the water-rise pattern in the river and the lake has changed, particularly this year. They mentioned that the late water rise in the river was a result of the weather change. Respondent MW-FI07 remarked, "Flooding (the rise of water in the lake and tributaries) now starts to rise very late. In the past, it started to rise from mid-June. Before June, there was abundant rainfall, and then the water started to rise. Now (late June), the lake (Tonle Sap Lake) and tributaries are still arid."

During the interviews, participants were also asked whether they had other feelings about the weather that they have experienced. Most of them said that the weather has become hotter in the last few years. Some participants believed that the irregularity of weather pattern was a cause of rising temperature, irregular water rise in the lake and tributaries, and prolonged drought. One fisher from the fishing village mentioned that:

"I noticed that the weather is changing. Sometimes, it is too hot, and the rainfall is not regular. I have also noticed that the weather has become hotter in the last five years. However, this year, the weather is extremely hot. As you can see in the lake and tributaries, there is no water. There is only mud. The flood is also irregular. Sometimes, it is low, and sometimes, it is high." (Respondent MW-FI04)

\subsection{Local perception of droughts and high temperature}

Based on the analysis of the interviews, all participants described that they were experiencing severe drought this year (2019). The participants noticed that drought was not something new to them, and it had already occurred for several years. However, the 2019 prolonged drought was the most critical occurrence they had encountered. As mentioned by Respondent ST-FFA02, "Drought has happened for a few years already. 
But this year, it is the most serious problem for us. In previous years, it was not too severe, and we could still do rice farming because there was still water to do so." The participants also said that the prolonged drought has caused the riverbeds, natural and man-made ponds, wells and other water reservoirs to become completely dry.

Besides this, most participants raised a concern about the extreme temperature that was happening during the drought. Some of them noticed that the temperature in 2019 was the most extreme they had ever experienced. One individual said that the temperature during the dry season was unprecedented. Respondent MW-FA03 remarked, "I find it is extremely hot and dry this year. It is way hotter than it was before. I think the temperature was 42 degrees Celsius during Khmer New Year (April). I have never felt this extreme heat before."

Remarkably, another individual mentioned that the high temperature that happened three or four years ago was even more extreme than this year (2019). Respondent MWFI07, "I noticed that it started to become hotter and dry since a few years ago, from 2015 or 2016. That year was too dry. It was even drier than this year, and the lake was extremely shallow. Since then, there has been less rainfall and drier."

Nevertheless, the majority of the participants have witnessed the weather becoming hotter and drier since 2015. But the temperature in 2019 was the most extreme, and it has led to water scarcity for the local people in the villages. Water scarcity, as a result of prolonged drought, was seen as the most critical issue for the local people in the two villages who rely on fishing and rice farming as their main sources of income. According to most respondents, the extreme temperature in 2019 caused the most severe shortage of water, which they had never experienced before. They mentioned that in previous years, there was still enough water for them to use for their daily consumption, rice farming, vegetable gardening and livestock despite the drought. In the two studied villages, there were several natural and human-made ponds and reservoirs, which the local communities could use all year round. The participants explained that in the past, the water in the natural and human-made ponds could be used until April or May after the water in the lake and tributaries started to recede in December and January. Then in May and June, which is the beginning of the wet season, there was rainfall again. The people have experienced and adapted to this cycle for their entire lives. However, in 2019, the participants said that they had experienced water shortage since March or 
April. Some of them even noticed that there had been only two rainfalls from September 2018 until late June 2019.

"In the past, we didn't lack water although there was drought. We used the ponds in our villages until Khmer New Year (April). Then in May, it started to rain when we had more water in the ponds and tributaries. I noticed this change of drought since 2005. Then it started to become slightly and gradually worse until now. For instance, in the past, we could use the water from the ponds for six months during the dry season. Later on, we could use it for only three months." (Respondent MWFA03)

The water scarcity in 2019 was the most burning issue for the local people in the region. Most participants in the farming village mentioned that they had to go further into Tonle Sap Lake to carry water for their daily consumption and livestock raising. The distance from the village to the lake is approximately seven kilometres. For better-off households, they bought water from the water station located in another village. As mentioned by Respondent ST-FA02 in this farming village, "I have never seen people in this village buy water from others like today. This is the first time that I see people are doing it." Likewise, the participants in the fishing village (the village which is located on a tributary and is adjacent to the lake) mentioned that all the natural and human-made ponds, wells, and tributaries were completely dry so people had to buy water from the water station for their daily consumption. Respondent MW-FA02 from this fishing village said, "It is too dry this year. All the ponds and wells in the village are completely dry. Some people have to buy water from others (water station)."

\subsection{Local perception of floods}

Flooding is considered one of the most dangerous natural hazards since it causes damage to infrastructure, people's livelihood and food security, and even endangers people's lives. Flooding in the region or Tonle Sap floodplain, however, is considered as the normal rise of water level in the lake and its tributaries following the monsoon rainfall during the wet season, from May to October. 
During the field research, the participants were asked how they perceived flooding in their areas as a result of climate change. $80 \%$ of the participants in Mukwat village (fishing village) defined flooding as a normal increase of water level in tributaries and the lake during the wet season. The participants mentioned that flooding is something that they have adapted to as it happens every year. Based on the observation, due to the high level of water in the tributaries during the wet season, the people in this village built their houses on very tall wooden stilts. These very tall stilted houses sit far above the water level during the dry season, but they are only a few centimetres above the water in the wet season.

However, two local authority participants, said that flooding was not a normal situation in their community when there was a sudden rise of water in the tributaries. They mentioned that it was also a severe problem when it occurred. Both of them remarked that flooding had caused damage to people's property and endangered people's lives in the past in their community.

"It (flooding) is not too normal. It affects people's lives, as well. If it is very severe, it floods the people's houses and affects their living. In 2011, the flood was very severe and destroyed people's houses and we had to evacuate them to a safe place such as the pagoda (where it was built on high land). Generally, flooding is not considered as bad as drought in our area. However, it causes negative impacts as well, especially when it happens suddenly, and people have not prepared for it. For those whose houses are not tall enough, flooding affects them, and they have to move to a safe place. It causes hardship for them to make a living as well since they cannot do any livelihood activities during severe flooding. If it is just a normal rise of water in the lake and its tributaries, it is fine." (Respondent MW-VH06)

In the farming village, where flooding does not occur regularly, most participants had a similar perception of floods. They said flooding was not a critical issue for them as it did not occur frequently, and if it occurred, it did not last long. Floods usually lasted a few days or a week and then they started to recede. However, two individuals stated that people in this village used to be affected by floods in 2011 and 2017 when they were severe and sudden. They explained that the floods in these two years destroyed roads, 
affected some people's houses and caused damage to their vegetable gardens. Nonetheless, the 2011 and 2017 floods were not extremely severe since they lasted less than two weeks.

Even though all participants recognised that floods were one of the natural hazards that could affect their livelihoods and infrastructure, they did not show serious concern about them. There were some reasons that the participants were not worried much about floods in their communities. In the farming village, according to the interview with the local authority, the 2011 flood was severe because the canals in the village were too small and the water could not flow quickly. Then, since 2017, the canals were restored and expanded in order to release water from the village if it flooded. In this village, seasonal flooding happens every year during the wet season. Typically, it only flooded rice fields, but not the village. Having experienced the seasonal flooding (rise of water level from the lake), the farmers in this village used a flood-tolerant rice variety to cope with the floods. Likewise, in the fishing village, where flooding was a normal phenomenon happening every wet season, the people built their houses on tall stilts in order to prevent the impacts of floods.

\subsection{Discussion}

The study reveals that all respondents have noticed the changes of weather pattern in the last five to ten years. They have all experienced increasing average temperatures and decreasing average annual rainfall. Concerning the cause of weather changes, nearly half of the respondents recognised that climate change was a result of human activities. They believed that deforestation was one of the leading causes of climate change. They witnessed that the climate had changed since more people had cut down flooded forests and cleared them for farmlands. They mentioned that the destruction of flooded forests in their communities has led to severe floods and droughts. The participants stated that flooded forests in their communities provided several advantages to the community people such as fish spawning zones, fish habitats, preventing big waves when floods happen, and helping prevent severe droughts. These participants compared the droughts and floods that happened nowadays to the past when the flooded forests were well maintained in their communities. All these participants claimed the floods and droughts that occurred in the past ten years were not as severe as they are in the present day. 
However, other respondents believed that climate change is a natural process that occurs without human intervention These participants claimed that floods and droughts have become gradually severe due to the process of nature.

The study indicates that local communities had a clear perception of the weather changes, floods and droughts, although they did not comprehend the complexities of the phenomenon. Moreover, the local communities in the region had different perceptions about the phenomenon even though they shared the same culture and background. The local perceptions could be influenced by their experiences, media, and taking part in NGOs' and local government's development programmes. However, personal experience and observation were found as the key influences on the participants' perception of climate change.

Even though the local knowledge about climate change is limited and unscientific, the community people were well aware of the impact climate change had on their daily lives. Based on their experiences and observations, the local people could judge that the extreme temperature, floods and droughts were the result of climate change. They even noticed that the phenomenon has become more severe in recent times. This finding is aligned with the previous study by (Thomas, 2017). Thomas, 2017 argues that extreme weather-related events such as floods, droughts, heat waves and storms, consequences of climate change, have enormously increased in the last four decades. The IPCC (2018), OECD (2016) reports and Reid (2014) also indicated that the poor communities in developing countries who rely on agricultural livelihood and fisheries were most affected by climate change.

Furthermore, the local people recognised that human actions, particularly deforestation, was the cause of climate change. Based on observation, the local communities acquired the knowledge of causes of climate change through their involvement with NGOs' development programmes, media (TV and Facebook), and peers. Since deforestation has been the main issue for both communities and the country as a whole, the knowledge about deforestation, especially the impact of deforestation, has been shared widely. In any case, this finding supports the previous research of Wuebbles (2018), which indicates that land-use change through deforestation is one of the factors that has caused the increasing temperature in the atmosphere. 
However, due to the limitation of the local knowledge, the local communities in the region were not aware of other factors that caused extreme-weather events such as high temperature, floods and droughts. According to Van Aalst (2006), Boyd (2014), and Morecroft \& Cowan (2010), besides deforestation, the industrial revolution, which contributes greenhouse gas and carbon dioxide $(\mathrm{CO} 2)$ in the atmosphere, has caused global warming. Global warming and changing weather result in floods and droughts.

According to the study, the communities were more concerned about the prolonged drought than flooding since it had severely affected their lives and livelihoods. The people were only aware that the unpredictable weather and abnormal rainfall were some of the causes of the prolonged drought. They noticed the delay of rainfall in the wet season had made the droughts worse. However, the current study about the impacts of hydropower dams in the Mekong River has been blamed for the unprecedented severe drought in the Tonle Sap Lake. Fawthrop (2019, August 26) and Sasipornkarn (2019, August 16) reveal that a serious shortage of rainfall due to the El Nino, a meteorological phenomenon in the Pacific Ocean, has affected the climate all over the Pacific basin. In the meantime, the operations of hydropower stations in China and closing of floodgates of a hydropower dam in Laos have made the drought in the Mekong River and the Tonle Sap Lake worse.

\subsection{Conclusion}

This chapter has indicated that the local communities in the region have observed and experienced the changes of weather in the last few years. The local communities have demonstrated that they were well aware of the climate change based on their observations and perceptions. According to the participants, in the last few years, the climate has become more extreme, leading to severe floods, intense temperature and prolonged drought. Most participants have only witnessed these changes of weather in recent years when they have become increasingly more apparent and severe although climate change has happened over a considerable period. Even though flooding is one of the most devastating natural hazards, most participants in the region did not show major concerns about it because flooding is a common phenomenon in the Tonle Sap floodplain. 


\section{Chapter 6: Impacts of Floods and Droughts on Local Communities and their Livelihoods}

\subsection{Introduction}

This chapter investigates the impacts of floods and droughts on communities' daily livelihoods in the Tonle Sap Lake region. Based on the findings from my field research, the impacts of floods and droughts are categorised as damage to community property and effects on rice farming, fishing activities, fish farming, livestock raising, vegetable growing, and other alternative livelihoods. The impacts of the floods and droughts were identified by the region's two villages' research participants.

\subsection{Impacts of floods}

\subsubsection{Impacts on individuals and community property}

According to the literature review, floods have had a great impact on people and their property. Based on the research participants' interviews, some of them agreed that floods obviously affected them and their properties in negative ways. The participants in the region defined flooding as an issue for them when there was a sudden rise of water level in the lake and its tributaries, following heavy rainfalls and rising water level in the Mekong River. They also considered flooding as extreme (extreme flooding) when the water level in tributaries and the lake was higher than the water level of the regular seasonal flooding during the wet season. Some participants mentioned that when these two types of flooding occurred, they destroyed people's houses and other property such as boats and fishing equipment. Some said that severe flooding caused great impacts on the community, especially poor households since their houses were not tall enough to deal with the phenomenon. These people had to evacuate from their houses to stay at a safe place such as a pagoda that was built on high land in the community. The participants added that some people had to build a temporary floor above the normal floor in their houses to deal with the severe flooding.

Extreme floods destroyed not only communities' houses but also damaged their fishing gear. According to some participants, big waves, strong winds and water hyacinth caused damage to their fishing gear. Strong winds and big waves often occur when the 
water level is very high during the wet season. The strong winds and big waves hit and cause communities' fishing gear such as cylindrical fish traps to collapse. Massive water hyacinth that floated from tributaries into the lake also destroyed their cylindrical fish trap and gillnets.

The local authorities in the studied village said the flooding that happened in 2011 was extremely severe. It even killed some people in the village. Other participants also stated that the extreme flood caused risk to their lives when they went fishing in the lake. They explained that big waves and strong winds could collapse their boats and endanger their lives. They added that they were afraid of going fishing in the lake when the water level was too high. Instead, they fished in tributaries and flooded forests near the lakeshores.

\subsubsection{Impacts on fishing activities and fish farming}

Extreme floods did not only affect communities' property but also impacted on fishing activities. Poor households that relied on small-scale fishing activities as their main source of income were most affected by extreme floods. These households used only small-scale fishing gear such as cylindrical fish traps and gillnets for their fishing activities. The participants reported that when the water level was too high, they had difficulty using cylindrical fish traps and gillnets to catch fish. They added that these two types of fishing gear could only be used within three to four metres deep in the water. Respondent MW-FI05 mentioned, "When there is too much water, bushes, forests and everything is flooded. It is hard to catch fish. As I only use gillnet, I cannot catch many fish to eat."

Besides this, the participants also observed that extreme flooding also had negative impacts on fish farming. They mentioned that the water quality was very poor when extreme flooding occurred. The participants added that they noticed the water was smelly and had acid in it. This water caused diseases and killed some of their fish. The participants also said that their fish grew very slowly during the extreme flooding because of poor water quality and diseases. As mentioned by Respondent MW-FI05, "Flooding also affects my fish farming because there is acid water and the water smell badly. It caused diseases and killed my fish. I noticed strange things happened to my fish. When I cut the fish at the bottom, I saw blood balls and the meat was tender." 
Another individual described how the extreme flooding affected his fish farming. He mentioned that, when extreme flooding occurred, he fenced the ponds with barrier nets to prevent fish from going out of his ponds. However, big waves and strong winds that often happened during the extreme flooding caused damage to the barrier nets and the fish escaped from the ponds.

Even though flooding did not often occur in the farming village, some farmers stated that extreme floods could cause damage to their rice farming as well. However, most of them said that the damage to their rice farming was not substantial since they used a flood-tolerant rice variety for their farming. Remarkably, one female farmer reported that the flood in 2017 affected her rice farming and killed her chickens. Respondent STFA07 mentioned that the rice productivity yield was low after the tide receded, "2017 flood affected my rice productivity. When the flood receded, the rice plants collapsed and then it rained again - too much water, and then it resulted in low productivity. The flood that year also killed heaps of my chicken. It flooded about a month."

\subsection{Discussion}

The findings from the study show that some local communities in the Tonle Sap Lake region have witnessed negative impacts on their lives and livelihoods from flooding. The impacts generally affected the local communities' physical assets (i.e., houses, boats and fishing equipment), fish farming and fishing activities. Due to the geographic location, people living in the Tonle Sap floodplain adjacent to the lake, were affected by floods. The study found that extreme flooding in this region is considered a hazard phenomenon for the local people since it flooded the community rapidly without warning. The extreme flooding in the region has caused physical and socioeconomic loss of the local people. As explained by the respondents, extreme floods have destroyed the fishers' fishing gear, boats and even houses. Poor households had been evacuated from their houses because of the extreme flooding. The extreme floods caused poor water quality for fish farming. They also destroyed the barrier net fences of the fish ponds and fish escaped, resulting in high production losses.

The result of this study underpins the previous findings of other scholars that indicate floods have immensely negative impacts on people's lives and socioeconomic activities 
such as fishing, farming, transportation and human health (Wongchuig Correa et al., 2017). As stated by Rapsomanikis et al. (2017), 20-300 million people worldwide are affected by floods each year. The vulnerability to flooding has increased, and more property, assets and lives have faced flooding. In the floodplain of northern Italy, severe flood events have been remarkable in the last two decades. From 2000-2014, floods in this floodplain region have resulted in 200,000 dead animals, more than 40,000 people becoming homeless, more than 500,000 people being displaced, 8 people missing and/or dead, and over a billion euros' worth of damages (including private, public, and industrial properties) (Roder et al., 2017). In Pakistan, between 2010 and 2011, more than 2,500 people died while 27 million others were affected by severe floods. The floods also killed livestock and destroyed agricultural lands, resulting in billions of US dollars loss (Smakhtin et al., 2014). Likewise, floods in South Africa caused damages to infrastructure, buildings and sewage-disposal systems. Floods in this country also damaged agricultural production and caused food insecurity for the local communities (Musyoki, Thifhulufhelwi, \& Murungweni, 2016).

Although some respondents in the floodplain community claimed that extreme floods have caused damage to their physical assets, fishing activities and fish farming, the damage was minimal for most of the local people in the region. Extreme flooding did not often occur in this region. Most importantly, the local people living in the Tonle Sap floodplain have adapted to the seasonal flooding very well. Most respondents, however, reported that flooding in their community was not a major issue for them. The respondents referred to the regular floods that happen during the wet season. Nonetheless, the periodic flooding in the region is an advantage for the local people who rely on agricultural and fishing activities as their main livelihood. The result of the study indicates that most respondents were pleased with floods since aquatic resources such as fish, plants and other aquatic animals are more abundant in the lake during flooding. According to Lamberts (2001), based on the amount of caught fish, the Tonle Sap ecosystem is one of the most productive inland waters in the world. During the wet season, the floodwater from the Mekong River flows into Tonle Sap Lake, making the lake four times bigger and increasing the water depth from 1 metre up to 10 metres (Nuorteva et al., 2010). Then fish from the Mekong River migrate into Tonle Sap Lake making fish more abundant in the lake and its tributaries (Lamberts, 2001). 
Flooding in the Tonle Sap Lake is not only beneficial for fishing activities, but is also an advantage for agricultural activities, particularly rice cultivation. The local people in this region could do rice cultivation two to three times because of the floodwater. There are several forms of rice cultivation in the region depending on the location of the communities in relation to the huge floods of the lake (Varis et al., 2006). The rice cultivation practices in the region are deep-water rice, rain-fed lowland and/or irrigation receding rice, and dry season rice.

Generally, floods are considered natural hazards that cause damages and loss to life, property, and infrastructure as well as disruption to public services. Nevertheless, floods in the Tonle Sap Lake provide several advantages for the local people such as fisheries resources and agricultural production.

\subsection{Impacts of droughts}

\subsubsection{Impact of droughts on rice farming}

Rice farming is the communities' main livelihood in the farming village Santey. People in this village rely heavily on rice farming as the primary source of income and food security. However, droughts have been felt to have a huge negative impact on rice farming in the community. All participants reported that severe drought in 2019 caused serious water shortages for their rice farming, resulting in the failure of rice growth. The participants mentioned that they were facing an unusual lack of water in the community, and it caused their rice to fail to grow. The participants stated that all the natural and human-made ponds and reservoirs that they used to store water for their rice farming were completely dry.

According to the participants, a large number of farmers used the IR66 rice variety, introduced by the Provincial Department of Agriculture, Forests and Fisheries, for their farming. This rice variety was known as dry-season irrigated rice and receding rice, and it was used in rain-fed and irrigation-receding conditions with a short maturity. Its growth duration was only three to four months. Farmers planted this rice variety during the dry season when the water had receded. The farmers started to grow this rice variety in April and expected to harvest in late July or early August. However, the participants reported that the severe lack of water in the rice fields had delayed their rice growth. 
They also described that the severe drought had affected their rice productivity from the previous year, 2018, because there had been no rainfall since last September. As one farmer said (Respondent ST-FA03), "Normally, the rice productivity was three tons per hectare, but this year I got even less than one ton."

One farmer said that water scarcity and pest increase, resulting from prolonged and severe droughts, had caused damage to his rice farming. He added that his rice productivity this year was lower than the productivity in previous years.

"Because of drought, we don't have enough water, and it makes rice fail to grow. I pumped water into the rice field, but it dried out because it is too hot. Another impact of the drought is increasing pests in the rice field. I tried to use pesticides, but it didn't work because there are too many pests. The more pesticides I used, the more pests increase. And rice productivity is lower than before." (Respondent MW-FA03)

Due to low rice productivity, the participants were also worried about the lack of rice seed that they needed to use for rice farming in the following year. Normally, farmers keep some rice that they get from harvesting to reserve as seeds for the next season rice planting. However, since their rice productivity was not high enough, it would be a challenge for them to reserve seeds for future use. One participant complained that he had used all the seeds for rice farming this year, and he was certain that he would not have them for use in the following year because his rice productivity was very low, and there was not even enough to provide food for the entire year.

The drought did not only impact on rice productivity but also reduced the duration of rice farming per year. Some participants said that they usually did rice farming twice a year. The periods of rice farming in this community were from April to August, and from August to November. Since the drought was too severe, in 2019, they could do rice farming only once per year.

\subsubsection{Impacts of droughts on fishing activities}

Fishing is the most important livelihood option in the fishing village. People in this village rely heavily on fishing activities as the primary source of income. However, all 
participants in this village reported that their fishing activities had negatively been impacted by severe drought. Prolonged droughts have caused the lake and its tributaries to become very shallow and muddy. High temperatures also caused water to become hot. Furthermore, the shallow lake and tributaries made it difficult for the community people to use their boats for fishing in the lake. Some of the participants said that muddy lake and tributaries also destroyed their fish traps as they got stuck in the mud and could not be pulled off. The participants also noticed that the prolonged drought had made it hard for them to catch fish when there was little water in the lake and its tributaries. They described that the high temperature and water shortage in tributaries and the lake have caused fish less abundant. As mentioned by Respondent MW-FI05, "The water is too hot, and I can catch very few fish. Sometimes, I catch nothing."

Additionally, the participants observed that this situation had happened for a few years already. They mentioned the fish had become less abundant when the water level in the lake and tributaries had become gradually lower since 2015 during the dry season. They added that in the previous years, when there was enough water during the dry season, they could catch enough fish for sale and household consumption. However, since the water level was too low, and all the tributaries, ponds and the lake were too shallow, they could not catch as many fish as before. One participant described that in the past he could catch up to $10 \mathrm{~kg}$ of fish per night in the dry season when there was enough water in the tributaries. But this year (2019), he could catch only 1 to $3 \mathrm{~kg}$ of fish per night. He added that sometimes, he caught fish less than $1 \mathrm{~kg}$.

Another individual consistently talked about the comparison of fish caught between the present day and in the past, before 2015. He mentioned that he could earn more in the past by catching fish with just one piece of fishing equipment, a cylindrical fish trap. As Respondent ST-FA05 remarked, "Before 2015, when there was enough water in the canals and streams, I could earn from catching fish approximately KHR500,000 within three days. I used only one cylindrical fish trap. But from 2018 until now, I could earn only about KHR300,000 within three to four days although I used more cylindrical fish traps."

Less fish abundance, resulting from prolonged drought and high temperature, has made the community people lose their profit from fishing. Since fishing is the primary source of their income, people spend more time on fishing activities than on other livelihood 
activities. According to the interviews, some participants explained that the impact of prolonged drought had affected their income markedly. The participants described that they had to buy gasoline for their boat to fish in the lake. Their boats consume a lot of gasoline compared to motorbikes and even cars. Thus, they spend a lot of money on their boats. However, since the fish are less abundant during the drought, they could not catch many fish. Sometimes, they could not even earn enough money from catching fish to pay for gasoline. As mentioned by Respondent MW-FA03, "During the drought, there are fewer fish in tributaries and the lake because of water shortage and high temperature. When I go fishing in the lake, I hire some people to help, and I pay them KHR30,000-KHR40,000 per day. I can only earn only KHR60,000-KHR70,000 from fishing. After paying for gasoline, I earn nothing."

Likewise, a local authority participant explained that because of the severe drought, people in the community lost their profit since they could not catch many fish for selling and household consumption. Since fishing is the most essential livelihood activity, some people had to work for others to earn money to buy gasoline for their boats to fish in the lake. He added that the people kept fishing although they could not catch many fish every day. At least, they sometimes could catch enough fish for eating.

Remarkably, some people emphasised that severe drought is not the only cause of fish population decline. They mentioned that they witnessed the fish population declining for several years already. One individual said that deforestation is one of the main causes of fish decline in the lake and tributaries. He explained that flooded forests were significant for fish spawning and fish habitats. However, in the last few years, more and more people have cut down the flooded forests and cleared them for agricultural farms. Dozens of hectares of flooded forests had been cleared every year.

Furthermore, other participants argued that illegal fishing activities and population growth in the Tonle Sap Lake also caused fish-population decline. They explained that the growing population in the region demanded more natural resources, especially fish because fish is the most essential food for their daily consumption and primary source of income. Since fish is the main source of income for the people in the region, people were very driven to catch more fish in the lake and its tributaries. Consequently, most fishers have used illegal and destructive fishing equipment to catch fish. Some of them even fished in fish preservation zones. However, one participant claimed that he did not 
fish in the fish preservation zones because he was afraid of the Fisheries Administration Officers who might collect and destroy his fishing equipment.

\subsubsection{Impacts of droughts on secondary livelihood activities}

\subsubsection{Impacts on livestock raising}

Livestock raising in the Tonle Sap Lake region plays important roles for local communities. Local people raise cattle, buffalo and poultry for their subsistence livelihoods, source of income, as labour for rice farming, and as an asset. Nevertheless, animal raising has also been affected by severe and prolonged drought. According to the participants, the severe drought has caused diseases in their cattle and chickens. The participants noticed that high temperature has caused cattle and chickens to get sick and die. They explained that their chickens had become pale and weak when the weather was too hot. Some chickens died after being sick for one or two weeks even though they tried to cure them. They also mentioned that water scarcity had caused difficulty for them in raising their chickens. Some of them had to buy water from the water stations in another village while others had to carry water from ponds or the lake to their houses.

As observed, water scarcity is one of the critical issues for their cattle and buffalo raising. The participants said that they lacked water and fresh grass to feed their cattle and buffalo since the weather was too hot and dry. They emphasised that severe and prolonged drought had caused water scarcity and fresh grass in their community. These participants had to take their cattle and buffalo to the lakeshores where there was water and fresh grass for their cattle and buffalo to eat. The participants then left their cattle and buffalo at the lakeshores for one or two months. Without proper care, some cattle and buffalo got sick and died. One participant noticed that his cow got bloody diarrhoea and died after a while.

In one case, cattle walked far from the village to find water in natural ponds and streams, and even to the lakeshores. Unfortunately, they got stuck in the mud and could not move.

"When it is too dry, my cows have to find water in natural ponds and reservoirs far from the village and near the lakeshore. They stuck in the 
mud in the lake and natural ponds. So, I need to go there to pull them out of the mud. Some people's cows even died when they stuck there and had not been pulled out." (Respondent ST-FA02)

All participants who owned cattle, buffalo and poultry claimed that loss of their animals was loss of their money and income. They claimed that they had to buy medicines to cure them. But since their animals could not survive, they lost money buying medicines and money that they could have earned from selling their animals.

\subsubsection{Impact on fish farming}

In the studied communities, fish farming is one of the income sources for local people. Most local people's fish farming was small-scale, family operated. The severe and prolonged droughts have had negative impacts on fish farming in the communities. Some participants who did fish farming as their secondary livelihood noticed that during the prolonged drought, the water volume in their fish ponds become very low and the water became very hot. The lack of adequate water in the ponds caused an issue for fish farming. The participants had difficulty raising fish during the drought. They said that their ponds needed to have enough water so that the fish could grow healthily. Shallow fish ponds and hot water had caused diseases in the fish. The participants also claimed that the water quality in their fish ponds was very poor. They believed that the poor quality of the water also caused diseases in their fish.

Moreover, the participants said that they spent a lot of money buying medicines to cure their fish. Some participants claimed that they could not save all their fish as some of the fish still died even though they had cured them. These participants believed that the severe droughts and high temperature occurring this year, 2019, had caused their fish to die. As mentioned by Respondent MW-FI04, "The weather is too hot. It makes the ponds shallow and the water hot. This causes disease and kills my fish. I spend a lot of money to buy medicines to cure it, but it could not help."

Because of the severe drought, one participant said that she had to quit doing fish farming. She said she used to do cage fish farming. She raised fish in cages in the tributary behind her house. Since the drought had been too severe and there was not enough water in the tributary, raising fish was too difficult. She said the tributary was 
too dry to raise fish in the cage. She also wanted to switch to raising fish in ponds, but she could not afford it. She did not even have land for ponds. Eventually, she quit raising fish.

\subsubsection{Impact on vegetables growing}

Severe and prolonged droughts have also affected vegetable growing in negative ways. All participants were experiencing water scarcity for their agricultural crops and vegetable gardening. The participants indicated that the impact of severe droughts on their vegetable growing was considerable. All participants observed that the phenomenon had delayed growth in crops such as corn, mung beans, eggplants and other garden vegetables. Some stated that the water shortage and high temperature had prevented their crops and vegetables from growing well. As a result, the productivity of crops was very low.

"The extreme heat and water shortage this year have affected my crops badly such as mung beans and eggplants. The productivity is very low. For instance, usually I could get $500 \mathrm{~kg}$ of mung beans per year. But this year, I got only 200-300 kg. One of my friends who grows beans used eight sacks of seeds over three to four hectares, but he got only seven sacks of total productivity. We did not only lose money, but we also lost our labour and time that we spent on our farms. This was because there had been no rain since we started to grow the crops until the time that we harvested them. The quality of the harvested productivity is also poor. Every farmer who grew beans this year suffered a significant loss. In previous years, they used to get three to four tons of productivity, but now they got only one ton of the total productivity." (Respondent MW-FI02)

Furthermore, the participants complained about the growth failure of their garden vegetables because of severe drought. Vegetable gardens consisting of a variety of vegetables and fruits are one of the subsistence livelihoods for the local people in the farming village. The participants claimed that their vegetable gardens helped them increase the diversity of food available to their households. Nevertheless, their gardens had failed to grow well this year, (2019). The participants indicated that water shortage 
and extreme heat are the leading causes of dry soil in the community, which made their vegetables and fruits failed to grow.

The participants also complained about spending more money on vegetables during the severe droughts. They said that they had to buy everything from the markets, including vegetables that they would not have bought if droughts had not destroyed their gardens. As Respondent ST-FA04 mentioned, "All small herbaceous plants in my garden such as lemon grass, chillies, and other vegetables died because of water shortage. So, we need to buy everything from the market. More daily expense for my family."

\subsubsection{Impact on other alternative livelihoods}

Besides the impacts described above, droughts have also affected other alternative livelihoods of the two studied villages. The alternative livelihood activities of the local people include wage labour and owning grocery stores. Wage labour in the studied communities is defined as selling labour power to other people either inside or outside the village with informal contracts such as working in farms, construction workers, house building, fixing fishing equipment, and working for other fishers who do largescale fishing. The participants mentioned that severe droughts also have an impact on their alternative livelihood activities such as working for large-scale fishers, selling groceries, and working in agricultural farms. Some participants who worked for largescale fishers claimed that they were not hired as often as before when the drought was too severe. They explained that the shallow lake and less fish have reduced the time they work for large-scale fishers. The large-scale fishers did not hire them when they could not catch as many fish because they could not make any profit from fishing after paying the hire. Some large-scale fishers reduced the number of working days of the participants. As mentioned by Respondent MW-FI01, "The severe drought obviously affected my other livelihood activity as well. I also work for other fishers who do largescale fishing. Although they still hire me during the drought, but not every day. But when there is enough water in the lake, I am hired more often."

Additionally, one individual claimed that severe drought also caused an impact on his grocery business. He said that fewer people bought his goods during the drought. Since fishing is the main source of income in this community, people could not earn much money when fish were less abundant. Hence, the people in the community tended to 
buy fewer goods such as food, drinks, cooking ingredients for their daily use. Respondent MW-FI07 mentioned, "I notice when it is too dry and people cannot make good money from fishing, they don't come to buy stuff or buy less stuff from my store."

Some participants who worked on others' agricultural farms also indicated that the prolonged and severe drought had impacted on their work. They consistently mentioned that they were hired less often or stopped being hired because the drought had delayed the growing crops such as corns, mung beans and cassava. One farmer describes the serious negative effect on his family that the severe 2019 drought had:

"All my children work in others' farms and construction work to earn money for the family. The money that they earn is used for family's expense and pay back the loan to Acleda Bank. We got a loan from the bank to buy a two-wheel tractor with a cart. We use the tractor for our rice farming and harvesting cassava in others' farms in a distant village, near Kulen Mountain. We harvest the cassava then we carry it with our tractor to the storehouse, then we can get money from the farm's owner. Without this tractor, it is hard for us to do so. The more cassava we can harvest and carry, the more money we can get. However, we do not have this work at the moment. Because there is no rainfall for nearly a year, the cassava is not grown well enough, so the farm's owner stopped hiring us (his children) for a while because they do not harvest and plant it at the moment. So, my children have to go to Siem Reap town to work in construction to earn money since we need to spend every day and pay back the loan to the bank." (Respondent ST-FA04)

\subsection{Discussion}

The results of this study suggest that severe and prolonged drought has been a critical issue for the local communities in the Tonle Sap Lake region. It has had great negative impacts on local livelihoods such as rice cultivation, fishing activities, fish farming, livestock raising, vegetable growing and other alternative livelihood activities. Rice farming, which is the main local livelihood activity in the land-based community, has been damaged by severe and prolonged drought. Serious water shortage, a result of prolonged drought, delayed rice growth in 2019. All local farmers reported that their 
rice failed to grow although they used a dry-season rice variety that is believed to be drought tolerant. It was also reported that the rice productivity in the previous year (2018) was very low due to the drought. Likewise, fishing, which is the primary livelihood in the land and water-based community, had also been severely affected by the prolonged drought. Severe and prolonged droughts have caused the lake and its tributaries become very shallow and muddy, and therefore in less abundant in fish. Consequently, the amount of fish catch per household was very low.

The study additionally indicates that due to its long period, the 2019 drought was the most severe that the local communities have ever encountered. The drought lasted for almost a year with low rainfall. This prolonged drought has severely affected other livelihood activities in the two communities. High temperature and water scarcity were the biggest impacts on livestock raising, fish farming and vegetable growing in the communities. Regarding livestock raising, high temperature caused diseases in cattle, buffalo and chickens, and some of these animals eventually died. For fish farming, poor water quality and warm water because of the high temperature have caused diseases and killed farmed fish. Besides, high temperature and water scarcity have caused vegetables and crops to fail.

Other alternative livelihood activities, in particular, wage labour, was also affected by severe drought. The local people who worked on cassava farms and for large-scale farmers explained how their working days had been reduced because of the severe drought. Those who worked to harvest cassava reported that they were asked to postpone their work since drought had delayed the plants growth. Likewise, the local people who worked for other large-scale fishers were not hired as often to work in fishing activities in the lake.

Given the fact that the livelihood activities have been affected by the severe drought, the local people reported that their food security has been threatened and their income has decreased. This result reinforces the findings of previous studies that explored the impacts of droughts on local livelihoods in India, Nepal, and other African countries. The studies in these countries showed that droughts have negative impacts on agricultural production, the main rural livelihood, and threatened their food security. For instance, severe drought in Maharashtra State of India in 2012 impacted greatly on local livelihood (Udmale et al., 2014). The local people were reported to have a 
shortage of water for their daily consumption and agriculture. The severe drought caused vegetable production to decrease by $11 \%$ compared to the previous year, and the inland fishery suffered $16 \%$ production loss. In Nepal, agriculture is an important livelihood activity for rural people. Crop farming, including rice, wheat, maize, millet, barley, and buckwheat, and livestock raising form a major way of food security for the rural communities. However, droughts that have happened for several years have made the agriculture in Nepal less stable and less productive (Adhikari, 2018). As stated by the UNDP (2009) report, roughly $90 \%$ of the crop or agricultural land loss in Nepal was caused by meteorological events from 1971-2007. Among the different disasters, drought had the most severe impact on agriculture with crop loss accounting for $39 \%$ of the impact. Likewise, in Africa, droughts have caused huge losses of crop and livestock production. Severe droughts have caused most countries in Africa to experience rapid declines in yields. Such losses pose a great threat to food availability, rural livelihoods and the overall economy, especially given the important contribution of agriculture to food security and the economies of sub-Saharan Africa (FAO, 2015).

\subsection{Conclusion}

This chapter has demonstrated that climate change in the past few years has had negative impacts on local livelihoods in the Tonle Sap Lake region. Severe droughts and floods, resulting from climate change, have affected rice farming and fish population, the main sources of the local livelihood and income. Prolonged droughts have also affected the local communities' secondary livelihood activities, such as vegetable growing, livestock raising, fish farming, and wage labour. These effects have led to food insecurity and income loss of the communities. Hence, climate change has contributed to the changes in rural society and affected the rural economy. 


\section{Chapter 7: Local Practices as Adaptation Strategies to Deal with Floods and Droughts}

\subsection{Introduction}

Various ongoing changes of weather, particularly floods and droughts discussed in previous chapters, have greatly impacted on local people in the Tonle Sap Lake region. The people in the studied villages have significantly suffered from the extreme events, particularly prolonged and severe droughts that threaten local daily livelihoods. The focus of this chapter is to provide an insight into the everyday adaptation practices used by local people in the region to deal with the phenomenon. The chapter starts by examining the preparation practices that the local people use before floods and droughts happens. Then it looks at how local people use their indigenous knowledge (IK) in adaptation strategies to deal with floods and droughts in terms of preventing and mitigating the impacts of the phenomenon on their daily livelihoods. The local practices as adaptation strategies are divided into two main parts; the first part is the practices that people use to generate income for their households, and the second part is the practices that they use to support their daily survival. Finally, the discussion on IK generation and practices demonstrates how effectively IK is used by local people to deal with floods and droughts.

\subsection{Preparation for floods and droughts}

This section explains the local practices that are used in preparation of the floods and droughts occurring in their local communities. The practices were developed locally in order to prevent impacts that would cause damage to property and livelihood activities.

\subsubsection{Preparation for floods}

According to the interviews, most participants did not prepare much for floods. The participants in fishing village indicated that flooding was just a normal phenomenon that happens every wet season, and they got used to it. However, the local authorities claimed that although flooding was not a huge issue for the local people in their communities, they did prepare for this phenomenon. They mentioned that the local 
people always prepared their houses, boats and other fishing equipment by getting them ready to withstand the floods, and how, in the last ten years when the flooding became more severe, people started to prepare and maintain their houses to make them strong enough to deal with strong winds and big waves that occurred during flooding:

"If we talk about ten years ago and before that, when the weather was not a problem for them, people tended not to prepare anything for floods, or they prepared their houses a little bit because the forests still existed, and they did not worry much about strong winds and waves. But floods nowadays cause damage to their houses. Therefore, before the water volumes increase (floods), they buy wood to maintain their houses and boats. Secondly, they buy medicines and foods to reserve for family members. They maintain their boats. In case their houses are flooded, they can live on the boats. They also prepare some woods in case the flood is too high. They can use the wood to build another floor, just above the normal flood in their houses to stay for a while during the flood." (Respondent MW-CC09)

Regarding mitigating the impact of floods on their daily livelihoods, some participants claimed that they prepared their fishing equipment such as horizontal cylinder traps and gillnets in advance of the rise in the tributaries' and lake's water levels. These two types of fishing gear were claimed to be suitable for catching fish in the wet season. The participants described that before flooding, they bought netting to build more and/or expand the size and length of fishing gear such as cylindrical fish traps and gillnets. As mentioned by one participant (Respondent - MW-FI03), "I prepare a netting and repair the gillnets and other equipment. When there is enough water in tributaries and the lake, we are ready to use the gear to catch fish."

\subsubsection{Preparation for droughts}

\subsubsection{Reserving water in ponds and reservoirs}

There are two main seasons (dry season and wet season) in Cambodia. All Cambodian people in the country are well aware that there is little or no rainfall in the dry season. Having experienced the scarcity of rainfall in the dry season, all participants claimed 
that they always prepared for the drought. Most participants stated that having enough water, both for household use and agricultural use, was the most important thing they needed to prepare for. They all claimed that, to avoid water shortage, they dug and restored their wells, ponds and other reservoirs to store water. Some participants dug ponds in their rice fields to store water for rice farming while others restored natural ponds and reservoirs to store water for other daily use such as household use, cattle and poultry raising, and vegetable gardening.

In the farming village, most participants who farmed rice twice a year, dug their own ponds in their rice fields so they would have enough water for their rice cultivation. They mentioned that before the dry season, they pumped water from the streams into their ponds to store for use when there was no rainfall and not enough water in their rice fields in the dry season. One participant who had been practising this method for several years believed that there was a cycle of water that he pumped from the pond to his rice field. Respondent STVH06 "I dug ponds in my rice field to store water for use when it is too dry and there is no rainfall. When it is very hot and dry, I pump water from the ponds into my rice field. Then the water dries out from the field and goes under the earth into the pond. Thus, I have water for entire year."

Likewise, the commune councillor in the fishing village indicated that the local people had been practising this method for more than ten years. In the past, people had relied only on the water in tributary and one commune-funded pond. Then the local people started to dig ponds near their houses for easy access after they had experienced a severe drought that happened before 2010. Now there are several ponds in the community. One pond was shared between three or four households, but other households dug their own ponds because of the multipurpose water usage such as household use, growing vegetables, fish farming and chicken raising.

It was observed during the transect walk in the fishing village that several households living on the other side of the road (not at the tributary shore) had their own ponds just behind their houses while other households shared the ponds. Some households who did fish farming had at least two ponds. One pond was for fish farming and the other was for household use. Although their ponds were close to their houses, most local communities needed to use pumping machines to pump water from the ponds up to their 
houses. Carrying water from the ponds up to their houses was not an easy task for the local people in this fishing village because their houses were built on very tall stilts.

\subsubsection{Selling fish before droughts occur}

As discussed in the previous chapter, droughts had serious impacts on small-scale fish farming in the studied communities. Having experienced the negative effects of drought on fish farming, the community people conceived a solution that prevented them from losing profit because of fish dying. The local people simply sold their fish before the drought happened. Based on their experience, the local people acknowledged that the drought usually occurred in the dry season between April and June. Normally, the high temperature during April and May could kill farmed fish. Hence, the people started to raise their fish in late June or early July.

According to the participants, they had to be cautious with the time they started to raise their fish because they needed to buy small wild fish to feed their farmed fish. They calculated and identified which month the small wild fish were affordable. If the small wild fish were too expensive, they could not make any profit from their fish farming. Generally, these local fish farmers started to raise their fish just before the water level in tributaries and the lake rose. As claimed by the participants, when the water level rose, small wild fish became more abundant in tributaries and the lake. Then, the price of small wild fish was affordable for the fish farmers to buy to feed their farmed fish. The participants also stated that fish raising took approximately eight months for fish to mature. Typically, the farmed fish were fully grown and ready for harvesting in February and March.

"To avoid the benefit loss, I have to sell my fish before the drought happens in April, May or June. I start to raise fish from July until March, and I have to sell them in early April before the Khmer New Year (MidApril). I know about the method based on my experience as the drought usually happens between April and June." (Respondent MW-FI07)

"For fish farming, we know that in March or April, it is very hot. I normally prepare medicines in case the fish have diseases. If the condition of the fish is too severe, I sell my fish before it is too late 
(before they die) to avoid benefit loss. I know that I don't have enough money to buy medicines to prevent fish from diseases. So, I need to sell them. Some well-off people spend lots of money to cure their fish, but the fish still keep dying. Then, they sell them out." (Respondent MW-FI04)

\subsubsection{Discussion}

Regarding the preparation for the disasters, the local people have learned how to adapt to changes in weather patterns from the past experiences. The traditional way of rice farming in the studied community relied very much on the availability of rainfall. Hence, the local prediction about the rainfall was significant for the local people in preparing for their rice farming. The participants claimed that they prepared themselves in accordance with the rainfall. The local people observed the rainfall pattern from the late dry season or early wet season and predicted whether there would be enough rainfall for their rice farming. This method has been developed and used since the ancient past. The local people learned about this method from their ancestors and their own experiences. It was reported that there was a religious event during the Khmer New Year in April when local people celebrated and predicted rainfall pattern in the upcoming wet season.

The method used in the studied community was similar to the method that the local people in one community in Tanzania used to prepare for their agricultural production. The local people in Tanzania used their IK systems to predict the rainfall pattern. The IK systems of the Tanzanian community people were developed using the combination of culture and belief systems, production systems and connections with the surrounding nature (Mwiturubani, 2017).

The local people in Cambodia, however, appeared to rely more on new technology for the weather. As observed, most people in the communities had smartphones, televisions and radios, on which they could easily access the information about rainfall pattern.

Concerning the effectiveness of the preparation for the droughts, the local people reported that the method of digging and restoring ponds and reservoirs previously helped them to have enough water for agriculture, livestock raising and household consumption. Nevertheless, the severe drought in 2019 exacerbated the water scarcity in 
their community. The method of digging and restoring ponds and reservoirs could not provide them enough water for their agriculture, livestock raising and daily household use. This finding aligns with Gyampoh et als' (2009) previous study on the Offin River basin, Ghana, where they explored how IK was used to cope with climate change. The study reveals that severe droughts and severe water scarcity in the Offin River basin caused a great negative impact on local agriculture and daily lives. In order to get water for their daily consumption, the local people had used a traditional way of harvesting rainwater by placing barrels under the roofs of their houses. Then this method was abandoned when the local communities installed wells and boreholes. However, most community people reported that they were not able to harvest enough rainwater due to severe droughts (Gyampoh et al., 2009).

Conversely, the method used by local fish farmers in the land- and water-based communities in the Tonle Sap Lake region of selling fish before the drought happened was efficient and practical. The local fish farmers used this method to avoid economic loss caused by drought on their fish farming.

\subsection{Local adaptation practices to generate income}

\subsubsection{Changing fishing methods}

\subsubsection{Switching fishing equipment during floods}

As mentioned in the previous chapter, fishing is the most important livelihood activity in Mukwat fishing village. The participants in this village mentioned that they switched their fishing equipment when the water was very high during the wet season because some of the fishing equipment could only be used in certain water conditions. To be able to catch fish, the local fishers switched from using Lob (cylindrical fish trap) to Leu (horizontal cylinder trap for gourami) and gillnets when the water level was high. Some participants said that they still kept using Lob (cylindrical fish trap) during floods, but they needed to expand its size in order to catch fish. However, some participants reported that Lob could not catch fish as much as Leu.

Leu (horizontal cylinder trap for gourami and other small fish) was a very popular fishing gear used during flooding. The gourami fish were usually sold to other fishers 
who used it as bait for their Sai Yern (small vertical cylinder trap for shrimp). Some people used gourami fish and other small fish caught by Leu to make salted and fermented fish paste. This fishing gear could be used for six months from August to January when their village was flooded.

The participants claimed that this fishing gear was easy to use and could even catch more fish compared to gillnets. As mentioned by one participant (Respondent MWFI01), "I switched to Leu (horizontal cylinder trap for gourami) when it floods. I use this gear (Leu) for more than 10 years now. I have also been using gillnets since I grew up. However, Leu is easier to use than gillnet. Using gillnet, you need to collect fish one by one from the net. For Leu, you just need to pour fish into the basket. It can also catch more fish than gillnet."

In this fishing community, shrimp was also one of the most popular aquatic resources that people caught daily. The local people could catch shrimp for the entire year, but they had to change their gear to catch it when the tributaries and the lake were flooded. The local communities reported that they switched to using a Sai Yern in order to catch shrimp during the flood. However, this fishing gear was not affordable for everyone in the community. One participant claimed that a Sai Yern was very expensive and only the better-off households could afford it.

In order to catch shrimps during the drought, the local communities used a different type of fishing gear locally known as a Kansom (brush bundle trap). According to the participants, a Kansom was made by tying branches, sticks, or brush into bundles for either placing on the bottom of the tributary or lake or suspending in the water. Once it was placed in the water, shrimps and small fish sheltered under the bundle. Then the fishers used a long-handled scoop net to collect the shrimp or fish from underneath the bundle.

The research study was conducted in June, which was the time when the local people in this fishing community prepared their fishing equipment before the water rise in the lake and its tributaries. As observed during the transect walk, the people were active fixing and making their fishing gear so that they had them ready for use when the water level in tributaries and the lake was high enough. As observed, each household had made and hung their fishing gear such as a Lob and/or Sai Yern on their balconies. 


\subsubsection{Switching fishing equipment during droughts}

Since the impacts of severe drought on the local communities' fishing activities were too great, most of the common and traditional fishing gear that they used in the dry season was no longer practical. The local communities reported that they could not use their traditional gear because the water was too shallow and muddy and switched to using a Proyong (seine net with lead sinkers) in order to catch fish during severe droughts. According to the commune councillor, the local people made this type of fishing gear from a net with a maximum size of 60-70 metres long and 2.5-4 metres high. Lead sinkers were tied at the bottom of the net and floaters were tied at the top of the net. However, the local communities claimed that they made this fishing gear up to 80-100 metres long. The Proyong is used with at least two fishers holding the end of each side and pulling and walking for about one kilometre in order to collect fish if the lake is very shallow. However, if the lake was not too shallow, the fishers used their boats to pull the Proyong instead.

Most participants claimed that they started to use this Pryong when the water was very shallow during the drought. It had been used in the community for the last few years since the drought became too severe. The village head noticed that the local people in his village had started to use the Proyong since 2015 when the weather had become more severe. He said that, before 2015, the local communities could still catch fish during the dry season since there was enough water in the lake. Likewise, the participants said that they used to use a Lob and/or gillnet in the dry season, when the water level was low. However, these two types of fishing gear were no longer practical when the lake and its tributaries were too dry and muddy because of severe droughts. Hence, the local people switched to use the Proyong instead.

The participants reported that they learned how to make and use the Proyong from people living in another commune. They said the people there used a smaller size of Proyong (about 30 metres long) to catch fish in small streams. The participants added that they had to make it in a larger size (80-100 metres) in order to catch fish in an open space in the lake. To use this fishing gear, they needed to work collectively with three to four households and fish together in the lake. They then shared the profit after selling fish. This method was generally used among relatives and friends only. However, most 
participants mentioned that this method could only help them get enough fish for household consumption and generate supplemental income for the household.

"We have used this fishing gear for about three to four years when the water became too shallow in the lake. We learnt about this fishing gear from the people who live in another commune, upper streams. They used it in small streams. Then we followed them, but we made the gear bigger and used it in the lake. Normally, we work with 3 to 4 households to pull this fishing gear in the lake. It is big and heavy. So, we need more people to pull it in the lake. After fishing we share the money that we earn from selling fish. Sometimes, we can earn about KHR30,000-40,000 per day. But sometimes, we cannot earn anything after paying for gasoline." (Respondent MW-FI05)

According to the participants, all the above methods they used could only help them get enough for eating and living during floods and droughts. Although these methods could not help them improve their livelihood, it was claimed that they were more comfortable to do than other wage labour, particularly construction work where they had to go away from their home and work in the town.

Moreover, the money that they earned from the above methods and wage labour was comparable. It was estimated that the money they could earn from construction was KHR25,000-30,000 per day. However, the income that local people could earn from fishing during severe floods and droughts was between KHR10,000-40,000 per day depending on water level in the lake.

\subsubsection{Changing fishing zones}

Another fishing-related method that the local communities in the studied villages used during severe drought was changing the fishing zones. The participants claimed that the lake near their villages was too shallow to fish. They had to go further in the lake and explored other places where there was enough water to fish. Some of them mentioned that they had to cross the lake, which was approximately $30 \mathrm{~km}$ away from their villages, to catch fish. They claimed that the water on the other side of the lake was not as shallow as the water near their villages, and fish were also more abundant. Hence, 
they could catch more fish there. In the last few years, the participants had started to go further afield for fishing when the lake became very shallow.

"We have to cross the lake to the other side of the lake, in Raing Til village, Pusat province to catch fish using Proyong. Over there, the water is deeper, and the fish is more abundant. We could not catch fish at our side because of shallow water." Respondent MW-FI05

"In the last two years, my husband goes further to the other side of the lake (in Pursat province) to catch fish. The water in the lake near the community has become too shallow and muddy and we could not catch many fish. So, he has to go there to catch more fish. Over there, there are more places to catch fish and the lake is not muddy and no water hyacinth. Sometimes, when there is enough rainfall in that area, he can catch many fish and earn about KHR100,000-200,000 per day. But this income is not regular because the rainfall is not regular either." (Respondent ST-FA02)

\subsubsection{Crop farming}

According to some participants, besides fishing and rice farming, they grew crops and vegetables for supplemental income. The local people had practised this method for decades, but some participants emphasised that they started to do crop farming when they realised that they could not earn as much money as before from their main livelihoods such as fishing and rice farming. It was observed that only some households in the studied villages had been doing crop farming for supplemental income. Crop farming was divided into two categories; large-scale farming and small-scale farming. Large-scale crop farming was done on large land sizes of several hectares of land owned by well-off households who could afford to buy land, a two-wheel tractor, and fertiliser. Small-scale crop farming was done on small land sizes of about one hectare or less. Every household in the studied villages that had land could do this small-scale farming. Typically, this small-scale farm was located in the village.

One participant claimed that he started to buy farmland and grew crops once he realised that rice farming could not help him earn as much money as he wanted to support the 
family. He also stated that the productivity of rice was not as regular as before. He noticed that the changing of weather and water scarcity caused the irregularity of rice productivity. The local people usually spent their time growing vegetables after they had finished their rice farming and fishing. Some well-off households in the farming village had their farmlands approximately $17 \mathrm{~km}$ far from their village. The participants reported that they grew soybeans and sesame on their farms. Since their farmlands were located in the land-based area, far from the Tonle Sap floodplain, the farmers could do their crop farming all year round. However, they claimed that their crop farming could only help them gain enough money to support their daily expenses in the family. They blamed the prolonged 2019 drought for the low productivity of their crops.

On the other hand, some households in the fishing village had their farmlands either in the village behind their houses or near the lakeshore. The farmland near the lakeshore was located approximately $3 \mathrm{~km}$ from the village. Commonly, the local people in this village grew corn and mung beans. It was observed that the people in this village could only grow their crops in the dry season after the water in the lake had receded. The period of farming was from February to April or May. The community people did their crop farming when they were free from fishing. They have practised this method for a long time. The participants reported that this method only helped gain supplemental income besides fishing. Similar to what farmers in the farming village mentioned, the local people in this village also complained about the impact of severe drought causing low productivity of their crops.

\subsubsection{Livestock raising}

Most participants recognised that livestock raising was one of the most important livelihoods that helped generate income when their main sources of income were affected by severe droughts. The people in the farming village commonly raised pigs and chickens for their supplemental income. Although livestock raising had been practised for decades, the participants claimed that they could earn extra income from this method. In this village, the local people also raised cattle (buffalo and cows). However, for most people in the community, cattle were considered an asset rather than an income. On the other hand, there was a small number of households raising pigs and chicken as their supplemental income in the fishing village. 
Nevertheless, the households who raised chickens reported that they only did it on a small scale for household use only. The participants said that they normally raised less than ten chickens in each household, and that they only used traditional knowledge learned from the elderly people to raise their chickens. As mentioned by a participant (Respondent MW-FI04), "Besides fishing, I also raise some chickens, but they are for household use only. I use traditional techniques to raise chickens. I never learn from outsiders."

In contrast, most people in Santey, the farming village, raised chickens on a large scale for their income. It was reported that the local communities in this village had been provided several NGO trainings on chicken raising. The NGOs also provided baby chicks to some households who could not afford to buy them. Besides chicken raising, some people in this village also raised pigs in order to generate additional income.

Some participants in the farming village claimed that they started to raise pigs and chickens to generate income when they could not earn as much from fishing as before due to the decline in the fish population in the lake and its tributaries. These people noticed that climate change was the cause of the fish population decline. One farmer emphasised that his rice production had also been destroyed by droughts:

"Six years ago, I quit fishing because I could not catch as many fish in the streams because fish became less abundant. Then I started to do vegetable farming and raised chickens instead of fishing. And this year, 2019, my rice production has been affected severely by drought. I usually did rice farming two times a year. But this year, I can do it only one time, and my rice has not grown maturely yet. Since my rice production failed, I decided to raise pigs to gain more income for the family" (Respondent ST-FA04)

\section{The use of indigenous medicines to cure cattle and chickens}

Regarding cattle and chicken raising, a village head in the farming village claimed that some people in his community still used traditional medicines to cure their livestock's diseases although the majority switched to use modern medicines. The village head explained that when the people's cows and chickens got sick because of the extreme heat, the local people used their IK that they had learned from the elderly people to 
make traditional medicines to cure their animals. He mentioned that high temperature during the dry season often caused cows and chickens to become sick. Cows usually had bloody diarrhoea while chickens became sick and died. The village head described that to cure a cow when it got diarrhoea, people fed it small insects such as crickets and other flying insects mixed with liquor. They did this for two to three days in order to make their cow recovered. To cure sick chickens, they fed them lemongrass, and the peel of kapok tree immersed in water mixed with some modern medicine.

\subsubsection{Hunting wild animals and birds}

Some participants were reported to catch wild animals and birds when their primary sources of income had been affected by droughts. The participants in the studied villages said that in order to find supplemental income for their family, they caught wild rats and snakes to sell. In the studied communities, wild rat meat was one of the most popular diets. As observed, rat meat was sold throughout the communities. Rat meat was not only sold in the communities but also to middlemen who sold it to Vietnamese people. This type of rat is known as a rice-field rat, which the local communities catch in their rice fields using rat traps.

Some participants stated that they hunted rats to sell while others hunted them for household consumption only. The participants mentioned that they caught rats to sell when they could not make an income from their fishing and rice farming. Rat hunting could help them earn some extra money that they needed to spend on their daily foods and other household expenses.

One participant in the farming village claimed that he started to hunt rats this year (2019) when the severe drought had affected his fishing greatly.

I buy some rat traps to catch rice-field rats when I go fishing. I catch them only for eating. Sometimes, I bring them home for my family as well. I started to do it this year because I could not earn much money from fishing and my rice production because of the severe drought. (Respondent ST-FA05)

The local authorities stated that the local people in the two studied villages sometimes hunted snakes and sold them to the middlemen. However, the participants stated that 
there were not many people hunting snakes for business in their communities. The people who hunted snakes were skilful in doing it. Ordinary people in the communities were not able to catch snakes. It was reported that the local people started to catch snakes, especially aquatic snakes, once they noticed the fish population in their communities had declined. Aquatic snakes were sold to food sellers in the communities who sold the snake meat to locals and middlemen.

Besides hunting rats and snakes, the local people in these two communities were also reported to hunt birds for their supplemental income. The commune councillor from the fishing village stated that some people in his communities used traps to catch birds in the forest near the lake and at the lakeshore. The birds that the local people caught included egrets, waterhens and herons. The caught birds were sold to the people in the communities who bought them for food. The local communities not only caught birds to sell, but they also for food.

According to the participants, the above methods have been practised for several years. Some participants claimed that they learned how to make traps and catch wild animals and birds from their parents and elderly people in their communities. The local people have been using these methods only to gain supplemental income to their farming and fishing. However, not many people practised these methods in the two communities because they could not use these methods to earn as much money as other livelihood activities.

\subsubsection{Wage labour}

Because of income loss from the damaging impacts of severe droughts, the local people in the Tonle Sap Lake region developed several adaptation methods to maintain food security and generate additional income. Wage labour was one of the adaptation strategies that the local communities used to generate income when their main source of income became negatively affected by severe droughts. The wage labour that the communities used included working in agricultural farms, working with fishing-related activities, working as a housebuilder and/or a construction worker in town. 


\subsubsection{Working in agricultural farms}

Most participants in the farming village reported that they worked on other farmers' agricultural farms to earn money to support their family. Some participants said that they decided to work for other farmers because droughts had negatively affected their main and secondary livelihood activities. As mentioned in the previous chapters, severe droughts had affected the communities' rice farming and fishing activities. The failure of rice growth and not being able to catch as many fish in the lake and its tributaries during the drought, had led to a shortage of food security and income loss for the local people. Therefore, the local people in this farming village decided to work for others' farms in order to gain additional income to support their family. As mentioned by Respondent ST-FA03, "Fishing is my secondary livelihood, but droughts had affected it. I noticed that I could not catch as many fish since 2018. This year the drought has been too severe, then I decided to work for other farmers to get wage instead of fishing."

However, some others stated that they have already been practising this method for several years even though their rice farming was not affected by droughts. They added that they had to work for other farmers since their rice farmland was small and could not help them earn good money. They stated that rice farming could only help them to have enough rice for household consumption. Consequently, they needed to do something else to generate income for their daily living. The participants were reported to work in cassava farms, which were about $17 \mathrm{~km}$ far from their village, where they were hired to plant and harvest cassava.

\subsubsection{Working in fishing-related activities}

Most participants in the fishing village reported that they worked for other fishers in their community to earn more income when they could not catch fish. The fishingrelated activities consist of fixing fishing gear, making fishing equipment, and being hired to work for large-scale fishing. Most participants, especially women, claimed that they worked for other fishers fixing torn nets of fishing gear when they could not catch fish in the lake during the drought. Typically, the fishing gear needed to be fixed every year after it was used. The participants were hired to fix fishing gear such as Lob (cylindrical fish trap) and Sai Yern (vertical cylinder trap). 
Besides fixing fishing gear, the participants were also hired to make fishing equipment such as small bamboo sticks used to attach Lob to the bottom of the lake. As claimed by the participants, it was just a casual job that they had to do to earn extra money. One fisher hired them to work for only a few days. Then they had to work for other fishers. Some were hired to work for only a few days for the entire year due to the severe drought. Respondent MW-FI01mentioned, "Besides growing vegetables and raising pigs, my wife works for other fishers to fix their Lobs (cylindrical fish traps). She earns KHR10,000 per day from fixing the fishing gear. We use this money to buy food and rice."

Moreover, some participants in this fishing community were hired to work with other large-scale fishers. These participants reported that they worked in fishing-related activities such as pulling Proyong (seine nets), collecting freshwater clams (using boats) and installing large fish traps with fences in the lake. They also emphasised that this method could help them gain good money. They worked for a full day and could earn between KHR20,000 and KHR35,000. Nevertheless, this work was not regular, and the fishers did not hire them to work long term. They could work for only a few days.

\subsubsection{Working as a housebuilder and a construction worker}

Besides working in fishing-related activities, some male participants mentioned that they worked as a housebuilder in their communities and as a construction worker in Siem Reap town. According to the participants, working as housebuilder was a casual job that they did during the drought. The participants stated that they were not professional housebuilders, and they could only work on what they were told to do. Mostly, the participants could work for a few days only when they were needed. They were needed when there was a lack of labour or when extra labour was needed for just a while. As mentioned by Respondent ST-FA04, “Working as a house builder is a casual and irregular job. They called me to help them when there is a lack of labour. Sometimes, I could work for a few days, then there is nothing for me to do. After a while, they called me to help out again."

However, one participant claimed that he was a full-time housebuilder during the dry season. He explained that he quit fishing in the dry season from March-June and became a housebuilder since he had noticed the decline of fish populations in the lake. 
Nonetheless, he went back to fishing when the water level rose in the lake and its tributaries in the wet season.

Some participants, particularly in the farming village also stated that they went to Siem Reap town to work in construction. Detecting income loss from the impacts of the severe drought, the local communities worked as construction workers to earn money for their daily household expenses. Since their rice production had been devastated by the severe drought, the participants claimed that they did not have enough rice to eat. They did not even have enough rice seeds for the next cultivation. Hence, they had to do anything to get income to maintain their food security. The participants stated that they went to Siem Reap town to work as construction workers. These participants received a daily wage, which enabled them to buy food and rice for their household consumption. One of the participants said that she sent one of her children to work in construction when her chickens had died because of high temperature and her rice production had been destroyed by severe drought. As Respondent ST-FA07 mentioned, "I could not imagine that the drought this year is too severe. It destroyed my rice production. I used all the seeds and could not get them back. Most of my chickens also died. What I can do is sending my elder son, who just quit school to work in construction to get money to buy medicines for chickens and support the family."

Regarding knowledge of building houses and construction work, all participants emphasised that they had learned from the people who were skilful at house building and construction. They were told how to do it and then they started to learn through experiences. According to participants, the practice of these adaptation strategies could only help get enough income to support their daily expenses for a short period of time. Therefore, they had to practise other methods in order to gain more income while they could not depend on their main livelihoods (rice production and fishing).

\subsection{Local adaptation practices for survival}

\subsubsection{Vegetable gardening}

The participants stated that their vegetable garden was essential for them to have enough food to eat while they could not rely much on the income from their rice 
production and fishing. As observed during the transect walk, most households, particularly in the farming village, had their own small vegetable garden. The local people in this community normally grow herbaceous plants such as chillies, lemongrass, spring onions and galangal roots in their small garden. Some people had a bigger garden in which they planted water spinach, potato, cucumbers, long sponge gourd, wax gourd and eggplants. These vegetables were grown for both selling and household consumption. Some participants claimed that they could earn a little money from selling the vegetables to their neighbours. This method has been used for decades in the community. As mentioned by Respondent ST-FI04, "I have a small vegetable garden. I grow a few types of vegetable such long sponge gourd and water spinach. I could earn a little money from it, KHR1,000 to KHR2,000 a day. And this money is for my children which I give them when they go to school."

Even though there was a water scarcity during the drought, the local communities tried to retain the vegetable growth by buying water or carrying water from a distance to water them. However, some participants reported that most of their vegetables failed to grow due to the high temperature. The participants stated that their small garden could at least help them reduce their daily expenses while they could not earn money from their rice production.

\subsubsection{Collecting wild edible vegetables and plants}

Some local people in the studied communities were reported to have been collecting wild vegetables and plants for their daily consumption when they could not rely on their main sources of income. It was noted that most poor households practised this method for their daily survival. According to the interviews, most participants from poor households reported that they picked edible vegetables and plants for their daily consumption when their income from fishing and rice production was lost. These participants said they picked vegetable and plant species that grew with minimal water, such as drumstick leaves, ivy gourd leaves, and edible amaranth. These species could be found in the village. Other plant species such as water spinach and sesbania flowers could be found at natural ponds and on the lakeshore, and freshwater mangrove leaves could be found at the lakeshore. As mentioned by Respondent ST-FA03 in the farming village, "We could not make income from our rice production this year. Sometimes, I 
just collect drumstick leaves and ivy gourd leaves in the village, and water spinach at the natural ponds for our food."

In the fishing village, where most households did not have a vegetable garden, the local people collected wild vegetables and plants, such as water spinach, sesbania flowers, freshwater mangrove leaves and other edible plants for their daily food. The participants reported that these vegetables and plants could be found in tributaries, ponds and the lakeshore. As mentioned by a village head, "In this village, most people do not grow vegetables for consumption. For those well-off households, they buy vegetables from the market. But for poor households, they go and collect wild vegetables and plants such as water spinach, sesbania flowers and mangrove leaves to eat. People can find these vegetables in the tributary, ponds and the lakeshore." (Respondent VH-MW06)

\subsubsection{Eating small fish}

Fish is both a source of income and vital food security for people in rural areas. The local people in the studied village relied on fish as their main source of income and daily food security. Fish that could be sold for a good amount of money must be in the right size. After fishing, the local fishers in the studied villages divided their fish into two groups of size, big and small. The big fish was for sale, and small fish was for household consumption. Some participants in the fishing village reported that they did not eat big caught fish during the drought because it was hardly caught and expensive. Instead, they had to eat small fish. The participants said that they had been using this method for several years after they noticed that they could not catch as many fish during the drought. They also mentioned that, in the past, the small fish were usually sold to other fishers who used it as bait to catch shrimps and big fish. As mentioned by Respondent MW-FI02, "We try to eat less or eat only small fish when we cannot catch as many fish during the drought. Mostly we can catch small fish. Once I catch big fish, I keep it for selling."

Likewise, the commune councillor mentioned that the people in his commune tended to eat small fish in the dry season when they could not catch as many fish. Then they started to eat big fish as normal when fish was more abundant in the wet season. 


\subsection{Discussion}

Climate change, particularly extreme floods and droughts have hugely affected the local livelihood in the Tonle Sap Lake region. In response to the effects of the floods and droughts on their livelihood, the local communities developed various livelihood adaptation approaches in order to survive. The adaptation strategies were developed based on their IK and experiences. Since the droughts have been the most devastating disasters to affect the local people, most of their adaptation strategies were used to cope with the severe droughts. Two main livelihood adaptation strategies have been adopted by the local people. The first and most important livelihood adaptation strategy was for income generation. The second strategy was for their daily food consumption.

The adaptation strategies adopted for income generation included switching fishing gear and changing fishing zones, vegetable and crop farming, livestock raising, wage labour and hunting wild animals and birds. The local fishers mainly used the methods of changing fishing zones and switching fishing gear in the land and water-based village (fishing village). The method of changing fishing zones has been practised since the local fishers noticed the lake had become too shallow in the last few years. The local fishers had to travel across the lake to fish in deeper fishing zones where they claimed that fish were more abundant than in fishing zones near their villages.

For the local fishers, the method of switching fishing gear has been used since the past even though there were no threats from floods and droughts. They had switched the fishing gear in accordance with the level of water in the lake of the two seasons. However, the current severe climate has meant the dry season is too dry and the lake is too shallow, which has led to a decline in the fish population. Since the fish were less abundant, the fishers switched to using fishing gear that had never been used in the past. They also changed the material of the fishing gear from bamboo to netting. It was reported that the fishing gear made from netting was lighter and more comfortable to carry. Most importantly, the netting gear could catch more fish than the bamboo gear when fish were less abundant.

Besides switching fishing methods, the local communities in the region also engaged in livestock raising, vegetable and crop farming, wage labour and hunting wild animals and birds as a mean of generating income while their primary livelihood has been affected by the severe drought. The methods of livestock raising and wage labour that 
the communities have adopted are similar with the adaptation strategies practised by local people in Northern Ghana, Nepal and Indonesia (Armah et al., 2013; Jones and Boyd, 2011; Binternagel, 2010). The studies in these three countries showed that the local people used various adaptation strategies to respond to floods and droughts. The studies in these countries revealed that the local communities adopted livestock farming and wage labour as their livelihood strategies to adapt to severe droughts that caused damage to their agricultural crops. Concerning wage labour, the study by Jones and Boyd (2011) showed that the local people in Nepal migrated for six months to find jobs further afield while the study in Indonesia by Binternagel (2010) indicated that the local communities mostly worked on other villagers' farms.

The adaptation strategies that the local communities adopted for daily food consumption consisted of vegetable gardening, collecting wild edible vegetables and plants, and eating small fish. These strategies are similar to the adaptation methods that local communities in Nepal, Indonesia and Bangladesh have used to deal with severe droughts. To adapt to severe droughts, the local people in Nepal harvested wild vegetables and plants for their food, while the local people in Indonesia reduced the food consumption (Jones \& Boyd, 2011; Binternagel 2010). The local people in Indonesia were reported to reduce the number of meals by eating twice instead of three times a day. Nonetheless, the communities kept eating three meals a day, but they ate less than usual during the severe drought. Most communities, especially in the landbased village, also had their own vegetable garden that they used for their household consumption. The community people claimed that this method was among other livelihood strategies for their survival while their income was reduced because of the drought.

Regarding vegetable gardening, the rural communities in northeastern Bangladesh also used this method for their livelihood adaptation strategy to cope with the disaster risks. However, the local communities in this region used a different technique for their vegetable garden because they adopted this method during the severe flooding. Instead of growing vegetables on the ground, the local communities used bamboo rafts for their vegetable gardens; these are known as floating gardens (Lebel 2013).

The results of my research also reinforce the previous study of Nuorteva et al. (2010) who conducted a study in the Tonle Sap Lake region to explore the traditional 
adaptation of the local people used to cope with unusual environmental changes. Nuorteva et al. (2010) reveal that the local communities take on short-term employment and collect edible aquatic plants for additional income when their agriculture and fishing activities are affected by floods and droughts. Nuorteva et al. also argue that the local people used savings and other kinds of physical assets to support and broaden their livelihood base. The well-off households commonly practised the saving method while the poor households had to borrow money or rice from their neighbours, relatives or middlemen and moneylenders. However, the method for saving was not mentioned by the local people in my study.

Concerning the competence of the livelihood adaptation strategies, the communities claimed that the methods they used to cope with droughts and floods could only help them have enough for household consumption. The money earned from the alternative livelihood activities was supplemental income while their main sources income had been lost. For most households in the studied communities, the adaptation strategies could not help them improve their livelihood.

\subsection{Indigenous knowledge generation and its roles in developing livelihood adaptation strategies}

The role of indigenous knowledge (IK) of the local communities is significant in developing those adaptation methods. The communities have developed their livelihood adaptation strategies based on their knowledge and experiences with the changes in climate/weather. The knowledge that the local people used to develop the adaptation strategies is classified into indigenous and western knowledge. The IK of the local communities in the two studied villages is the knowledge that they learned from elderly people, family members and their ancestors. The western knowledge of the community people is defined as the knowledge they gained from being involved with the local governments' and NGOs' development programmes and from other community people who shared this knowledge with them. Although the local communities have adopted western knowledge, the IK is still the primary source of knowledge that the local communities used to develop their livelihood adaptation practices to deal with floods and droughts. Most of the adaptation strategies have been developed based on their IK and experiences. Those strategies include fishing-related activities such as switching fishing gear and changing fishing zones, repairing fishing equipment, vegetable 
gardening, hunting wild animals and birds, collecting wild vegetables and plants, and eating small fish. The local communities claimed that they gained the knowledge from older people in their community and their parents and ancestors, and from the experiences they have encountered daily with the surrounding environment. This IK is typically shared among family members, relatives and best friends. The local people tended not to share their knowledge with other communities. Hence, most of the livelihood adaptation strategies were adopted individually, not collectively.

The western knowledge used by the local people comprises making fishing equipment, fish farming, rice farming and livestock raising. This knowledge was introduced by NGOs and local government officials through their development programmes in the Tonle Sap Lake region. The western knowledge has also been shared among communities in the region. Most western knowledge was about the techniques for rice farming, livestock raising and fish farming. These techniques were about how to improve productivity and prevent animals and fish from diseases and death. Although western knowledge was introduced to the local communities, IK still has its roles in the livelihood strategies. Instead of using IK alone, some local people integrated it with western knowledge in doing their rice farming, fish farming and livestock raising. For example, some communities in the region still used indigenous medicine and treatment for their livestock.

\subsection{Conclusion}

This chapter has indicated that the Tonle Sap Lake communities have adopted a number of adaptation strategies to deal with severe floods and droughts. The chapter began with an explanation of how the communities used their IK to mitigate the impacts of floods and droughts. Then, it demonstrated how various adaptation strategies had been developed with a mixture of IK and new knowledge. The local adaptation strategies were classified into two categories. The two categories were household income generation and daily survival. The communities were aware that using IK alone was not sufficient to deal with severe floods and droughts. The communities, therefore, integrated new knowledge that they gained from the outsiders and by being involved in NGOs' and local government's development programmes, with IK to create a new opportunity for their daily livelihood. Nevertheless, the adaptation strategies with a mixture of IK and new knowledge could only help them survive during the severe 
floods and droughts. These adaptation methods were unable to improve the local livelihoods of the local people. 


\section{Chapter 8: Conclusion}

This chapter presents a summary of the thesis comprising research objectives, research location, conceptual framework, core research questions, methodology, participants, key research findings and final comments. The chapter is divided into three sections. The first section summarises the research process. The second section presents the key research findings, and the last part presents some final comments regarding the future of the topic.

\subsection{Summary of the research process}

Tonle Sap Lake is the biggest freshwater lake in Southeast Asia. It is rich in fishery resources and is a highly productive area for rice production that supports the livelihoods of nearly two million people (Holtgrieve et al., 2013; Johnstone et al., 2013; Kummu et al., 2014). However, in the last few decades, the local people who rely on fishery resources and agriculture in the region have been affected by climate change, particularly floods and droughts. The main objective of this research was to find out how local people in the region use their IK to adapt to floods and droughts. The study specifically focused on livelihood adaptation strategies that the local communities used to respond to floods and droughts.

The research was conducted in two villages in the Tonle Sap Lake region. One village is located along the tributary of the lake and is adjacent to Tonle Sap Lake. This village is known as a fishing village because the primary livelihood activity of the local communities in the village is fishing. The other village is located about $7 \mathrm{~km}$ from the lake and is predominantly a farming village because the primary livelihood activity of the villagers is rice cultivation.

The research firstly investigated how local communities in the region perceived climate change, especially floods and droughts. In this part, how the patterns of floods and droughts have evolved over time was also explored. Then, the effects of severe floods and droughts on local communities were examined. In this section, I addressed the impacts of severe floods and droughts on local livelihood activities, then turned to how the communities developed preparation methods for floods and droughts. Lastly, I 
examined how the communities used their IK to develop livelihood adaptation strategies to respond to severe floods and droughts. In this part, the question of how the adaptation strategies have changed over time following the patterns of floods and droughts was addressed. Finally, I studied the effectiveness of using adaptation strategies to adapt to floods and droughts.

To fulfil the main objective of this research, I employed four sub-core questions:

1. What are the local people's perceptions of the floods and droughts? (see 8.2.1)

2. How have the local people and their livelihoods been affected by floods and droughts? (see 8.2.2)

3. What strategies do local people use to recover from the effects of floods and droughts? (see 8.2.3)

4. How might indigenous knowledge be incorporated into adaptation policies? (see 8.3)

To answer the above questions, I adopted a qualitative methodological approach using semi-structured interviews and observations as the primary methods. The semistructured interview was suitable for my research study as it allowed me to interact with the participants to explore their viewpoints about the impacts of floods and droughts. Because of the open-ended questions and informal approach, the semi-structured interview allowed the participants to have enough space to answer different questions. It also enabled me to discover how the local people in the region used their knowledge and experiences to develop livelihood adaptation strategies to respond to floods and droughts.

To conduct the interviews, I approached the participants individually. I used a snowball sampling technique to approach farmers and fishers in the two villages. There were 19 participants in total, including fishers, farmers, commune councillors, village heads and NGO staff.

Besides the semi-structured interviews, I also employed non-participant and unstructured observation, which included transect walks and informal meetings with other non-participant villagers in the studied communities to observe how IK was used to develop livelihood adaptation strategies to adapt to severe floods and droughts. Non- 
participant and unstructured observation allowed me to study how the local communities practise their daily livelihood activities. The transect walk helped me to capture the essential things that the participants did not mention in the interviews. I was also able to see the reality of resource use and compare it with the information that I collected from the interviews.

\subsection{Key research findings}

The findings of this thesis are divided into three major themes. The first theme presents the perceptions of local communities in the region about climate change, floods and droughts. The second theme reveals the impacts of floods and droughts on local communities and their livelihoods. The last theme indicates various livelihood adaptation methods that the local communities have adopted to prepare for, and respond to, floods and droughts.

\subsubsection{Local perception of climate change, floods and droughts}

The first core question of this thesis sought to understand the perceptions of the local communities about climate change, and floods and droughts. The research specifically explored how the local farmers and fishers perceived floods and droughts, which occur regularly in the region. The study found that the communities had clear perceptions of climate change, floods and droughts although they had little knowledge about the complexities of the phenomenon. They all said they had experienced increasing average temperatures and decreasing average annual rainfall. All participants claimed that they had experienced severe drought since 2015. The communities observed that the 2019 drought was the most extreme one they had ever encountered. Water scarcity, which was a result of prolonged drought, was seen as the most critical issue for the local people in the region who rely on fishing and rice farming as their main sources of income. All participants recognised that prolonged drought and high temperature that occurred in 2019 were the most critical issues for them, causing damage to their agricultural production, especially rice cultivation, and affecting their fishing and other livelihood activities. In the last few years, they suggested, climate has become more extreme, which has led to severe floods, intense temperature and prolonged drought. Most participants have just noticed the change of weather in recent years when it has 
become increasingly evident and severe, although climate change has apparently happened over a considerable period.

In terms of flooding, most participants did not show much concern. Although they recognised that flooding was one of the natural hazards that can affect their livelihoods, properties and endanger their lives, the participants claimed that it was not a significant issue for them. There were some reasons that the participants thought that flooding was not a big issue for the communities. In the farming village, extreme flooding did not happen often. Even though the seasonal flooding happened every wet season, it flooded only the farmers' rice fields, not the village. Having experienced seasonal flooding, the farmers in this village adopted flood-tolerant rice varieties to cope with the flood. Likewise, in the fishing village, where flooding is a normal phenomenon happening every wet season, the local people built their houses on tall stilts to avoid the impacts of floods.

Regarding the cause of weather change, nearly half of the respondents recognised that climate change is a result of human activities. However, they looked to more local human activities as a cause, rather than seeing it as a global phenomenon caused by increasing $\mathrm{CO}_{2}$ emissions worldwide. They believed that deforestation is one of the leading causes of climate change. They noticed that the climate had changed since more people cut down flooded forests and cleared them for farmlands. They believed the destruction of flooded forests in their communities has led to severe floods and droughts. The participants indicated that flooded forests in their communities provided several advantages to the community people such as fish spawning zones, fish habitats, preventing big waves when floods happened, and helping to prevent severe droughts. These participants compared the droughts and floods that had happened recently to those in the past when the flooded forests were well maintained in their communities. All these participants claimed floods and droughts that occurred ten or more years ago were not as severe as those of the present day. However, other respondents believed that climate change was a natural process that occurred beyond the control of humankind. These participants claimed that floods and droughts have become gradually severe due to the process of nature. 


\subsubsection{Impacts of floods and droughts on local livelihoods}

The study revealed that flooding was one of the natural hazards that affected local communities and their livelihood. For some participants in the fishing village, extreme flooding was considered as a hazard since it flooded the villages rapidly without warning. The extreme flooding caused damage to local assets such as houses, boats and fishing equipment, and affected fish farming, and fishing activities of the local communities. The local authorities claimed that the extreme flooding in the past years had caused damage to low-income families' houses and forced people to evacuate from their houses to a safe place. For some communities who did fish farming, the extreme flooding caused poor water quality for fish farming. It also destroyed the barrier net fences of the fish ponds and the farmed fish escaped from the ponds, resulting in high production losses. However, for most communities, the impact of extreme floods was not a critical issue since the extreme flooding did not often occur in their region. Moreover, the local communities were well prepared for regular floods that happened every wet season.

In terms of the impacts of droughts, the study indicated that severe and prolonged droughts had caused significant negative impacts on local communities and their livelihoods. The severe and prolonged droughts affected local livelihoods such as rice cultivation, fishing activities, fish farming, livestock raising, vegetable growing and other alternative livelihood activities. Rice cultivation, which was the main livelihood and source of income of the communities in the farming village, was severely affected by prolonged drought. Severe water scarcity, which was a result of prolonged drought, delayed rice growth. All farmers reported that their rice failed to grow even though they used a flood-tolerant variety of rice. Due to the prolonged drought, the local farmers' rice productivity was very low. In the fishing village, fishing activities were the main livelihood and source of income. However, the prolonged drought caused rivers, and the lake to become very shallow and muddy, and therefore less abundant in fish. The amount of fish catch per household was meagre.

The prolonged drought has also severely affected other livelihood activities in the two communities. High temperatures and water shortages were the most significant issues for livestock raising, fish farming and vegetable growing in the communities. Regarding livestock raising, high temperatures have caused diseases in cattle, buffalo and chickens, and some of these animals died eventually. For fish farming, poor water 
quality and warm water because of high temperatures have caused diseases and killed farmed fish. Likewise, high temperatures and water shortages have caused vegetables and crops to fail. Wage labour was also affected by the prolonged drought. The working day of local communities who worked in cassava farms was reduced because of the drought. The local communities who worked to harvest cassava were asked to postpone their work because the severe drought had delayed the plants' growth. Likewise, the local fishers who worked for other large-scale fishers were not hired as often. Given the impacts of droughts on livelihood, the food security of the communities has been threatened, and their income has decreased. Droughts have also contributed to the changes in rural society and affected the rural economy as a whole.

\subsubsection{Local practices and roles of indigenous knowledge in developing adaptation strategies to deal with floods and droughts}

Different challenges within climate change, specifically floods, and droughts, had high impacts on local people in the region. To cope with these natural hazards, the communities have practised various preparation and adaptation methods. Regarding the preparation for floods and droughts, the local people have learned how to adapt to changes in weather patterns from past experiences. The traditional way of rice farming in the studied community relies very much on the availability of rainfall. Hence, local predictions regarding rainfall is significant for the local people when preparing their rice cultivation. The communities prepared themselves in accordance with the rainfall. The local people observed the rainfall pattern from the late dry season or early wet season and predicted if there would be enough rainfall for their rice cultivation. This method has been developed and used since ancient times. The local people learned this method from their ancestors and their own experiences. It was reported that there was a religious event during the Khmer New Year in April when the local communities celebrated and predicted the rainfall for the upcoming wet season.

The Tonle Sap Lake communities were found to be practising two main preparation methods for droughts. The first and most important method was to reserve water in ponds and reservoirs. Having experienced the scarcity of rainfall in the dry season, the local communities dug and restored their wells, ponds and other reservoirs to store water. The stored water was used for different purposes, including household use, vegetable gardens, livestock raising, rice cultivation and crop growing. The second 
method, commonly used by fish farmers in the fishing village, is based on having experienced the adverse effects of drought on fish farming. The local communities found a solution that could prevent them from losing profit because of fish dying. The local communities sold their fish before the drought happened. Based on their experience, the fish farmers acknowledged that the drought usually occurred in the dry season between April and June. Normally, high temperatures during April and May could kill farmed fish. Hence, the fish farmers started to raise their fish in late June or early July and sold it in February or March.

In terms of adaptation strategies, the communities have developed various livelihood adaptation methods to respond to floods and droughts. These adaptation methods were developed based on their indigenous knowledge (IK) and lived experiences. The IK has played a significant role in local communities, which allows the local people to use it to adapt to severe floods and droughts. The knowledge that the local people used to develop the adaptation strategies is classified into indigenous and western or new knowledge. Although the communities have adopted western or new knowledge, the IK is still the primary source of knowledge that the communities used to develop their livelihood adaptation practices dealing with floods and droughts. The adaptation strategies were classified into two main categories. The first and most crucial livelihood adaptation strategy was for income generation. The second strategy was for their daily food consumption.

The adaptation strategies for income generation comprised changing fishing zones and fishing gear, vegetables and crops farming, livestock raising, wage labour, and hunting wild animals and birds. The local fishers mainly used the methods of changing fishing zones and switching fishing gear in the fishing village. The method of changing fishing zones has been practised since the local fishers noticed the lake becoming very shallow in the last few years. The fishers in the studied communities had to travel across the lake to fish in deeper zones where they claimed that fish were more abundant than fishing zones near their villages.

For the local fishers, the method of switching fishing gear has been used in the past even though there were no threats from floods and droughts. The local fishers switched their fishing gear in accordance with the level of water in the lake of the two seasons. However, the current severe climate has meant the dry season is too dry, and the lake is 
too shallow, which has led to a decline in the fish population. Since the fish were less abundant, the fishers changed to use some fishing gear that they had never used before. The local fishers also changed the material of making the fishing gear from bamboo to netting. The gear made from netting was lighter and more comfortable to carry. Most importantly, the netting gear could catch more fish than the bamboo gear while fish was less abundant.

The adaptation strategies for daily food consumption comprised vegetable gardening, collecting wild edible vegetables and plants, and eating small fish. Typically, the local communities had their small vegetable garden in which they commonly grow herbaceous plants such as chillies, lemongrass, spring onions and galangal roots. Some households had bigger gardens where they grew a greater variety of vegetables. The vegetable garden could provide enough food for their daily consumption. The poor households that did not have a vegetable garden were found to collect wild vegetables, which they could either find inside or outside the villages. Moreover, these community people were found to catch wild animals (such as rice-field rats and snakes) and birds for both consumption and supplemental income. The local communities were also found to eat only small fish when fish were not abundant during the drought.

On the whole, the Tonle Sap Lake communities have just noticed the growing severity of climate change in the past few years when it has become more apparent and extreme. Nonetheless, instead of mitigating the effects of climate change, the communities developed various adaptation strategies to adapt to it. Some methods have been practised for some time while others have been adopted recently, providing the local communities more opportunities to deal with climate change, especially severe droughts. However, due to the current severe climate, particularly severe and prolonged drought in 2019, the adaptation methods that the communities adopted were only sufficient for their daily survival. Although a mixture of IK and new knowledge has been used to develop the strategies, the sufficiency of the adaptation was still limited. Most of the adaptation strategies, particularly for income generation, could only help the local communities gain enough supplemental income for their daily consumption. These methods could not help them improve their livelihoods.

IK has been considered a basic and undervalued knowledge practised by indigenous people. However, IK should be seen not so much as a fixed set of practices and skills 
developed from the past. IK should be seen or considered more as a dynamic set of ideas and practices used to read the environment and adapt accordingly. To adapt to the current environmental changes, IK can also absorb new technologies and resources from the outside world. What is important is the way these technologies and resources are used in wider environmental knowledge.

\subsection{Final comments}

This study has shown that the local people in the Tonle Sap Lake region see climate change as a result of local causes rather than global. The local people referred to local deforestation when they were asked about the cause of climate change. They assumed that the destruction of flooded forests in their communities had led to severe floods and droughts. These communities believed that if the flooded forest were well maintained, the effects of floods and droughts would not have been as severe. This local perception and knowledge could be useful to inform local environmental practices. Although it does not link to global action, it may help mitigate some effects of climate change. As mentioned by Shukla et al. (2016), local knowledge and perception reflect local issues because they live closely with nature and have a close interactive understanding of their environment. Hence, local knowledge plays a significant role in adaptation strategies. Likewise, other scholars suggest that local or indigenous knowledge is a key resource for local communities that can be used for designing local adaptation and mitigation policy to not only mitigate the effects of climate change, but also to manage natural resources in an effective and sustainable way (Agrawal, 1995; Briggs, 2014; Deeb et al., 2011; Hiwasaki et al., 2015; Raygorodetsky, 2019). Therefore, the IK and perceptions of the communities should be taken into consideration and incorporated into local environmental practices in this region so that the local environmental practices could be used more effectively to reduce negative impacts of climate change at the local level.

Tonle Sap Lake is a region of climatic variation where floods and droughts occur naturally. However, the intensity of the floods and droughts has increased in the last few years. Since the effects of floods and droughts have threatened their livelihoods and food security, the local communities in this region have been found to adopt various established practices so that they are able to respond to the hazards. The Tonle Sap Lake people are not passive. They have actively adopted various livelihood adaptation 
practices to deal with such natural hazards. This finding underpins the previous study of Nuorteva et al. (2010), which was also conducted in the region. Nuorteva et al. (2010) reveal that the local communities in both fishing and farming villages in the region actively increase their adaptive capacity to respond to climate change. Having faced extreme environmental phenomena, the communities have formed different kinds of response aiming to increase the local communities' possibilities to cope with current and future events.

Various climate change adaptation methods have been developed in local communities in the region. However, there appears to be little official involvement in climate change adaptation from the government and NGOs. The communities have been left to themselves to deal with climate change. Most local communities claimed that their climate change adaptation methods had been developed from their own knowledge and experiences with little support from NGOs. Most of the adaptations being used are primarily low-cost and low-tech. This may be questionable in terms of sustainability. For instance, the communities were found to change their fishing zones when fish became less abundant in the fishing zones near their villages. These fishers go further into the lake in order to find deeper pools to fish. This method is seen as not sustainable if the intensity of floods and droughts keeps increasing.

Local adaptation and IK are essential for local communities to respond to such natural hazards. However, the local adaptation and IK have their limits if climate change continues. As noted by Nuorteva et al. (2010), the communities' capacity to respond to climate change is still limited due to the current severity of climate change. The adaptation methods that the local people have used are uneven both between and within the villages, making the fishing villages and the poorest households in the region vulnerable to climate change. Nuorteva et al. (2010) also suggest that, in order to strengthen and expand existing livelihood strategies of the communities, local adaptation strategies need to be complemented with higher-level and long-term policy responses. Therefore, the involvement of the government and NGOs is obviously crucial in developing climate change adaptation policy at the local level. The contribution from the government and NGOs will not only strengthen local resilience and adaptive capacity to climate change, but it will also help the adaptation methods be more productive and sustainable. 


\section{References}

Abid, M., Schilling, J., Scheffran, J., \& Zulfiqar, F. (2016). Climate change vulnerability, adaptation and risk perceptions at farm level in Punjab, Pakistan. Science of the Total Environment, 547, 447-460.

Adhikari, S. (2018). Drought impact and adaptation strategies in the mid-hill farming system of western Nepal. Environments, 5(9), 1-12.

Agrawal, A. (1995). Dismantling the divide between indigenous and scientific knowledge. Development and Change, 26(3), 413-439.

Ahmed, M., \& Atiqul Haq, S. (2019). Indigenous people's perceptions about climate change, forest resource management, and coping strategies: a comparative study in Bangladesh. Environment, Development and Sustainability, 21(2), 679-708.

Armah, R. N., Al-Hassan, R. M., Kuwornu, J. K., \& Osei-Owusu, Y. (2013). What influences farmers' choice of indigenous adaptation strategies for agrobiodiversity loss in Northern Ghana? British Journal of Applied Science \& Technology, 3(4), 1162-1176.

Binternagel, N. B., Juhrbandt, J., Koch, S., Purnomo, M., Schwarze, S., Barkmann, J., \& Faust, H. (2010). Adaptation to climate change in Indonesia - livelihood strategies of rural households in the face of ENSO related droughts. In T. Tscharntke, C. Leuschner, E. Veldkamp, H. Faust, E. Guhardja, \& A. Bidin (Eds.), Tropical Rainforests and Agroforests under Global Change: Ecological and Socio-Economic Valuations (pp. 351-375). Berlin: Springer.

Boyd, E. (2014). Climate change and development. In V. Desai \& R. B. Potter (Eds.), The Companion to Development Studies (pp. 341-346). Abingdon, Oxon: Routledge.

Breidlid, A. (2009). Culture, indigenous knowledge systems and sustainable development: A critical view of education in an African context. International Journal of Educational Development, 29(2), 140-148.

Briggs, C. L. (1986). Learning How to Ask: A Sociolinguistic Appraisal of the Role of the Interview in Social Science Research. Cambridge: Cambridge University Press.

Briggs, J. (2014). Climate change and development. In V. Desai \& R. B. Potter (Eds.), The Companion to Development Studies (pp. 127-130). Abingdon, Oxon: Routledge. 
Brockington, D., \& Sullivan, S. (2003). Qualitative research. In R. Scheyvens \& D. Storey (Eds.), Deveopment Fieldwork (pp. 58-74). London: SAGE Publications. Call-Cummings, M., \& Ross, K. (2019). Re-positioning power and re-imagining reflexivity: Examining positionality and building validity through reconstructive horizon analysis. In K. K. Strunk \& L. A. Locke (Eds.), Research Methods for Social Justice and Equity in Education (pp. 3-13). Cham: Springer International Publishing.

Carvajal, L. (2007). Impacts of Climate Change on Human Development. IDEAS Working Paper Series from RePEc.

Collier, M., \& Webb, R. H. (2002). Cutting edges of climate. In M. Collier \& R. H. Webb (Eds.), Floods, Droughts, and Climate Change (pp. 7-19). Tucson: The University of Arizona Press.

Creswell, J. W. (2014). Research Design: Qualitative, Quantitative, And Mixed Methods Approaches. Thousand Oaks: SAGE Publications.

Dada, S. O. (2016). Post-development and the role of tradition in the process of development. Trames, 20(1), 75-93.

DCC. (2019, 2014). History. Retrieved from http://www.camclimate.org.kh/en/ccd/history.html

Deeb, A., French, A., Heiss, J., Jabbour, J., LaRochelle, D., Levintanus, A., . . . McKeown, R. (2011). Climate Change Starter's Guidebook: An Issues Guide for Education Planners and Practitioners. Paris: UNESCO.

Devisti, H., \& Motamed, M. K. (2012). Environmental and socio-economic impacts of drought from the viewpoint of Guilan paddy farmers, north Iran. Caspian Journal of Environmental Sciences, 10(2), 227-235.

Dudovskiy, J. (2019). Constructivism research philosophy. Retrieved from https://research-methodology.net/researchphilosophy/epistomology/constructivism/

Edwards, R., \& Holland, J. (2013). What is Qualitative Interviewing? London: Bloomsbury.

FAO. (2012). Cambodia. In K. Frenken (Ed.), Irrigation in Southern and Eastern Asia in Figures (pp. 205-222). Rome: Food and Agriculture Organization of the United Nations (FAO).

FAO. (2015). The Impact of Natural Hazards and Disasters on Agriculture, Food Security and Nutrition. Retrieved from http://www.fao.org/3/a-i4434e.pdf 
FAO. (2016). Damage and Losses from Climate-Related Disasters in Agricultural

Sectors. Retrieved from http://www.fao.org/3/a-i6486e.pdf

FAO. (2019a). Cambodia at a glance. Retrieved from http://www.fao.org/cambodia/faoin-cambodia/cambodia-at-a-glance/en/

FAO. (2019b). Fishery and aquaculture country profiles: The Kingdom of Cambodia. Retrieved from http://www.fao.org/fishery/facp/KHM/en

Fawthrop, T. (2019, August 26). Something is very wrong on the Mekong River: This year's drought is just a preview of more dire problems to come if government don't change course. Retrieved from https://thediplomat.com/2019/08/something-is-very-wrong-on-the-mekongriver/

Ford, J. D., Cameron, L., Rubis, J., Maillet, M., Nakashima, D., Willox, A. C., \& Pearce, T. (2016). Including indigenous knowledge and experience in IPCC assessment reports. Nature Climate Change, 6(4), 349-353.

Gamble, D. W., Campbell, D., Allen, T. L., Barker, D., Curtis, S., McGregor, D., \& Popke, J. (2010). Climate Change, Drought, and Jamaican Agriculture: Local Knowledge and the Climate Record. Annals of the Association of American Geographers, 100(4), 880-893.

Gopalakrishnan, C. (2013). Water and disasters: a review and analysis of policy aspects. International Journal of Water Resources Development, 29(2), 250-271.

Green, D., \& Raygorodetsky, G. (2010). Indigenous knowledge of a changing climate. An Interdisciplinary, International Journal Devoted to the Description, Causes and Implications of Climatic Change, 100(2), 239-242.

GSSD. (2015). Cambodia's Second National Communication under the United Nations Framework Convention on Climate Change. Phnom Penh: General Secretariat, National Council for Sustainable Development/Ministry of Environment. Retrieved from https://unfccc.int/resource/docs/natc/khmnc2.pdf GSSD. (2017). National Adaptation Plan Process in Cambodia. Phnom Penh: Department of Climate Change, General Secretariat of National Council for Sustainable Development/Ministry of Environment. Retrieved from http://www.camclimate.org.kh/en/ccd/dcc-news/422-new-released-cambodianational-adaptation-plan-process.html

Güneralp, B., Güneralp, İ., \& Liu, Y. (2015). Changing global patterns of urban exposure to flood and drought hazards. Global Environmental Change, 31, 217 225. 
Gyampoh, B., Amisah, S., Idinoba, M., \& Nkem, J. (2009). Using traditional knowledge to cope with climate change in rural Ghana. Unasylva, 60(281/232), 70-74.

Hiwasaki, L., Luna, E., Syamsidik, J., \& Marçal, J. (2015). Local and indigenous knowledge on climate-related hazards of coastal and small island communities in Southeast Asia. An Interdisciplinary, International Journal Devoted to the Description, Causes and Implications of Climatic Change, 128(1), 35-56.

Holtgrieve, G., Arias, M., Irvine, K., Lamberts, D., Ward, E., Kummu, M., . . Richey, J. (2013). Patterns of Ecosystem Metabolism in the Tonle Sap Lake, Cambodia with Links to Capture Fisheries. PLoS ONE, 8(8), 1-11.

Hunn, E. (2007). Ethnobiology in four phases. Journal of Ethnobiology, 27(1), 1-10.

IPCC. (2014). Climate change 2014: Synthesis Report. Contribution of Working Groups I, II and III to the fifth assessment report of the Intergovernmental Panel on Climate Change / R. Pachauri and L. Meyer (Eds.). Geneva: IPCC.

IPCC. (2018). Summary for policymakers. In Masson-Delmotte, V., P. Zhai, H.-O. Pörtner, D. Roberts, J. Skea, P.R. Shukla, A. Pirani, W. Moufouma-Okia, C. Péan, R. Pidcock, S. Connors, J.B.R. Matthews, Y. Chen, X. Zhou, M.I. Gomis, E. Lonnoy, T. Maycock, M. Tignor, and T. Waterfield (Eds.), Global Warming of $1.5^{\circ} \mathrm{C}$ (pp. 32). Geneva: World Meteorological Organization.

Jackson, A. (2014, August 2). Flooding. Retrieved from

https://geographyas.info/rivers/flooding/

Joffre, O., Mam, K., Kura, Y., Sereywath, P., \& Thuok, N. (2012). Community Fish Refuges in Cambodia: Lessons Learned. Phnom Penh: The WorldFish Center. Johnson, B. (2014). Educational Research: Quantitative, Qualitative, And Mixed Approaches (Fifth edition). Thousand Oaks: Sage Publications.

Johnstone, G., Ranjitha, P., Fabrice, D., Mam, K., Il, O., Mak, S., . . Rest, S. (2013). Tonle Sap Scoping Report. Penang: The WorldFish Center.

Jones, L., \& Boyd, E. (2011). Exploring social barriers to adaptation: Insights from Western Nepal. Global Environmental Change, 21(4), 1262-1274.

Kawulich, B. B. (2005). Participant Observation as a Data Collection Method. Forum: Qualitative Social Research, 6(2), 1-28.

KEI. (2018). Environmental Sustainability in Asia: Progress, Challenges and Opportunities in the Implementation of the Sustainable Development Goals, Series 2 - Cambodia. Sejong: Korea Environment Institute.

Keo, K. (2014, 23 September 2014). Cambodia turns climate change crisis into opportunity. Retrieved from 
https://www.undp.org/content/undp/en/home/blog/2014/9/23/cambodia-turnsclimate-change-crisis-into-opportunity.html

Kim, S., Chem, P., So, S., Kim, S. S., \& Pech, S. (2014). Methods and Tools Applied for Climate Change Vulnerability and Adaptation Assessment in Cambodia's Tonle Sap Basin. Phnom Penh: Cambodia Development Resource Institute (CDRI).

Kozlowski, T. T. (2002). Physiological-ecological impacts of flooding on riparian forest ecosystems. Wetlands, 22(3), 550-561.

Kummu, M., Tes, S., Yin, S., Adamson, P., Józsa, J., Koponen, J., . . Sarkkula, J. (2014). Water balance analysis for the Tonle Sap Lake-floodplain system. Hydrological Processes, 28(4), 1722-1733.

Laidler, G. (2006). Inuit and scientific perspectives on the relationship between sea ice and climate change: The Ideal Complement? Climatic Change, 78(2-4), 407444.

Lamberts, D. (2001). Tonle Sap Fisheries: A Case Study on Floodplain Gillnet Fisheries. Bangkok: Food and Agriculture Organisation of the United Nations (FAO).

Lancaster, J. W., Preene, M., \& Marshall, C. T. (2004). Development and Flood Risk: Guidance for the Construction Industry. London: Construction Industry Research \& Information Association (CIRIA).

Lebel, L. (2013). Local knowledge and adaptation to climate change in natural resourcebased societies of the Asia-Pacific. Mitigation and Adaptation Strategies for Global Change, 18(7), 1057-1076.

Levina, E., \& Tirpak, D. (2006). Adaptation to Climate Change: Key Terms. Paris: OECD/International Energy Agency (IEA). Retrieved from https://www.oecd.org/environment/cc/36736773.pdf

Li, P., Omani, N., Chaubey, I., \& Wei, X. (2017). Evaluation of drought implications on ecosystem services: Freshwater provisioning and food provisioning in the Upper Mississippi River basin. International Journal of Environmental Research and Public Health, 14(5), 1-23.

Magni, G. (2017). Indigenous knowledge and implications for the sustainable development agenda. European Journal of Education, 52(4), 437-447.

Manandhar, S., Pratoomchai, W., Ono, K., Kazama, S., \& Komori, D. (2015). Local people's perceptions of climate change and related hazards in mountainous areas 
of northern Thailand. International Journal of Disaster Risk Reduction, 11, 4759.

Margaret, S.-L., Daniel, B., Adjei, P. O.-W., \& Foli, E. G. (2018). Perceptions and knowledge on climate change in local communities in the Offinso Municipality, Ghana. Information Development, 1-20.

Martinez-Covarrubias, J., \& Garza-Reyes, J. A. (2017). Establishing framework: Sustainable transition towards a low-carbon economy. In P. Baranova, E. Conway, N. Lynch, \& F. Paterson (Eds.), The Low Carbon Economy: Understanding and Supporting a Sustainable Transition (pp. 15-31). Cham: Springer International Publishing.

McCarthy, J. (2001). Climate Change 2001: Impacts, Adaptation, and Vulnerability:

Contribution of Working Group II to the Third Assessment Report of the Intergovernmental Panel on Climate Change. Cambridge: Cambridge University Press.

Merriam, S. B., \& Tisdell, E. J. (2016). Qualitative Research: A Guide to Design and Implementation (Fourth edition.). San Francisco, CA: Jossey-Bass, a Wiley brand.

Mickle, P., Herbig, J., Somerset, C., Chudzik, B., Lucas, K., \& Fleming, M. (2018).

Effects of annual droughts on fish communities in Mississippi Sound estuaries. Journal of the Coastal and Estuarine Research Federation, 41(5), 1475-1485. Ministry of Agriculture, Forest and Fisheries. (2015). Agricultural Sector Strategic Development Plan 2014-2018. Phnom Penh: Ministry of Agriculture Forestry and Fisheries. Retrieved from http://extwprlegs1.fao.org/docs/pdf/cam155661.pdf

Ministry of Environment. (2006). National Adaptation Programme of Action to Climate Change (NAPA). Phnom Penh: Ministry of Environment.

Ministry of Environment. (2009). Cambodia Environment Outlook. Retrieved from http://wedocs.unep.org/bitstream/handle/20.500.11822/8689/Cambodia_environ ment_outlook.pdf?sequence $=3 \&$ isAllowed $=y$

Morecroft, M. D., \& Cowan, C. E. (2010). Responding to climate change: An essential component of sustainable development in the 21st century. Local Economy: The Journal of the Local Economy Policy Unit, 25(3), 170-175.

Mosley, L. (2015). Drought impacts on the water quality of freshwater systems review and integration. Earth - Science Reviews, 140, 203-214. 
MRC. (2010). Assessment of Basin-Wide Development Scenarios: Impacts on the Tonle Sap Ecosystem. Retrieved from http://www.probeinternational.org/Impacts-onthe-Tonle-Sap-Ecosystem(June-10).pdf

Musyoki, A., Thifhulufhelwi, R., \& Murungweni, F. M. (2016). The impact of and responses to flooding in Thulamela Municipality, Limpopo Province, South Africa. Jamba (Potchefstroom, South Africa), 8(2), 166-166.

Mwiturubani, D. A. (2017). The role of indigenous weather forecast in enhancing agricultural production in Tanzania. Journal of the Geographical Association of Tanzania, 37(1), 38-55.

NCSD \& CCCA. (2018). Addressing Climate Change Impacts on Economic Growth in Cambodia. Phnom Penh: National Council for Sustainable Development/The Royal of Cambodia. Retrieved from https://www.climatefinancedevelopmenteffectiveness.org/sites/default/files/CEGIM_FullReport.pdf Netherlands Embassy. (2018). Agriculture in Cambodia. Bangkok: Embassy of the Netherlands.

Nguyen, H., \& Shaw, R. (2011). Adaptation to droughts in Cambodia. In R. Shaw, S. Rajib, \& N. Huy (Eds.), Droughts in Asian Monsoon Region (Vol. 8, pp. 49-66). Bingley: Emerald Group Publishing.

Nuorteva, P., Keskinen, M., \& Varis, O. (2010). Water, livelihoods and climate change adaptation in the Tonle Sap Lake area, Cambodia: Learning from the past to understand the future. Journal of Water and Climate Change, 1(1), 87-101.

Nyong, A., Adesina, F., \& Osman Elasha, B. (2007). The value of indigenous knowledge in climate change mitigation and adaptation strategies in the African Sahel. An International Journal Devoted to Scientific, Engineering, SocioEconomic and Policy Responses to Environmental Change, 12(5), 787-797.

OECD. (2016). Mitigating Droughts and Floods in Agriculture: Policy Lessons and Approaches. Paris: OECD Publishing.

OECD. (2017). Social Protection System Review of Cambodia. Paris: OECD Publishing.

Palutikof, J. P., Agnew, M. D., \& Hoar, M. R. (2004). Public perceptions of unusually warm weather in the UK: impacts, responses and adaptations. Climate Research, 26(1), 43-59.

Pech, S. (2015, 24 November 2015). Another drought year in store for Cambodia.

Retrieved from https://www.phnompenhpost.com/national/another-droughtyear-store-cambodia 
Pettenger, M. (2007). The Social Construction of Climate Change: Power, Knowledge, Norms, Discourses. Aldershot: Ashgate.

Rapsomanikis, S., Trepekli, A., \& Dalezios, N. R. (2017). Climate change and climate extremes. In N. R. Dalezios (Ed.), Environmental Hazards: Methodologies for Risk Assessment and Management (pp. 476-502). London: IWA Publishing. Raygorodetsky, G. (2019, 13 December 2011). Why traditional knowledge holds the key to climate change. Climate Change, Culture and Religions. Retrieved from https://unu.edu/publications/articles/why-traditional-knowledge-holds-the-keyto-climate-change.html

Reid, H. (2014). Climate Change and Human Development. London: Zed Books.

Reuy, R. (2012, 21 August 2012). Drought hits Cambodia's rice exports. Retrieved from https://www.phnompenhpost.com/business/drought-hits-cambodias-rice-exports

Richardson, R. B. (2013). Building a Green Economy: The case for an economic paint job. In R. B. Richardson (Ed.), Building a Green Economy (pp. 3-18). East Lansing: Michigan State University Press.

Rockström, J., Steffen, W., Noone, K., Persson, Å., Chapin III, F. S., Lambin, E. F., . . . Schellnhuber, H. J. (2009). A safe operating space for humanity. Nature, 461(7263), 472-475.

Roder, G., Sofia, G., Wu, Z., \& Tarolli, P. (2017). Assessment of social vulnerability to floods in the floodplain of northern Italy. Weather, Climate, and Society, 9(4), 717-737.

Rosa, E., \& Dietz, T. (2012). Human drivers of national greenhouse-gas emissions. Nature Climate Change, 2(8), 581-586.

Royal Government of Cambodia. (2013a). Cambodia Climate Change Strategic Plan 2014-2023. Phnom Penh: National Climate Change Committee/The Royal Government of Cambodia. Retrieved from https://www.cambodiaip.gov.kh/DocResources/ab9455cf-9eea-4adc-ae9395d149c6d78c_007729c5-60a9-47f0-83ac-7f70420b9a34-en.pdf

Royal Government of Cambodia. (2013b). National Policy on Green Growth. Phnom Penh: National Council on Green Growth/The Royal Government of Cambodia. Retrieved from https://www.greengrowthknowledge.org/sites/default/files/downloads/policydatabase/2013\%20Cambodia\%20National\%20Policy\%20on\%20Green\%20Gro wth.pdf 
Royal Government of Cambodia. (2018). Rectangular Strategy for Growth,

Employment, Equity and Efficiency: Building the Foundation Toward Realizing

the Cambodia Vision 2050. Phnom Penh: Royal Government of Cambodia.

Retrieved from http://cnv.org.kh/wp-content/uploads/2012/10/Rectangular-

Strategy-Phase-IV-of-the-Royal-Government-of-Cambodia-of-the-Sixth-

Legislature-of-the-National-Assembly-2018-2023.pdf

Sasipornkarn, E. (2019, August 16). A dam-building race threatens the Mekong River.

Retrieved from https://www.dw.com/en/a-dam-building-race-threatens-themekong-river/a-50049206

Scheyvens, R., \& Storey, D. (2003). Development Fieldwork: A Practical Guide. London: SAGE Publications.

Schwartz, J. (2018). More floods, more droughts: Climate change delivers both.

Retreived from https://www.nytimes.com/2018/12/12/climate/climate-change-

floods-droughts.html

Seiff, A. (2017). When there are no more fish: Climate change, drought, and development have devastated Cambodia's Tonle Sap Lake, which feeds millions across Southeast Asia. Retrieved from

https://www.eater.com/2017/12/29/16823664/tonle-sap-drought-cambodia

Semali, L. M., \& Kincheloe, J. L. (1999). Introduction: What is indigenous knowledge and why should we study it? In L. M. Semali \& J. L. Kincheloe (Eds.), What is Indigenous Knowledge?: Voice from the Academy. (pp. 3-57). New York: Falmer Press.

Senanayake, S. (2006). Indigenous knowledge as a key to sustainable development. Journal of Agricultural Sciences-Sri Lanka, 2(1), 87-94.

Serageldin, I. (2009). Food, feed, fuel, and climate change: challenges, threats, and possible actions. In R. D. van den Berg \& O. N. Feinstein (Eds.), Evaluating Climate Change and Development (pp. 3-18). New Brunswick, N.J: Transaction Publishers.

Shi, J., Visschers, V. H. M., \& Siegrist, M. (2015). Public perception of climate change: The importance of knowledge and cultural worldviews. Risk Analysis, 35(12), 2183-2201.

Shukla, G., Kumar, A., Pala, N., \& Chakravarty, S. (2016). Farmers perception and awareness of climate change: a case study from Kanchandzonga Biosphere 
Reserve, India. Environment, Development and Sustainability, 18(4), 11671176.

Sillitoe, P. (1998). The Development of Indigenous Knowledge: A New Applied Anthropology. Current Anthropology, 39(2), 223-252.

Slovic, P. (1987). Perception of Risk. Science, 236(4799), 280-285.

Smakhtin, V., Pavelic, P., Amarnath, G., McCartney, M., \& Campbell, B. (2014). Managing water variability: Floods and droughts. IDEAS Working Paper Series from RePEc.

Stewart-Withers, R., Banks, G., Mcgregor, A., \& Meo-Sewabu, L. (2014). Qualitative research. In R. Scheyvens (Ed.), Development Fieldwork (pp. 59-80). London: SAGE Publicaitons.

Stuyt, L., Reinders, J., Hermans, E., De Keizer, M., \& Icke, J. (2007). The environmental impact of flooding of the Dutch 'Delta-Metropole'. In Flood Risk Management in Europe: Innovation in Policy and Practice (Advances in Natural and Technological Hazards Research Series) (pp. 107-129).

Sullivan, M. (2019, November 2019). The lake that feeds the Mekong basin is facing a shortage of fish. Retrieved from https:/wamu.org/story/19/11/09/the-lake-thatfeeds-the-mekong-basin-is-facing-a-shortage-of-fish/

Sun, R., An, D., Lu, W., Shi, Y., Wang, L., Zhang, C., . . Wang, Q. (2016). Impacts of a flash flood on drinking water quality: Case study of areas most affected by the 2012 Beijing flood. Heliyon, 2(2), 1-14.

Taylor, A. L., Dessai, S., \& Bruine de Bruin, W. (2014). Public perception of climate risk and adaptation in the UK: A review of the literature. Climate Risk Management, 4-5(C), 1-16.

Thomas, V. (2017). Climate Change and Natural Disasters: Transforming Economies and Policies for a Sustainable Future. New York: Routledge.

Tracy, S. J. (2013). Qualitative Research Methods: Collecting Evidence, Crafting Analysis, Communicating Impact. West Sussex: John Wiley \& Sons.

Trenberth, K. E. (2005). The impact of climate change and variability on heavy precipitation, floods, and droughts. Encyclopedia of Hydrological Sciences, 111 .

Udmale, P. D., Ichikawa, Y., Kiem, A. S., \& Panda, S. N. (2014). Drought impacts and adaptation strategies for agriculture and rural livelihood in the Maharashtra State of India. The Open Agriculture Journal, 8(1), 41-47. 
Uk, S., Yoshimura, C., Siev, S., Try, S., Yang, H., Oeurng, C., . . Hul, S. (2018). Tonle Sap Lake: Current status and important research directions for environmental management. Lakes \& Reservoirs: Research \& Management, 23(3), 177-189.

Ultanir, E. (2012). An Epistemological Glance at the Constructivist Approach: Constructivist Learning in Dewey, Piaget, and Montessori. International Journal of Instruction, 5(2), 195-212.

Un, S. (2018). Review of Implementation Challenges Posed by the Climate Change Action Plan 2014-2018 in Cambodia: Case Studies of Three Ministries. Phnom Penh: Parliamentary Institute of Cambodia (PIC).

UNFCCC. (2019). What do adaptation to climate change and climate resilience mean? Retrieved from https://unfccc.int/adaptation/items/4159.php

UNDP. (2009). Country Report on Global Assessment of Risk: ISDR Global Assessment Report on Poverty and Disaster Risk 2009. Kathmandu: United Nations Development Programme (UNDP).

UNDP. (2016). Sustainable Development Goals. Retrieved from

http://www.undp.org/content/undp/en/home/sustainable-development-goals.html UNDRR. (2019, 8 April 2019). Cambodia steps up fight against climate change.

Retrieved from https://www.unisdr.org/archive/64687

UNESCO. (2009). Learning and Knowing in Indigenous Societies Today (M. C. P.

Bates, S. Kube \& D. Nakashima Eds.). Paris: UNESCO.

UNESCO. (2017). Local and Indigenous Knowledge System. Retrieved from http://www.unesco.org/new/en/natural-sciences/priority-areas/links/relatedinformation/what-is-local-and-indigenous-knowledge/

UNESCO. (2019). Local and Indigenous Knowledge Systems (LINKS). Retrieved from https://en.unesco.org/links

UNISDR. (2002). Impacts of Disasters Since the 1992 Rio de Janeiro Earth Summit. Retrieved from https://www.unisdr.org/files/27162_infographic.pdf

UNISDR. (2015). Making Development Sustainable: The Future of Disaster Risk Management. Global Assessment Report on Disaster Risk Reduction. Geneva: United Nations Office for Disaster Risk Reduction (UNISDR). Retrieved from https://www.preventionweb.net/english/hyogo/gar/2015/en/garpdf/GAR2015_EN.pdf

University of Notre Dame. (2019, 30 November 2019). Notre Dame Global Adaptation Initiative: country index, Cambodia. Retrieved from https://gain.nd.edu/ourwork/country-index/ 
USAID. (2019a, 23 August 2019). Cambodia: agriculture and food security. Retrieved from https://www.usaid.gov/cambodia/agriculture-and-food-security

USAID. (2019b). Climate Risk Profile: Cambodia. Retrieved from https://www.climatelinks.org/sites/default/files/asset/document/2019_USAID_C ambodia\%20CRP.pdf

Van Aalst, M. K. (2006). The impacts of climate change on the risk of natural disasters. Disasters, 30(1), 5-18.

Van den Ban, A. W., \& Hawkins, H. S. (2000). Agricultural Extension (2nd Ed.). Oxford: Blackwell Science.

Varis, O., Kummu, M., Keskinen, M., Sarkkula, J., Koponen, J., Heinonen, U., \& Makkonen, K. (2006). Tonle Sap Lake, Cambodia: Nature's Affluence Meets Human Poverty. Retreived from http://hdr.undp.org/sites/default/files/olli_varis_tonlesap_study.pdf Walliman, N. (2011). Research Methods: The Basics. London: Routledge.

Wongchuig Correa, S., Paiva, R. C. D. d., Espinoza, J. C., \& Collischonn, W. (2017). Multi-decadal Hydrological Retrospective: Case study of Amazon floods and droughts. Journal of Hydrology, 549, 667-684.

World Bank. (2011). Vulnerability, Risk Reduction, and Adaptation to Climate Change. Washington, USA. Retrieved from https://climateknowledgeportal.worldbank.org/sites/default/files/201810/wb_gfdrr_climate_change_country_profile_for_KHM.pdf

World Bank. (2017). Cambodia - Sustaining Strong Growth for the Benefit of All. Washington, D.C.: World Bank Group.

World Bank. (2019a, 25 September 2019). Cambodia. Retrieved from https://data.worldbank.org/country/cambodia

World Bank. (2019b, 25 September 2019). The World Bank in Cambodia. Retrieved from https://www.worldbank.org/en/country/cambodia/overview

World Bank. (2019c, 30 September 2019). Cambodia: climate data. Retrieved from https://climateknowledgeportal.worldbank.org/country/cambodia/climate-datahistorical

Wuebbles, D. J. (2018). Climate Change in the 21st Century: Looking Beyond the Paris Agreement. In Climate Change and Its Impacts (pp. 15-38). Cham: Springer.

Yohe, G. W., Lasco, R. D., Ahmad, Q. K., Arnell, N. W., Cohen, S. J., Hope, C., . . Perez, R. T. (2007). Perspectives on climate change and sustainability. In M. L. Parry, O. F. Canziani, J. P. Palutikof, P. J. van der Linden, \& C. E. Hanson 
(Eds.), Climate Change 2007: Impacts, Adaptation and Vulnerability:

Contribution of Working Group II to the Fourth Assessment Report of the Intergovernmental Panel on Climate Change. (pp. 811-841). Cambridge: Cambridge University Press. 


\section{Appendices}

\section{Appendix 1. Ethical approval}

TE WHARE WÃNANGa O TE Ũ POKO O TE IKA A MÃUI

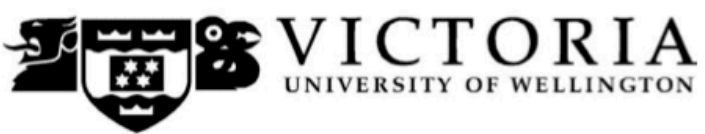

MEMORANDUM

Phone $\quad 0-4-4636028$

Email_judith.loveridge@vuw.ac.nz

\begin{tabular}{l|l}
\hline TO & Sopheak Seng \\
\hline FROM & Dr Judith Loveridge, Convenor, Human Ethics Committee \\
\hline
\end{tabular}

\begin{tabular}{l|l}
\hline DATE & 24 May 2019 \\
\hline PAGES & 1 \\
\hline
\end{tabular}

\begin{tabular}{l|l}
\hline SUBJECT & $\begin{array}{l}\text { Ethics Approval } \\
\text { Number: } 27397\end{array}$ \\
& $\begin{array}{l}\text { Title: How Local People Use their Indigenous Knowledge to } \\
\text { Respond to Floods and Droughts. A study of a Community in } \\
\text { Tonle Sap Lake Region, Cambodia }\end{array}$ \\
\hline
\end{tabular}

Thank you for your application for ethical approval, which has now been considered by the Human Ethics Committee.

Your application has been approved from the above date and this approval is valid for three years. If your data collection is not completed by this date you should apply to the Human Ethics Committee for an extension to this approval.

Best wishes with the research.

Kind regards,

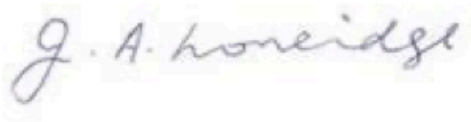

Judith Loveridge

Convenor, Victoria University of Wellington Human Ethics Committee 


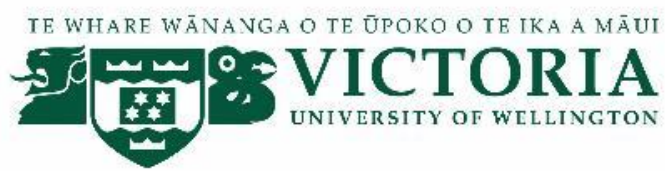

\title{
How Local People use their Indigenous Knowledge to Respond to Floods and Droughts:
}

\author{
A Case Study of Tonle Sap Lake communities, Cambodia
}

\section{INFORMATION SHEET FOR PARTICIPANTS}

You are invited to take part in this research. Please read this information before deciding whether or not to take part. If you decide to participate, thank you. If you decide not to participate, thank you for considering this request.

\section{Who am I?}

My name is Sopheak Seng and I am a master's student in Development Studies at Victoria University of Wellington. This research project is work towards my thesis.

\section{What is the aim of the project?}

This project is going to explore the existing indigenous knowledge system in the Tonle Sap region and study how the people in this region use their knowledge to respond to floods and droughts. In this regard, the project will particularly look at how local people prepare for regular floods and droughts and what livelihood strategies they use in order to survive.

\section{How can you help?}

If you agree to take part, I will interview you at your place or anywhere convenient for you. I will ask you questions about your perception of floods and droughts, how you prepare for floods and droughts, and what livelihood activities you use during floods and droughts. The interview will take between 30 to 60 minutes. I will audio record the interview with your permission and write it up later. You can choose to not answer any question or stop the interview at any time, without giving a reason. You can withdraw from the study by contacting me at any time within 7 days of the interview. If you withdraw, the information you provided will be destroyed or returned to you.

\section{What will happen to the information you give?}

This research is confidential. I will not use your name or the name of your village or organisation in any outputs, and I will not use the information that would identify you. Only my supervisor and I will read the notes or transcript of the interview. The 
interview transcripts, summaries and any recordings will be kept securely and destroyed on 1 January 2021.

\section{What will the project produce?}

The information from my research will be used in my Master thesis. I may also use the findings from the project for conference presentations and academic publications. Your information will not be identified in any of these outputs.

\section{If you accept this invitation, what are your rights as a research participant?}

You do not have to accept this invitation if you don't want to. If you do decide to participate, you have the right to:

- $\quad$ choose not to answer any question;

- $\quad$ ask for the recorder to be turned off at any time during the interview;

- $\quad$ withdraw from the study up to one week after your interview;

- $\quad$ ask any questions about the study at any time;

- $\quad$ reflect whether it will be recorded;

- $\quad$ read over and comment on a written summary of your interview;

- be able to read reports of this research by emailing the researcher to request a copy.

\section{If you have any questions or problems, who can you contact?}

If you have any questions, either now or in the future, please feel free to contact either:

\section{Student:}

Name: Sopheak Seng

School: School of Geography, Environment, and Earth Sciences

Email: sengsoph@myvuw.ac.nz

Phone: +64 211688331 (New Zealand)

+85516399066 (Cambodia)

\section{Human Ethics Committee information}

\section{Supervisor:}

Name: Prof. John Overton

Role: Programme Director and lecturer of Development Studies

School: School of Geography, Environment, and Earth Sciences

Phone: +6404 4635281

Email: john.overton@vuw.ac.nz

\footnotetext{
If you have any concerns about the ethical conduct of the research, you may contact the
Victoria University HEC Convenor: Dr Judith Loveridge. Email hec@vuw.ac.nz or

If you have any concerns about the ethical conduct of the research, you may contact the
Victoria University HEC Convenor: Dr Judith Loveridge. Email hec@vuw.ac.nz or telephone +64-4-463 6028 .
} 


\section{Appendix 3. Participant information sheet in Khmer}

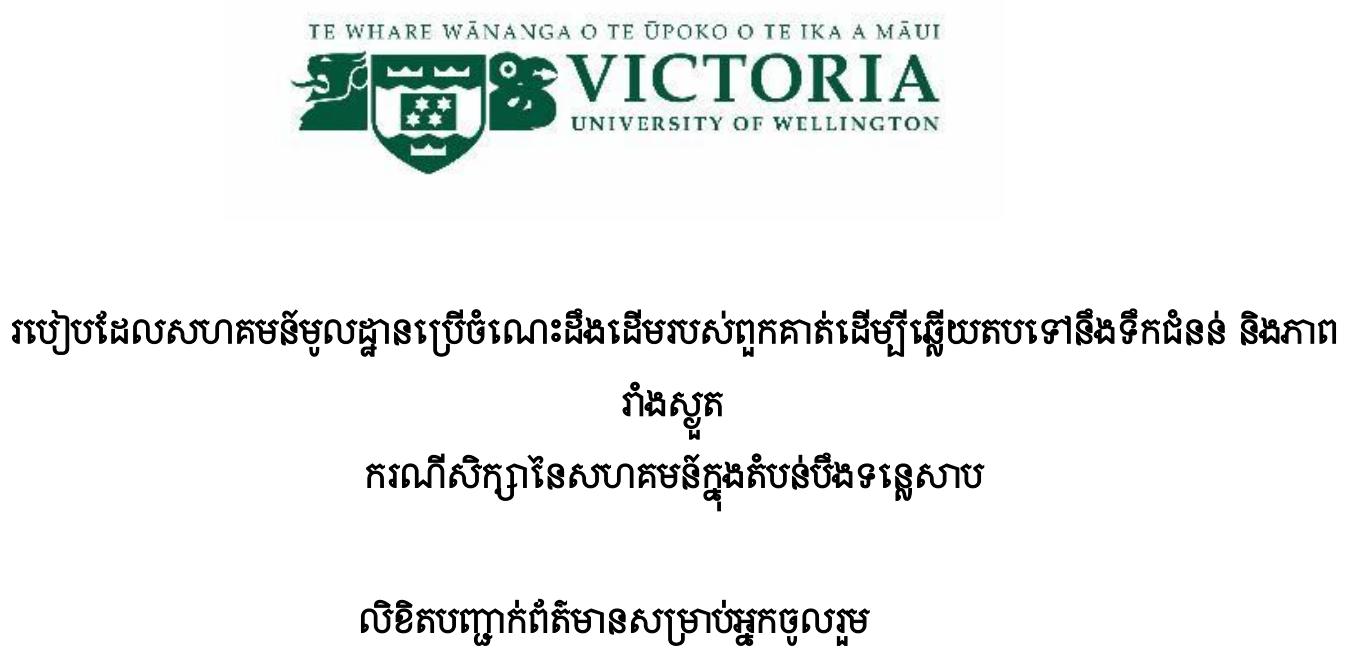

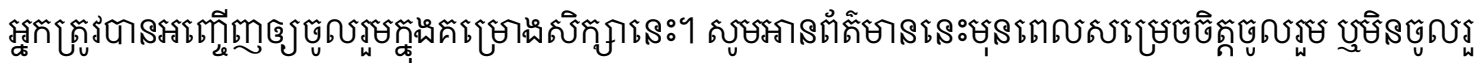

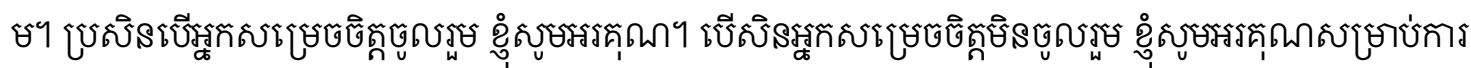

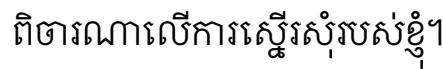

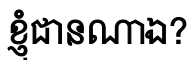

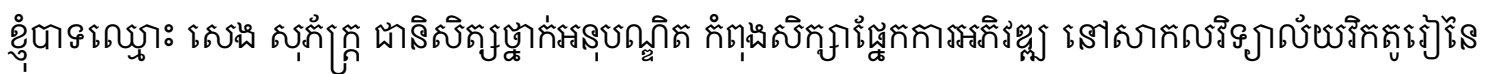

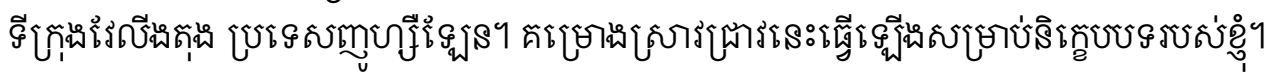

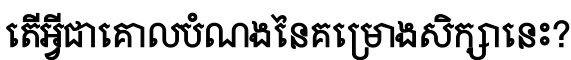

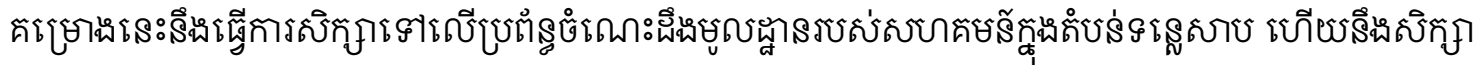

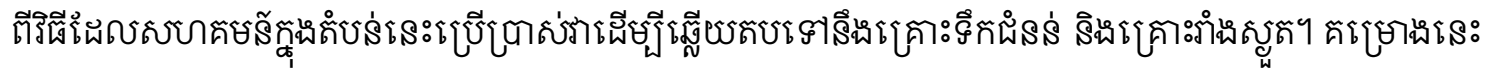

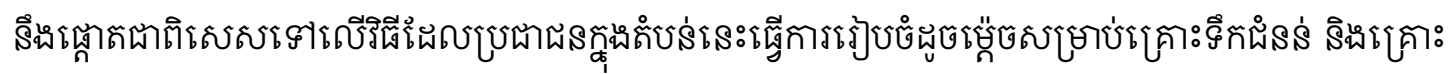

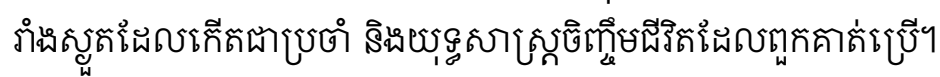

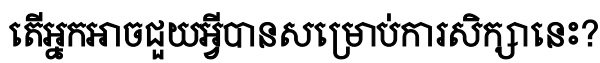

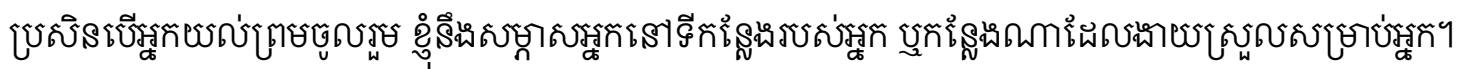

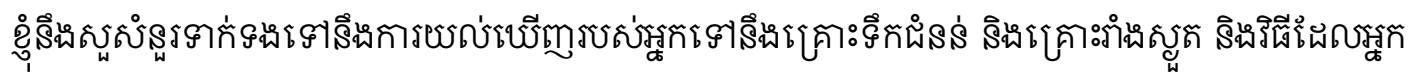

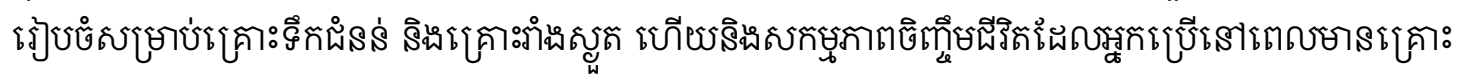

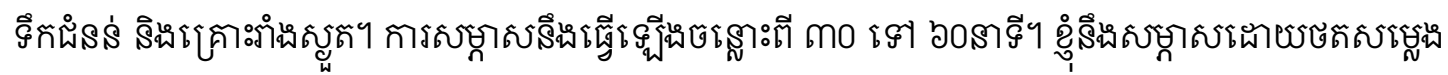

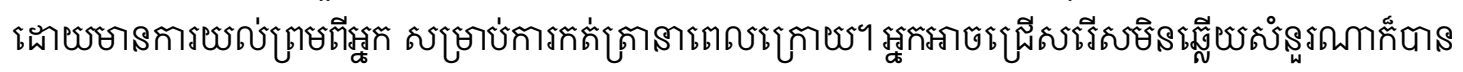

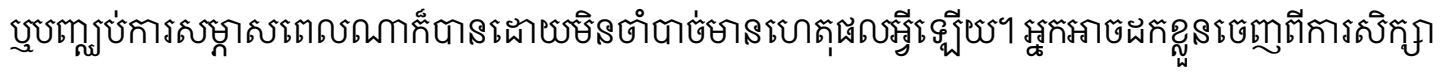




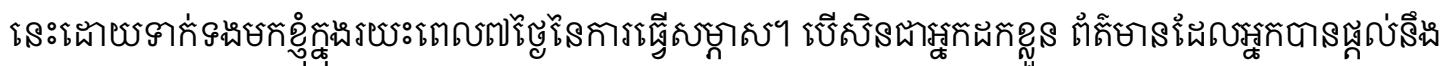

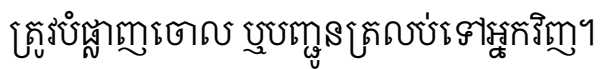

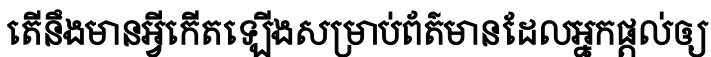

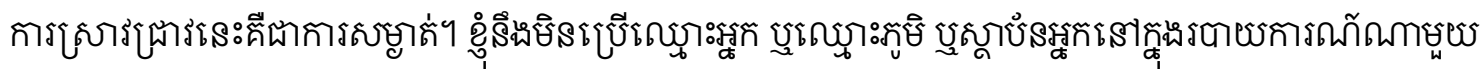

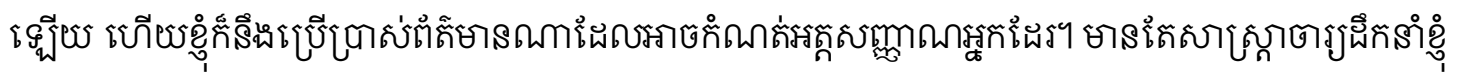

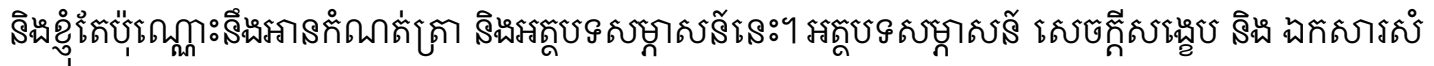

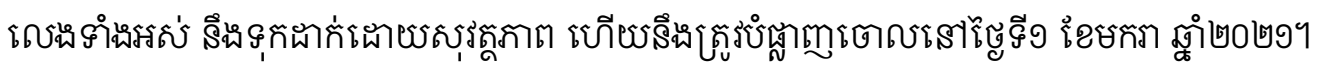

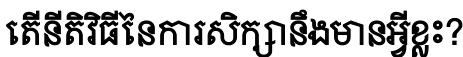

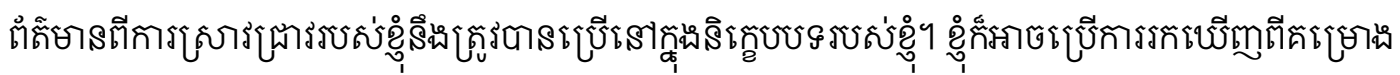

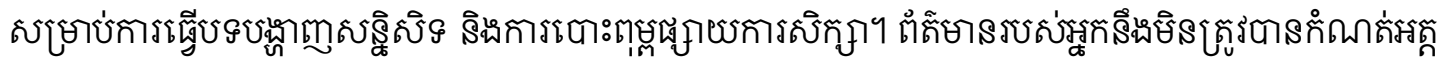

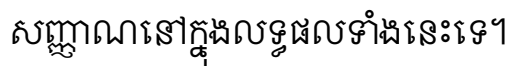

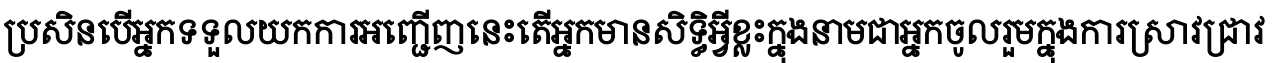

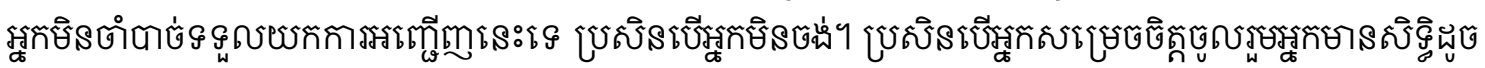
角으ํ

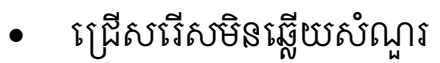

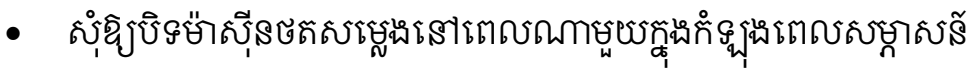

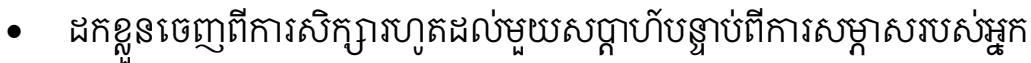

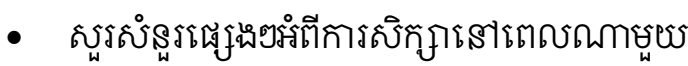

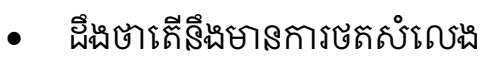

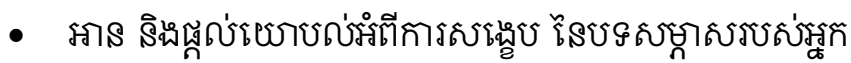

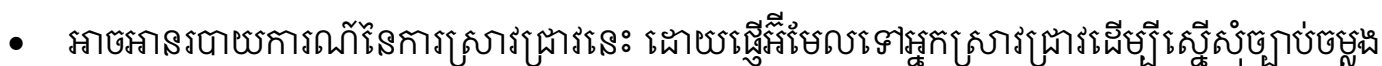

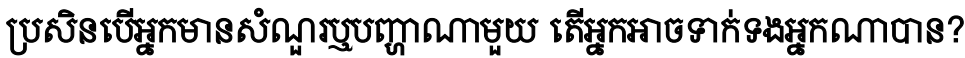

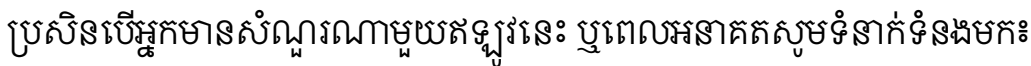

ริธิที:

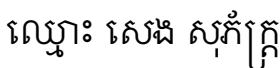

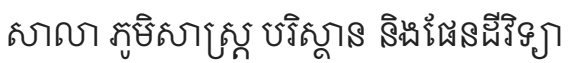

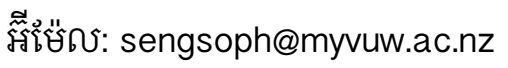

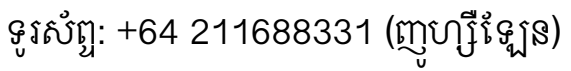

+85516399066 (กซ్ฺ

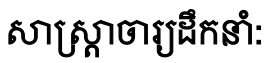

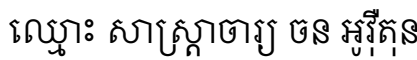

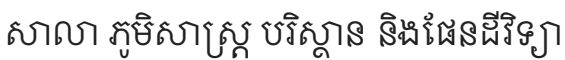

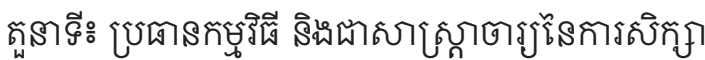

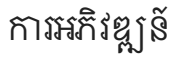

รูรถัติ + 64044635281

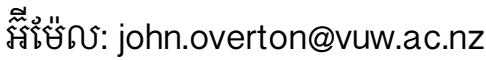




\section{Appendix 4. Participant consent form in English}

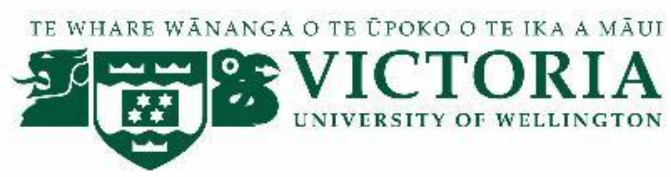

\section{How Local People use their Indigenous Knowledge to Respond to Floods and Droughts:}

\section{A Case Study of Tonle Sap Lake communities, Cambodia}

\section{CONSENT TO INTERVIEW}

This consent form will be held for 5 years.

Researcher: Sopheak Seng, School of Geography, Environment and Earth Sciences, Victoria University of Wellington.

- I have read the Information Sheet and the project has been explained to me. My questions have been answered to my satisfaction. I understand that I can ask further questions at any time.

- I agree to take part in audio recorded interview.

I understand that:

- I may withdraw from this study up to one week after the interview, and any information that I have provided will be returned to me or destroyed.

- $\quad$ The identifiable information I have provided will be destroyed 18 months after the research ends.

- Any information I provide will be kept confidential to the researcher and the supervisor.

- I understand that the results will be used for Sopheak's thesis and a summary of the results may be used in academic reports and/or presented at conferences.

- My name will not be used in reports, nor will any information that would identify me.

- I would like a summary of my interview: $\quad$ Yes $\square \quad$ No

- I would like to receive a summary of the final report and have added my email address below.

Signature of participant:

Name of participant:

Date:

Contact details: 


\title{
Appendix 5. Participant consent form in Khmer
}

\section{TE WHARE WĀNANGA O TE L̄POKO O TE IKA A MĀUI 59 \\ * * University of wellington

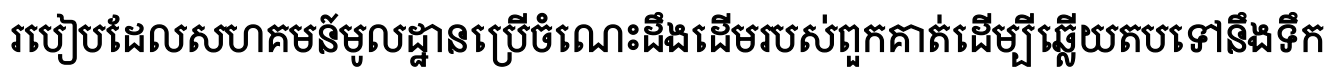

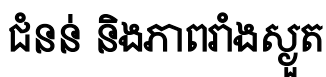

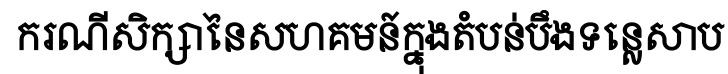

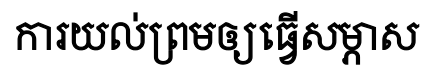

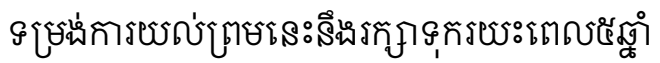

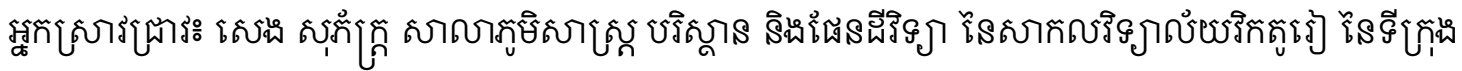

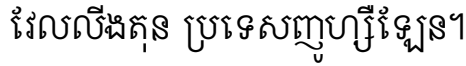

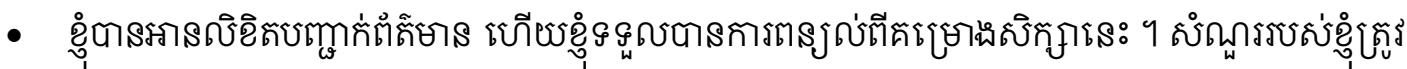

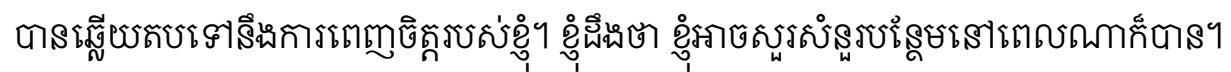

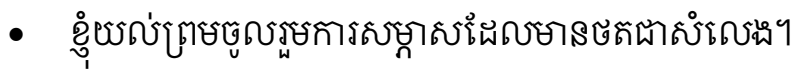

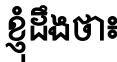

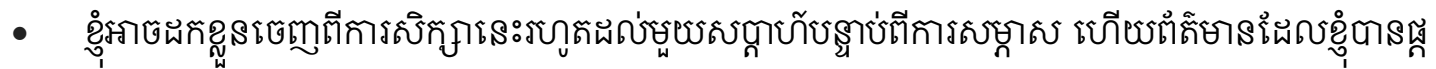

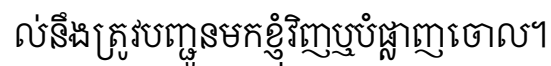

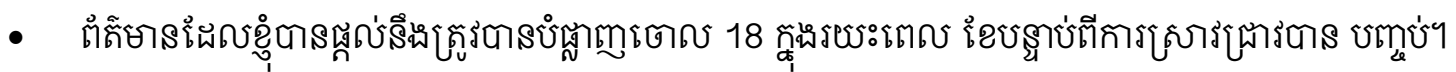

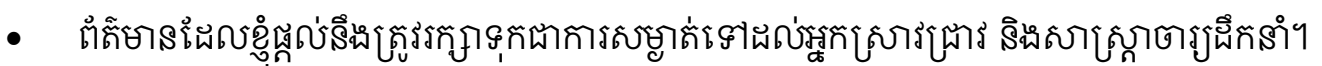

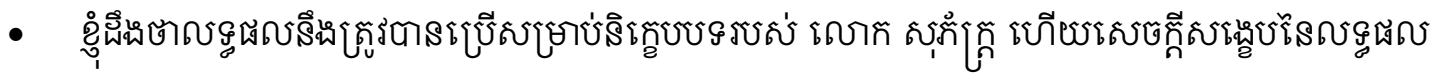

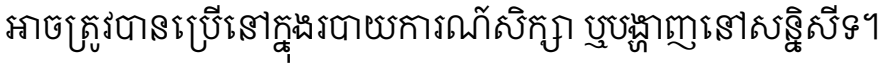

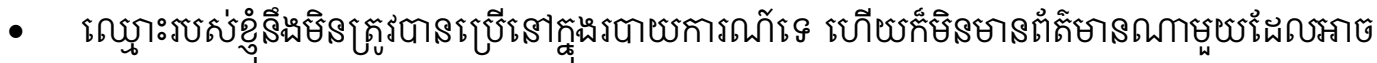

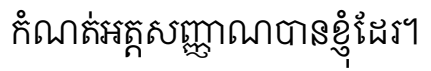

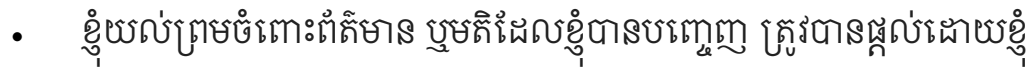

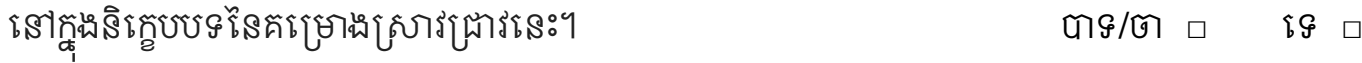




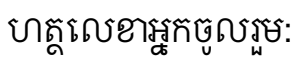

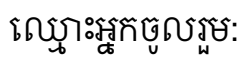

กาலชชิริตู้

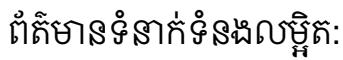




\section{Question guide for local communities}

Date:

Name of respondent:

Gender:

Occupation:

\section{Climate Change and its impacts}

1. What changes in climate patterns have you noticed in your area?

2. What about floods and/or droughts? Compared to the past 10 years, are they more serious?

3. What have been the major changes in floods and/or droughts?

4. How long have you noticed the changes?

5. How do they impact on your family and community?

6. What are your primary livelihood activities?

7. What are your secondary livelihood activities?

8. How do floods and/or droughts impact on your primary livelihood?

9. How do floods and/or droughts impact on your secondary livelihood?

\section{Preparation for floods and/or droughts}

10. Given the impact of floods and/or droughts on your daily livelihood, how do you prepare for them (before they occur)? What strategies do you use?

11. How long have you been practicing these strategies/activities?

12. What strategies are being practicing now which were not done in the past (or vice versa)?

13. How did you know/learn about these strategies/activities?

14. How effective are these strategies?

\section{Strategies to respond to floods and/or droughts}

15. In order to survive, what strategies do you use during floods and/or droughts?

16. How long have you been practicing these strategies?

17. What strategies are being practicing now which were not done in the past (or vice versa)? 
18. How did you know/learn about these strategies?

19. How effective are these strategies?

20. Do the strategies improve your livelihood situation? If yes, how?

21. Have this strategies/knowledge been shared in the family or community? If yes, how?

22. Have these strategies been changing due to the pattern of floods and/or droughts? If yes, how?

\section{Future hazards and solutions/support}

23. What do you think about possible changes in floods and/or droughts that may occur in the future?

24. How should you and the community prepare for the changes?

25. Do you think the livelihood strategy solutions should be done collectively in the community? If yes, how?

26. Any support that you think you would need from the government, local authorities or other development agencies? If yes, what are they? 
Appendix 7. Question guide for local authorities

\section{Question guide for local authorities}

Date:

Name of respondent:

Gender:

Occupation:

\section{Climate Change and its impacts}

1. What changes in climate patterns have you noticed in your area?

2. What about floods and/or droughts? Compare to the past 10 years, are they more serious?

3. What have been the major changes of floods and/or droughts?

4. How long have you noticed the changes?

5. How do they impact on this community?

6. What are the primary livelihoods of this community?

7. What are the secondary livelihoods of this community?

8. How do floods and/or droughts impact on communities' livelihood?

\section{Preparation for floods and/or droughts}

9. Given the impact of floods and/or droughts on community's daily livelihood, how do they prepare for them (before they occur)? What strategies do they use?

10. How long have the community been practicing these strategies/activities?

11. What strategies are being practicing now which were not done in the past (or vice versa)?

12. How did the community know/learn about these strategies/activities?

13. How effective are these strategies?

\section{Strategies to respond to floods and/or droughts}

14. In order to survive, what strategies do the community use during floods and/or droughts?

15. How long have the community been practicing these strategies?

16. What strategies are being practicing now which were not done in the past (or vice versa)? 
17. How did the community know/learn about these strategies?

18. How effective are these strategies?

19. Do the strategies improve communities' livelihood situation? If yes, how?

20. Have this knowledge been shared in the family or community? If yes, how?

21. Have these strategies been changing due to the pattern of floods and/or droughts? If yes, how?

\section{Future hazards and solutions/support}

22. What do you think about possible changes in floods and/or droughts that may occur in the future?

23. How should the community prepare for the changes?

24. Do you think that the livelihood strategy solutions should be done collectively in the community? If yes, how?

25. Does the commune/village have any plan to support communities' livelihood in this village? If yes, how?

26. Does the government have any plan to support communities' livelihood in this village? If yes, how?

27. Are there any NGO working to improve local livelihood in this village? What are their activities?

28. Have there been activities of NGOs to improve communities' understanding on livelihood activities to adapt to natural hazards? If yes, what are the activities?

29. Should indigenous knowledge be integrated into adaptation policy of the government? If yes, how? 


\section{Question guide for NGO staff}

Date:

Name of respondent:

Gender:

Occupation:

1. How long have you been working in this area?

2. What are the project activities that your NGO is involved in in this area?

3. What changes in climate pattern have you noticed in your area?

4. Are floods and/or droughts serious problems in this community? Why?

5. Do you think the local farmers and fishermen are seriously affected by floods and/or droughts? If yes, in what ways are they affected?

6. What are the methods used by local communities to combat floods and/or droughts?

7. Which of the above methods involves indigenous knowledge and which methods provided by outsiders, such as development agencies and government officials?

8. What are the livelihood strategies developed by local people using their indigenous knowledge?

9. Do you think these livelihood strategies are effective enough for them to survive? If yes, why?

10. Does your NGO provide new knowledge for local people to use in order to improve their livelihood? What are they?

11. Is the new knowledge integrated with indigenous knowledge of local community? If yes, how?

12. Does your organisation have adaptation policy for local community who are affected by floods or droughts? If yes, what are they?

13. How should indigenous knowledge should be integrated in adaptation policy?

14. How long has your NGO supported the local communities?

15. How long has this support been planned to last?

16. Do you think the NGO support will be sustainable? Why? 